Técnicas determinísticas para acompanhamento musical automatizado

\author{
Roberto Piassi Passos Bodo
}

DiSSERTAÇÃO APRESENTADA

$\mathrm{AO}$

Instituto De Matemática e EstatísticA

DA

Universidade DE SÃo PAUlo

PARA

OBTENÇÃO DO TÍTULO

$\mathrm{DE}$

Mestre EM CIÊNCIAS

Programa de Pós Graduação em Ciência da Computação

Orientador: Prof. Dr. Marcelo Gomes de Queiroz

São Paulo, Dezembro de 2015 


\section{Técnicas determinísticas para acompanhamento musical automatizado}

Esta versão da dissertação contém as correções e alterações sugeridas pela Comissão Julgadora durante a defesa da versão original do trabalho, realizada em 08/12/2015. Uma cópia da versão original está disponível no

Instituto de Matemática e Estatística da Universidade de São Paulo.

Comissão Julgadora:

- Prof. Dr. Marcelo Gomes de Queiroz (orientador) - IME-USP

- Prof. Dr. Fabio Kon - IME-USP

- Prof. Dr. Fernando Henrique de Oliveira Iazzetta - ECA-USP 


\section{Agradecimentos}

Ao Marcelo Gomes de Queiroz pela orientação acadêmica, à Ana Clara Duarte Gavião pela orientação pessoal, aos meus pais - Luciana Piassi Passos Bodo e Roberto Bodo - pelo apoio incondicional e aos meus amigos pelos bons momentos compartilhados durante todos os anos de mestrado. 


\section{Resumo}

BODO, R. P. P. Técnicas determinísticas para acompanhamento musical automatizado. Dissertação (Mestrado) - Instituto de Matemática e Estatística, Universidade de São Paulo, São Paulo, 2015.

Sistemas de acompanhamento musical automatizado são de grande utilidade como ferramentas didáticas. Com eles, um aluno de música consegue ensaiar uma peça musical sendo acompanhado pelo computador, com a liberdade de tocar na velocidade em que desejar e, além disso, de cometer erros acidentais ou desvios intencionais em relação ao esperado (definido em partitura).

Um sistema de acompanhamento musical deve ter as habilidades de analisar a execução ao vivo de um músico (pré-processador da entrada), comparar os eventos recebidos com os de uma partitura pré-carregada (rastreador), gerar o acompanhamento conforme o andamento inferido (acompanhador) e sintetizar os sons relativos a esse acompanhamento (sintetizador).

O trabalho apresentado neste texto consistiu em estudar diversas técnicas relativas ao problema de acompanhamento musical, implementar alguns algoritmos baseados na literatura abordada, validar a qualidade obtida com tais algoritmos e disponibilizar um sistema de código aberto modular com mais de uma alternativa de algoritmo para cada módulo.

Além disso, foi desenvolvido um elemento adicional para o sistema - o MetaRastreador - que combina todas as técnicas de rastreamento implementadas, executando-as em paralelo e obtendo uma maior confiabilidade nas informações extraídas da entrada, considerando diversas opiniões diferentes sobre a posição do músico na partitura.

Palavras-chave: computação musical, acompanhamento musical, rastreamento de partitura. 


\section{Abstract}

BODO, R. P. P. Deterministic techniques for automated musical accompaniment. Dissertation (Masters) - Institute of Mathematics and Statistics, University of São Paulo, São Paulo, 2015.

Automated musical accompaniment systems are very useful as didactic tools. With them, a music student can rehearse a musical piece being accompanied by the computer, with the freedom to play at the desired speed and, moreover, to perform accidental errors or intentional deviations from the expected (defined by a musical score).

A musical accompaniment system should have the skills to analyze the live performance of a musician (input preprocessor), compare the events received with those of a preloaded score (matcher), generate the accompaniment according to the inferred tempo (accompaniment), and synthesize the sounds related to this accompaniment (synthesizer).

The work presented in this text consisted of studying several techniques related to the musical accompaniment problem, implementing some algorithms based on the literature, validating the quality obtained with such algorithms, and providing a modular open source system with more than one alternative algorithm for each module.

Furthermore, an additional element was developed for the system - the MetaMatcher - that combines all the tracking techniques implemented by running them in parallel and obtaining a greater reliability in the information extracted from the input, considering several different opinions about the position of the musician in the musical score.

Keywords: computer music, musical accompaniment, score following. 


\section{Sumário}

$\begin{array}{ll}\text { Lista de Figuras } & \text { ix }\end{array}$

1 Introdução 1

2 Fundamentação teórica 5

2.1 Formato para as entradas do sistema . . . . . . . . . . . . . . . . . . 5

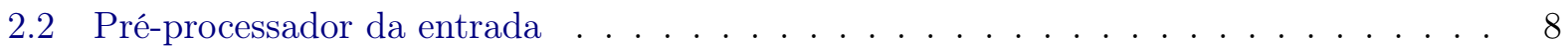

2.3 Métodos rastreadores . . . . . . . . . . . . . . . . . . . . . . . . 10

2.3.1 Dannenberg (1984) f . . . . . . . . . . . . . . . . . . 10

$2.3 .2 \quad$ Lippe $(1992) \quad \ldots \ldots \ldots \ldots \ldots \ldots$

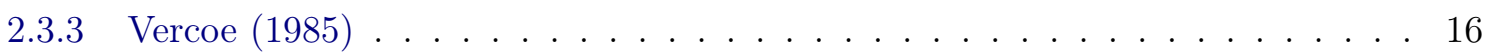

2.3 .4 Baird $(1993) \ldots \ldots \ldots \ldots \ldots \ldots \ldots$

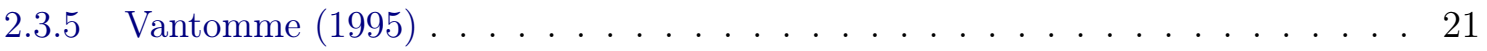

2.4 Acompanhador . . . . . . . . . . . . . . . . . . . . 23

2.4 .1 Gerenciamento do relógio virtual . . . . . . . . . . . . . . . . 24

2.4.2 Evolução preditiva do relógio virtual . . . . . . . . . . . . . . . . . . 28

2.4.3 Deteç̧ão e tratamento de assincronia . . . . . . . . . . . . . . . . . . 31

2.4.4 Deteç̧ão e tratamento de fuga . . . . . . . . . . . . . . . . . . . 32

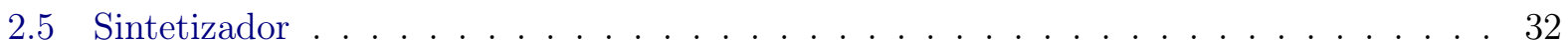

3 Desenvolvimento $\quad 35$

3.1 Escolhas técnicas . . . . . . . . . . . . . . . . . . . . 35

3.2 Implementação do sistema principal . . . . . . . . . . . . . . . . . 37

3.2.1 Etapas de desenvolvimento do carregador de partitura . . . . . . . . . . . 37

3.2.2 Alterações nas implementações dos algoritmos rastreadores . . . . . . . . . 38

3.2 .3 MetaRastreador . . . . . . . . . . . . . . . . . . . . . . . . 41

3.3 Sistemas periféricos . . . . . . . . . . . . . . . . . . . 44

3.3 .1 Tocador de MIDI . . . . . . . . . . . . . . . . . . . . . . . . 44

3.3 .2 Execução em lote . . . . . . . . . . . . . . . . . . . . . . 45

3.3 .3 Gerador de entradas . . . . . . . . . . . . . . . . . . . . . . 45

$\begin{array}{lll}4 & \text { Experimentos } & 49\end{array}$

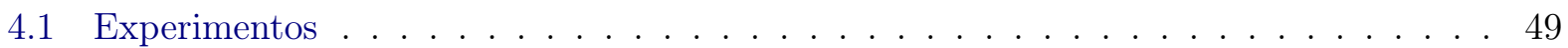

4.2 Resultados e Discussões . . . . . . . . . . . . . . . . . . . . . . 51

4.2.1 Discussão sobre os valores estimados para os parâmetros . . . . . . . . . . . . 51 
viii SUMÁRIO

4.2.2 Discussão sobre os erros médios do MetaRastreador . . . . . . . . . . . . . . . . 54

$\begin{array}{lll}5 & \text { Conclusão } & 61\end{array}$

$\begin{array}{ll}\text { Referências Bibliográficas } & 65\end{array}$ 


\section{Lista de Figuras}

1.1 Arquitetura de um sistema modularizado de acompanhamento musical [BD85]. . . . 2

2.1 MOCO - conversor entre MIDI e OSC (http://addi.tv/moco/) . . . . . . . . . 6

2.2 Exemplo de um arquivo CSV convertido de um arquivo MIDI. . . . . . . . . . . . . 8

2.3 Exemplos de símbolos musicais contemplados pela extensão expMIDI [CNB97]. . . . 8

2.4 Relação entre diversos domínios para representação de altura musical. . . . . . . . . 9

2.5 Segunda condição para agrupamento de notas em um evento composto. . . . . . . . . 9

2.6 Equivalência de oitavas para os números de notas MIDI $(\bmod 12)$. . . . . . . . . 10

2.7 Exemplo de casamento entre símbolos da entrada com símbolos da partitura [Dan84]. 10

2.8 Exemplo de matriz calculada para o problema da maior subsequência comum [Dan84]. 12

2.9 Cálculo em tempo real das colunas da matriz conforme eventos da entrada são recebidos $[$ Dan84] . . . . . . . . . . . . . . . . . . . . . . . . . . . . . . . . . . . . . . 12

2.10 Utilização de janelas para cálculo das colunas da matriz [Dan84] . . . . . . . . . . . . 12

2.11 Comportamentos do algoritmo de Dannenberg1984 com a janela estática (a) e dinâmica (b) . . . . . . . . . . . . . . . . . . . . . 13

2.12 Atualizações da matriz que irão gerar relatos de casamentos [Dan84] . . . . . . . . . . 13

2.13 Regiões consideradas pelo algoritmo de Lippe92 [LP92] . . . . . . . . . . . . . . . . . 14

2.14 Exemplo de atualização das estruturas de dados após a detecção de um casamento. 14

2.15 Exemplo de uma nota alcançada pelo parâmetro N (em contraste ao parâmetro T). . 15

2.16 Diferentes comportamentos para diferentes skip numbers. . . . . . . . . . . . . . . 15

2.17 Exemplos de notas sendo consideradas pelo parâmetro T (em contraste ao parâmetro

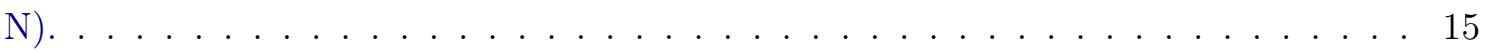

2.18 Exemplo de acordes de durações diferentes cujos tempos de ataques são próximos da mesma maneira. . . . . . . . . . . . . . . . . . . . . . 16

2.19 Exemplo de subamostragem de notas da partitura. . . . . . . . . . . . . . . . 16

2.20 Regressão linear pelo método dos mínimos quadrados. . . . . . . . . . . . . . . . 17

2.21 Mapeamento dos eventos da entrada nos eventos da partitura. . . . . . . . . . . . . 17

2.22 Padrão com N eventos da entrada e sua comparação com M padrões da partitura. . . 19

2.23 Modelo literal de casamento [BBZ93]. . . . . . . . . . . . . . . . . . . . . . . . 19

2.24 Modelo amalgamado de casamento [BBZ93] . . . . . . . . . . . . . . . . . . . . . . 19

2.25 Modelo sem interrupções de casamento [BBZ93]. . . . . . . . . . . . . . . . . . . . 19

2.26 Modelo de pausas de casamento [BBZ93]. . . . . . . . . . . . . . . . . . 20

2.27 Exemplo de dois padrões a serem comparados com 5 notas fictícias cada. . . . . . . . 20

2.28 Possibilidades de agrupamento de pares de notas no padrão da entrada. . . . . . . . 20 
2.29 Possíveis pareamentos com as 5 unidades do padrão da partitura (o padrão de entrada possui agora 4 unidades). . . . . . . . . . . . . . . . . . . . . . . . 20

2.30 Passos do algoritmo de Vantomme1995 [Van95]. . . . . . . . . . . . . . . . . . . . 21

2.31 Curvas original e modificada do modelo de Rosenthal [Van95]. . . . . . . . . . . . . . 22

2.32 Curva de evolução do tempo virtual em relação ao tempo real. . . . . . . . . . . . . . 24

2.33 Pontos de relatos no gráfico de tempo real versus virtual. . . . . . . . . . . . . . . . . 24

2.34 Extrapolação do relógio virtual a partir da inclinação dos dois últimos pontos. . . . . 25

2.35 Extrapolação do relógio virtual a partir da inclinação dos pontos (N - 1) e (N - 4). . 26

2.36 Extrapolação do relógio virtual a partir de regressão linear. . . . . . . . . . . . . . . 27

2.37 Extrapolação do relógio virtual a partir de regressão quadrática. . . . . . . . . . . . . 28

2.38 Tempos do processo para emissão de um evento na saída $\left(t_{4}-t_{1}\right.$ deveria ser zero). $\quad 28$

2.39 Exemplo de um ponto da partitura no qual eventos do solo e do acompanhamento devem soar sincronizados. . . . . . . . . . . . . . . . . . . . . . . . . . . . 29

2.40 Exemplo de possíveis curvas armazenadas no histórico para um dado trecho da música. 30

2.41 Sobreposição das curvas do histórico com a curva da execução atual em um dado trecho da música. . . . . . . . . . . . . . . . . . . . . . . . . . . . . . . . . . . . . . 30

2.42 Duas execuções do mesmo evento note on em $t_{3}$ e $t_{9}$. Considere $t_{i}$ tempos reais, $t_{i}<$

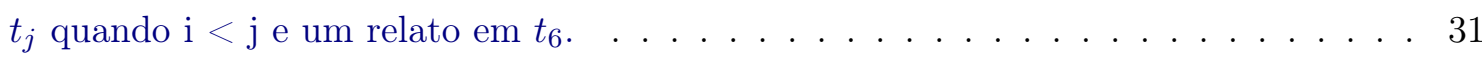

2.43 Rotina para ativar notas percorrendo a partitura de trás para frente. . . . . . . . . . 32

2.44 Detecção de fuga do músico por inatividade na execução solo. . . . . . . . . . . . . . 32

2.45 Envelope ADSR (Attack Decay Sustain Release) que representa as fases da amplitude de uma nota. . . . . . . . . . . . . . . . . . . . . . . . . . 33

3.1 Interface gráfica do sistema no modo estático global. . . . . . . . . . . . . . . . 37

3.2 Valores indefinidos ao redor das colunas anterior e atual para um deslocamento de janela de tamanho 1. . . . . . . . . . . . . . . . . . . . . . . . . . . . . . . . . . . . . 38

3.3 Valores indefinidos ao redor das colunas anterior e atual para um deslocamento de janela de tamanho 2. . . . . . . . . . . . . . . . . . . . . . . . . . . . . . . . . . . . . 39

3.4 Diferentes possibilidades de casamentos na skip list para a nota D recém chegada. . . 39

3.5 Casos de penalização de notas por durações diferentes. . . . . . . . . . . . . . . . . . . 41

3.6 Exemplo no qual a última nota emitida na entrada foi excluída do pareamento. . . . 41

3.7 Dois rastreadores sendo executados em paralelo [DM88]. . . . . . . . . . . . . . . . . . 42

3.8 N rastreadores sendo executados em paralelo [AW10b] . . . . . . . . . . . . . . . . . . 42

3.9 Diversos pontos de relatos para um mesmo tempo real de recebimento de uma nota. 43

3.10 Comparação entre média e mediana. . . . . . . . . . . . . . . . . . . . . . . . . . . . 43

3.11 Estrutura de dados que armazena os relatos emitidos para uma nota e a respectiva mediana. . . . . . . . . . . . . . . . . . . . . . . . . . . . . . 44

4.1 Estatísticas de estimação de parâmetros de Dannenberg1984. . . . . . . . . . . . . . 52

4.2 Estatísticas de estimação de parâmetros de Lippe1992. . . . . . . . . . . . . . . . . . . . 52

4.3 Estatísticas de estimação de parâmetros de Vercoe1985. . . . . . . . . . . . . . . . . . 53

4.4 Estatísticas de estimação de parâmetros de Baird1993. . . . . . . . . . . . . . . . . . . 54

4.5 Médias de valores para erros de Substituição . . . . . . . . . . . . . . . . . . . 55

4.6 Médias de valores para erros de Deleção . . . . . . . . . . . . . . . . . . . . . . 55 
4.7 Médias de valores para erros de Adição (antes) . . . . . . . . . . . . . . . . 56

4.8 Médias de valores para erros de Adição (depois) . . . . . . . . . . . . . . . . . 56

4.9 Médias de valores para erros de Antecipação . . . . . . . . . . . . . . . . . 57

4.10 Médias de valores para erros de Atraso . . . . . . . . . . . . . . . . . 57

4.11 Médias de valores para erros de Encurtamento . . . . . . . . . . . . . . . . 58

4.12 Médias de valores para erros de Prolongação . . . . . . . . . . . . . . . . 58

4.13 Variação da curva de evolução do tempo virtual conforme porcentagem de erros de deleção. . . . . . . . . . . . . . . . . . . . . . . . 59 59

4.14 Variação da curva de evolução do tempo virtual conforme porcentagem de erros de adição. . . . . . . . . . . . . . . . . . . . . 60 60

4.15 Exemplo de como um erro de deleção influencia na detecção de um andamento menor. 60

4.16 Exemplo de como um erro de adição influencia na detecção de um andamento maior. 60 


\section{Capítulo 1}

\section{Introdução}

A popularização dos computadores permitiu sua inserção em áreas nas quais não eram usualmente utilizados, como na Música, por exemplo. Dentre as aplicações da computação na música temos os sistemas em tempo real, ou seja, sistemas cujas tarefas possuem restrições de tempo em suas execuções. Sistemas musicais em tempo real incluem instrumentos digitais, sistemas de composição interativa e sistemas de acompanhamento musical automatizado [Dan89].

Iremos abordar essa última classe de sistemas, considerada de grande utilidade como recurso didático. Podemos imaginar um aluno de música que deseja ensaiar, por exemplo, um concerto para piano; consideraremos a seguir algumas das possibilidades à sua disposição para realizar tais ensaios.

A primeira alternativa é ensaiar diretamente com a orquestra que irá acompanhá-lo no dia de sua apresentação. Porém, isso exige o comprometimento de diversas pessoas e acaba sendo a solução menos prática. Além disso, com o envolvimento de outros músicos não existe muito espaço para os erros intrínsecos das primeiras execuções do aluno. Portanto, torna-se necessário um mínimo de treinamento prévio, o que não resolve o nosso problema.

Uma segunda alternativa seria utilizar algum método comercial de estudo, como o bem conhecido Music Minus $O n e^{1}$, no qual o aluno adquire gravações do concerto sem o seu instrumento e, assim, ele consegue tocar junto com o acompanhamento pré-gravado. No entanto, tais gravações normalmente não são disponibilizadas em diversos andamentos e, mesmo quando são, o aluno não teria a flexibilidade de poder executar trechos de diferentes dificuldades em diferentes andamentos. Ele teria que treinar primeiramente em um andamento mais lento (mais confortável para os trechos mais difíceis) e depois passar para o andamento final do concerto. Nesse cenário ainda é exigido um pré-treinamento por parte do aluno.

Surge, então, a ideia de inverter os papéis: não é mais o músico que deve seguir o acompanhamento, mas o acompanhamento que deve seguir o músico. Um sistema de acompanhamento musical deve gerar o acompanhamento apropriado em tempo real a partir do andamento inferido da execução do músico, que tem a liberdade de tocar na velocidade em que desejar e, além disso, cometer alguns tipos de erros (situação normal durante o processo de ensaio) ou mesmo desvios intencionais em relação ao texto musical (ornamentações).

Para que o sistema consiga efetuar tal papel ele precisa realizar as seguintes tarefas:

- interpretar a entrada do músico em tempo real;

- comparar as notas da entrada com as de uma partitura pré-armazenada com a execução esperada;

- gerar o acompanhamento de acordo com o andamento inferido da execução;

- sintetizar os sons relativos a esse acompanhamento.

\footnotetext{
${ }^{1}$ http://musicminusone.com/
} 
As quatro tarefas acima podem ser realizadas pelo sistema a partir da implementação de quatro módulos específicos para cada uma delas, conforme sugerido por Roger Dannenberg [BD85] e ilustrado na figura 1.1. Iremos chamá-los neste texto, respectivamente, de Pré-processador da entrada, Rastreador, Acompanhador e Sintetizador.

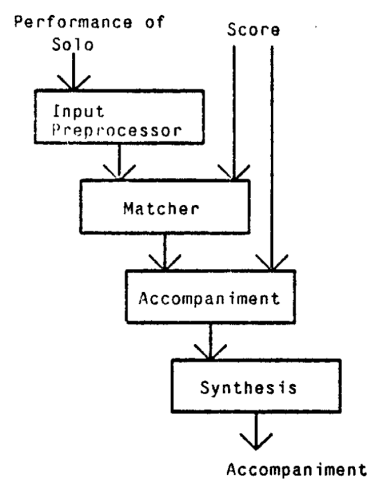

Figura 1.1: Arquitetura de um sistema modularizado de acompanhamento musical [BD85].

O objetivo do trabalho apresentado neste texto é estudar diversas técnicas relativas ao problema de acompanhamento musical, implementar alguns algoritmos baseados na literatura abordada, validar a qualidade obtida com tais algoritmos e disponibilizar um sistema modular de código aberto, bem documentado e com mais de uma alternativa de algoritmo para cada módulo.

Diversas características desejáveis na fase de desenvolvimento e depuração podem ser explicitadas nos objetivos escolhidos acima. O fato do sistema ser implementado de forma modularizada fornece um cenário amigável para experimentações. As combinações geradas com as diferentes implementações poderão ser testadas e poderemos encontrar a origem dos problemas detectados com maior facilidade do que se estivéssemos trabalhando com sistemas caixas-pretas. Por exemplo, se observarmos que o acompanhamento está sendo gerado de forma antecipada, podemos descobrir se o Rastreador está relatando os casamentos com tempos adiantados ou se o Acompanhador está gerando os eventos da saída antes do esperado.

O fato do software possuir código aberto também traz algumas vantagens em relação ao código proprietário. A Free Software Foundation ${ }^{2}$ aponta quatro liberdades básicas associadas ao uso de software livre: a liberdade de executar o programa para qualquer propósito, a de estudar como o programa funciona e modificá-lo conforme suas necessidades, a de redistribuir cópias com o intuito de ajudar outras pessoas e a de aperfeiçoar o programa e lançar novas versões com seus aperfeiçoamentos de modo que todos os usuários se beneficiem ${ }^{3}$. Além disso, sistemas que mantêm seus códigos abertos permitem a criação de uma comunidade de desenvolvedores que trabalha de forma coordenada, dando uma maior agilidade no desenvolvimento de novas funcionalidades ou na correção de bugs, em comparação com uma equipe restrita e interna caso o código fosse proprietário [Web04].

Por último, o fato do sistema possuir mais de uma alternativa de algoritmo para cada módulo é considerado desejável, pois fornece a possibilidade do usuário utilizar as técnicas que mais se encaixam às suas necessidades, seja pelo seu nível de aperfeiçoamento técnico musical (alternando entre técnicas de diferentes níveis de tolerâncias a erros), pela quantidade de improvisação que ele deseja executar (algumas técnicas são mais receptivas a notas extras e ornamentos), ou pelo repertório escolhido para ser estudado (músicas de alguns gêneros musicais possuem algumas estruturas que são mais facilmente rastreadas).

Todos os módulos apresentados acima apresentam desafios relativos aos seus subproblemas, sendo que a literatura da área apresenta técnicas diversas e interessantes. Porém, a fim de melhor delimitar o escopo deste trabalho, iremos dar maior atenção aos dois subproblemas intermediários: rastreamento de partitura e geração do acompanhamento. Os primeiros trabalhos dedicados

\footnotetext{
${ }^{2}$ http://www.fsf.org/

${ }^{3}$ texto parcialmente alterado de http://br-linux.org/2008/01/faq-softwarelivre.html
} 
a resolver esses subproblemas surgiram na década de 1980 [Dan84, Ver84, BD85, VP85], sendo o subproblema do rastreamento até hoje o mais explorado dentre eles.

Os primeiros algoritmos de rastreamento de partitura (score tracking) [Dan84, Ver84, BD85, VP85] são essencialmente determinísticos. A partir de diversas informações obtidas da entrada, buscam encontrar o melhor emparelhamento entre a entrada e a partitura. Alguns algoritmos consideram as alturas musicais como as informações primordiais dos eventos da entrada [Dan84, LP92], enquanto outros consideram também o tempo de ataque das notas [VP85, Van95] e as suas durações [BBZ93].

Independentemente das informações tratadas da entrada, todos têm um comportamento muito parecido ao compararem a cada instante apenas um subconjunto de eventos da entrada com um subconjunto de eventos da partitura (em prol de um melhor desempenho computacional) e criando diversas suposições sobre o emparelhamento local desses eventos. Isso é feito com intuito de encontrar o emparelhamento global entre entrada e partitura com uma abordagem bottom-up.

A cada evento que chega na entrada, os subconjuntos de eventos a serem comparados da entrada e da partitura são atualizados e diversas teorias são consideradas sobre como eles poderiam se emparelhar. Normalmente, custos são calculados para determinar quão distante cada teoria de emparelhamento está do que é considerado uma execução ideal.

Os custos são calculados a partir de penalidades definidas para classes de erros na entrada, tais como notas extras, faltantes, mais longas, mais curtas, antecipadas, atrasadas, etc. O emparelhamento de menor custo dá uma boa estimativa da posição do músico na partitura, e o tempo decorrido entre os últimos eventos emparelhados fornece uma boa estimativa do andamento do músico.

No final da década de 90, os pesquisadores que trabalhavam com esse problema mudaram a abordagem e começaram a utilizar processos estocásticos nos algoritmos de rastreamento de partitura, partindo do princípio de que uma execução musical é um processo não-estacionário [CLB99, Rap99]. A utilização de algoritmos probabilísticos predomina até os dias de hoje com a ampla utilização de modelos ocultos de Markov [OD01, OLS03, Rap04, Rap10, NNS13].

Apesar das técnicas probabilísticas serem mais atuais e apresentarem bons resultados, optamos por restringir o escopo deste trabalho ao universo determinístico que apresenta por si só uma variedade considerável e representativa das técnicas usadas em acompanhamento musical automático.

Em relação à geração do acompanhamento, observamos na literatura duas abordagens principais. Os primeiros sistemas [Dan84, BD85, Ver84, VP85] tinham comportamento reativo e por isso possuíam uma dependência muito grande das ações do músico. Um casamento era detectado e, apenas após o relato da posição do músico na partitura, o sistema adaptava seu andamento e gerava o acompanhamento da forma mais suave possível.

Porém, esse processo completo pode introduzir um atraso na resposta do sistema. Imagine dois eventos (um do solo, outro do acompanhamento) que deveriam ocorrer concomitantemente conforme a partitura. Como o sistema irá esperar a detecção do evento do solista para sintetizar o evento do acompanhamento, ambos serão executados dessincronizados. Além disso, se o músico cometer muitos erros ou até mesmo parar de tocar, o computador não terá muitos dados confiáveis da entrada para tomar decisões e poderá se comportar de forma pouco natural.

Alguns sistemas mais recentes [HH93, Con08, Rap10] já foram implementados com uma certa autonomia em relação ao músico e, assim, conseguem caminhar por conta própria quando as informações da execução não são muito confiáveis. Essa abordagem tenta, de certa forma, simular o comportamento de músicos humanos que, usualmente, não iriam encerrar uma apresentação caso o membro principal do conjunto se perdesse ou parasse de executar sua parte.

Tais sistemas tomam decisões de forma antecipada. Isso normalmente é alcançado utilizando técnicas de predição temporal nas quais o sistema calcula novos valores de andamento de forma autônoma, ou por aprendizado de máquina a partir de execuções anteriores, situação na qual o sistema se aproveita de um histórico de curvas de andamento da peça para inferir o andamento da execução atual. Assim conseguimos resolver o problema de ataques simultâneos de notas tanto no acompanhamento quanto no solo, que seriam executados em instantes diferentes se o sistema fosse 
puramente reativo.

No próximo capítulo iremos apresentar a teoria por trás de todos os módulos apresentados acima. No terceiro capítulo, iremos dar detalhes das implementações dos algoritmos escolhidos e das escolhas técnicas para o sistema. No quarto capítulo, iremos descrever os experimentos realizados e mostrar os resultados obtidos. Ao final, no quinto e último capítulo, iremos apresentar as conclusões e os trabalhos futuros para o projeto. 


\section{Capítulo 2}

\section{Fundamentação teórica}

Conforme vimos no capítulo anterior nosso sistema terá quatro módulos: pré-processador da entrada, rastreador, acompanhador e sintetizador. Neste capítulo iremos apresentar os algoritmos selecionados da literatura para cada um desses módulos. Antes disso, iremos discutir sobre o formato escolhido para a execução em tempo real e para a partitura.

\subsection{Formato para as entradas do sistema}

A entrada em tempo real proveniente do músico pode ser obtida de diversas maneiras, desde a utilização de instrumentos eletrônicos cujas notas são recebidas pelo computador de forma simbólica (por exemplo, bytes provenientes de um teclado digital) até a utilização do áudio capturado diretamente de instrumentos acústicos. Nesse último caso, temos um outro leque de possibilidades que incluem técnicas de transcrição melódica automática [MQ05] e extração de características sonoras [Pir11].

Trabalhar com áudio direto possui diversas vantagens e consideramos principalmente a possibilidade de utilizar instrumentos acústicos. No entanto, as técnicas relacionadas à transcrição melódica automática fogem consideravelmente do escopo de interesse principal deste projeto e, portanto, decidimos utilizar música simbólica como solução para a entrada do sistema. Ao fazermos essa escolha existem alguns pontos a serem considerados.

Inicialmente, precisamos escolher o protocolo de comunicação entre os instrumentos digitais e o computador. Nos dias de hoje, os dois principais protocolos utilizados são o MIDI ${ }^{1}$ e o OSC ${ }^{2}$.

MIDI é acrônimo de Musical Instrument Digital Interface e seu protocolo define diversas mensagens que podem ser emitidas por um controlador. Mensagens de controle musical são definidas com no máximo 3 bytes. O primeiro byte possui o tipo do evento (nos 4 primeiros bits) e os bytes seguintes possuem informações específicas do evento. Veja na tabela abaixo os principais tipos de eventos MIDI:

\begin{tabular}{|l|l|l|l|l|}
\hline evento & \multicolumn{2}{|l|}{ byte 1} & byte 2 & byte 3 \\
\hline & 4 bits iniciais & 4 bits finais & & \\
\hline note off & 1000 & canal MIDI & número da nota & intensidade \\
note on & 1001 & canal MIDI & número da nota & intensidade \\
note aftertouch & 1010 & canal MIDI & número da nota & nível de pressão \\
controller & 1011 & canal MIDI & número do controle & valor do controle \\
program change & 1100 & canal MIDI & número do instrumento & não utilizado \\
channel aftertouch & 1101 & canal MIDI & nível de pressão & não utilizado \\
pitch bend & 1110 & canal MIDI & valor (LSB) & valor (MSB) \\
\hline
\end{tabular}

Com os eventos note on e note off (emitidos quando uma nota é iniciada e finalizada, respectivamente) podemos obter o tempo de ataque $t_{\text {noteon }}$ e a duração $t_{\text {noteoff }}-t_{\text {noteon }}$ de uma nota.

\footnotetext{
${ }^{1}$ http://www.midi.org/

${ }^{2}$ http://opensoundcontrol.org/
} 
Com o evento note on ainda podemos obter a altura musical (MIDI number) e a intensidade (MIDI velocity) de cada nota tocada $\left[\mathrm{A}^{+} 96\right]$.

Ainda temos as mensagens dos tipos note aftertouch e channel aftertouch que declaram mudanças na quantidade de pressão aplicadas na produção de uma nota específica e de todas as notas de um mesmo canal, respectivamente, entre os eventos note on e o note off. O evento do tipo pitch bend é bastante utilizado também e promove inflexões nas alturas musicais relativas a todas as notas soando em um dado instante $\left[\mathrm{A}^{+} 96\right]$.

OSC é acrônimo de Open Sound Control e seu protocolo, diferentemente do MIDI, não possui um modelo de mensagens padrão. Isso, segundo seus criadores, é de extrema vantagem, pois os usuários têm a liberdade de criar suas próprias mensagens de forma hierárquica com uma sintaxe mais legível [FS09].

No entanto, para viabilizar a comunicação entre dispositivos de controle e o nosso sistema, um conjunto de mensagens precisa ser predefinido. Encontramos uma ferramenta de conversão entre MIDI e OSC que nos fornece uma representação para OSC dos eventos MIDI vistos anteriormente de exemplo, conforme ilustrado na figura 2.1.

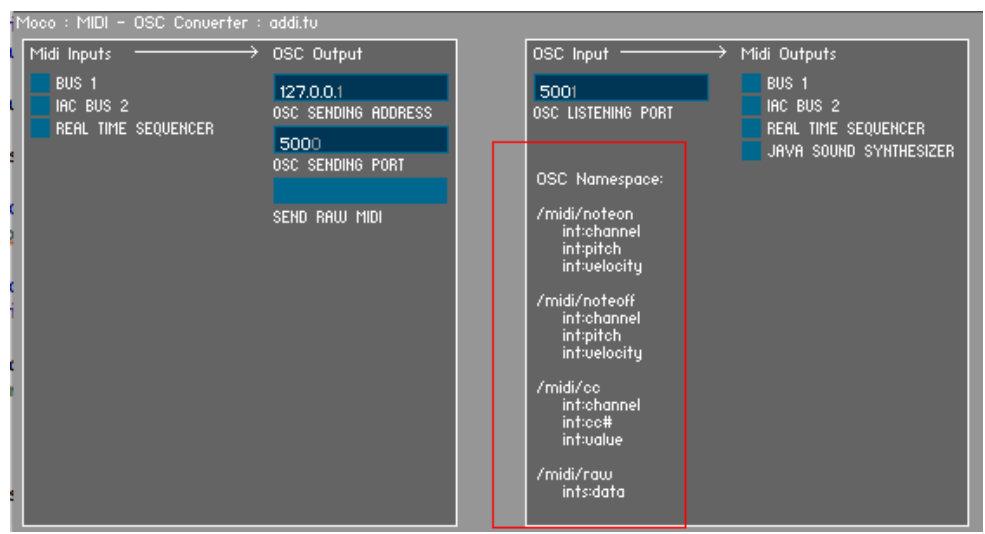

Figura 2.1: $M O C O$ - conversor entre MIDI e OSC (http://addi.tv/moco/).

Podemos encontrar na literatura algumas discussões em relação a qual desses dois protocolos é o mais adequado a cada tipo de tarefa [FSZ07, $\mathrm{A}^{+} 08$ ], e decidimos utilizar o MIDI devido a vários motivos, que incluem:

- MIDI possui diversas mensagens padrões que suprem todas as nossas necessidades em relação à entrada. Por serem específicas, tais mensagens são definidas com poucos bytes de informação, o que torna o tráfego de dados baixo.

- MIDI é praticamente ubíquo quando pensamos em hardware. Exatamente por definir um conjunto padrão de mensagens, o MIDI maximiza a interoperabilidade de dispositivos e foi escolhido por diversas empresas como o padrão da indústria.

Escolhido o protocolo, devemos considerar o fato de estarmos restringindo, de certa forma, o conjunto de instrumentos que poderão ser utilizados na entrada. Isso se deve ao fato de que nem todos os instrumentos musicais possuem versões MIDI, ou boas adaptações digitais através de interfaces MIDI. Instrumentos de sopro e de cordas são bons exemplos disso: controladores de sopro perdem muito da sensibilidade da interação dos lábios com os bocais, e controladores de cordas perdem muito do feedback táctil das cordas com os dedos.

A classe de instrumentos que teve a melhor adaptação para dispositivos digitais é, sem dúvida nenhuma, a dos instrumentos de teclas similares as do piano. As mensagens MIDI vistas acima casam perfeitamente com a interface de controle de tais instrumentos. A associação entre o pressionar de uma tecla com o evento note on e a liberação com o evento note off, por exemplo, é tão natural que não é de se espantar que essa classe se tornou a interface mais popular para dispositivos MIDI. 
Uma última consideração a ser feita é que a escolha do MIDI como solução para a entrada não impede que os usuários utilizem o nosso sistema com instrumentos acústicos. Existem diversas aplicações de transcrição melódica que podem analisar o áudio e converter a frequência fundamental de cada nota para o número MIDI relativo. Tal conversão poderá apresentar alguns erros como, por exemplo, de arredondamento. Uma frequência detectada de $190,5 \mathrm{~Hz}$ poderia ser associada ao número MIDI $55(\sim 196 \mathrm{~Hz})$ ou ao número MIDI $54(\sim 185 \mathrm{~Hz})$. No entanto, nosso sistema será robusto o suficiente para lidar com erros de conversão desse tipo, como o leitor poderá observar no decorrer deste capítulo.

Definido o formato de entrada para a execução em tempo real, precisamos definir o formato de partitura da música a ser acompanhada. Escolher um bom formato de partitura é fundamental para a qualidade de nosso sistema. Não desejamos fazer restrição nenhuma de gênero musical que será escolhido pelo usuário. Porém, pelo caráter pedagógico do mesmo, precisamos escolher um formato digital que represente bem partituras ocidentais tradicionais, pois esse é o contexto de maior uso desse tipo de sistema. Tal formato deve contemplar um conjunto mínimo de símbolos necessários para os algoritmos de rastreamento de partitura que iremos implementar.

Um arquivo de texto com uma lista de notas ordenadas no tempo com suas alturas musicais e durações seria suficiente. No entanto, existem alternativas melhores do que essa, como veremos a seguir. Existem diversos formatos de arquivos para notação musical na Internet: ABC, GUIDO, MIDI, MusicXML, MusiXTeX, NIFF, os formatos próprios de softwares como Finale, Forte, LilyPond, MuseScore, Sibelius, SongWrite, etc ${ }^{3}$. Para escolhermos qual deles vamos adotar como padrão, utilizamos os quesitos discutidos a seguir:

1. O primeiro quesito de escolha é que o formato seja aberto. Um formato proprietário normalmente vem acompanhado de um software proprietário e isso fere a liberdade do usuário de diversas maneiras [Sta94]. De acordo com Richard Stallman, usuários deveriam poder ler, consertar, adaptar e melhorar os dados e as aplicações, não só usá-los [Sta94].

2. O segundo quesito é a facilidade dos usuários encontrarem arquivos na Internet. Como o nosso sistema possui papel fundamental pedagógico, consideramos de alta importância a disponibilidade de arquivos no formato escolhido em repositórios online.

3. O terceiro é o suporte a diversos símbolos musicais. Muitos dos algoritmos de rastreamento de partitura precisam somente de informações básicas, como alturas e durações das notas. No entanto, conforme o leitor irá observar no decorrer do texto, algumas marcações na partitura referentes a variações de andamento (como accelerando e ritardando, por exemplo) poderiam ajudar a aumentar a qualidade do sistema.

4. O quarto e último quesito é a quantidade de software disponível para a edição de arquivos no formato escolhido. Muitos arquivos disponibilizados em repositórios públicos contêm erros e é imprescindível nesse caso que o usuário possa editar e corrigir os erros na mão, tarefa essa que requer um editor de partitura. Hoje em dia temos vários editores que realizam tal tarefa e queremos adotar um formato que dê muitas opções ao usuário.

Levando em consideração esses quesitos, o formato de arquivo escolhido foi o MIDI. Apesar do formato ser fortemente controlado pela MIDI Manufacturers Association ${ }^{4}$, a especificação não é fechada e pode ser obtida facilmente pela Internet. Além disso, a transparência dos arquivos não é afetada pelo fato de serem binários. Existem programas, como por exemplo o MIDICSV ${ }^{5}$, que convertem arquivos MIDI para arquivos CSV (Comma-Separated Values) tornando a sua leitura mais amigável. O tipo do evento vem escrito por extenso (Note_on_c e Note_off_c), o canal MIDI é convertido para base 10 e os valores de número MIDI e de intensidade são apresentados dentro do intervalo $[0,127]$ (conforme podemos ver na imagem 2.2).

\footnotetext{
${ }^{3}$ http://www.music-notation.info/en/compmus/notationformats.html

${ }^{4}$ http://www.midi.org/aboutus/aboutmma.php

${ }^{5}$ http://www.fourmilab.ch/webtools/midicsv/
} 


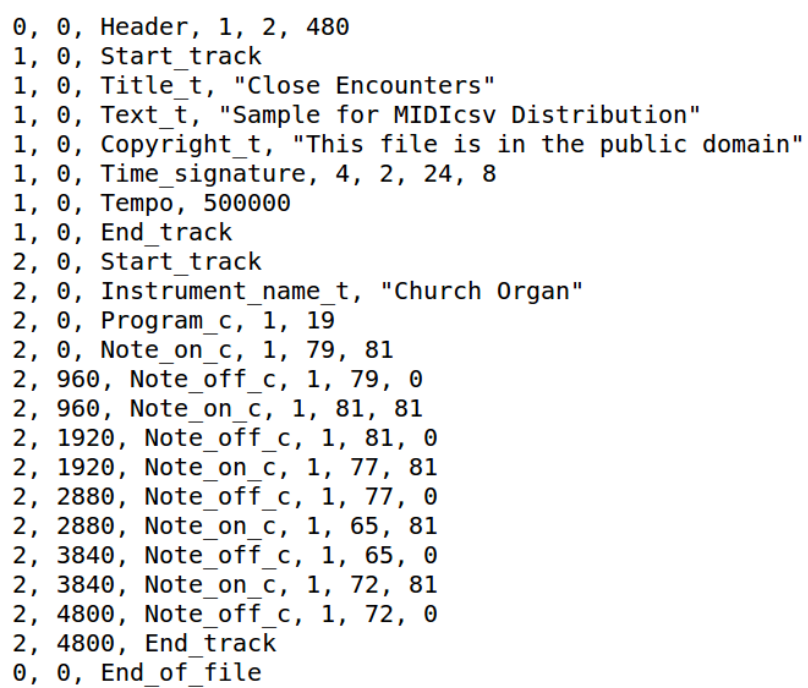

Figura 2.2: Exemplo de um arquivo CSV convertido de um arquivo MIDI.

Além disso, o MIDI é o formato que aparece com maior frequência em repositórios online como o International Music Score Library Project ${ }^{6}$, Project Gutenberg ${ }^{7}$ e Mutopia ${ }^{8}$. A popularidade se mantém em relação a programas de edição também. Todos os editores de partitura citados acima Finale, Forte, LilyPond, MuseScore, Sibelius e SongWrite - trabalham com o formato MIDI.

O único quesito que o MIDI não supriu por padrão é a abrangência no suporte a diversos símbolos musicais. No entanto, isso é resolvido pelo fato da especificação permitir a criação de novas mensagens personalizadas. Mais ainda, David Cooper e coautores [CNB97] criaram uma extensão da especificação MIDI - expMIDI - compatível com o formato de arquivo padrão do MIDI de 1988, que contém diversos símbolos de dinâmica, articulação, entre outros (conforme podemos ver na figura 2.3), implementados como mensagens exclusivas de sistema (MIDI System Exclusive), e que poderiam ser utilizadas para tornar o sistema mais robusto.

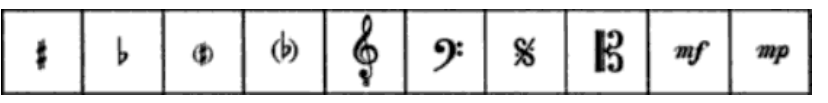

Figura 2.3: Exemplos de símbolos musicais contemplados pela extensão expMIDI [CNB977].

Além dos argumentos apresentados acima, a escolha do MIDI como formato de partitura e como protocolo de comunicação com os instrumentos da entrada eliminará qualquer necessidade de conversão de dados que ocorreria caso estivéssemos trabalhando com domínios diferentes de representação na entrada e na partitura.

\subsection{Pré-processador da entrada}

O módulo pré-processador irá lidar com a entrada do sistema. Ele receberá um stream em tempo real relativo à execução musical do usuário e será responsável por interpretá-lo e alterá-lo. O formato dos eventos desse stream já foi apresentado na seção anterior; precisaremos extrair deles informações como, por exemplo, altura musical, tempo de ataque e duração. A extração dessas informações é de extrema importância tanto para a execução correta dos algoritmos (precisamos identificar precisamente o que o músico está tocando, pois os eventos serão propagados para os próximos módulos), quanto para o tempo de resposta do sistema (precisamos gerar a saída com pouca latência para tornar satisfatória a experiência do usuário).

\footnotetext{
${ }^{6}$ http://imslp.org/

${ }^{7}$ http://www.gutenberg.org/

${ }^{8}$ http://www.mutopiaproject.org/
} 


\begin{tabular}{|c|c|c|c|c|c|c|}
\hline \multirow{2}{*}{$\begin{array}{l}\text { MIDI } \\
\text { number } \\
4 i\end{array}$} & $\begin{array}{l}\text { Note } \\
\text { name }\end{array}$ & Keyboard & \multicolumn{2}{|c|}{$\frac{\text { Frequency }}{\mathbf{H z}}$} & \multicolumn{2}{|c|}{$\frac{\text { Period }}{\mathrm{ms}}$} \\
\hline & & & 130.81 & & 7.645 & \\
\hline $\begin{array}{ll}48 & 49 \\
50 & 51\end{array}$ & D3 & & $\begin{array}{l}146.83 \\
164.81\end{array}$ & $\begin{array}{l}138.59 \\
155.56\end{array}$ & 6.811 & $\begin{array}{l}7.216 \\
6.428\end{array}$ \\
\hline 3 & F3 & & 174.61 & & 5.727 & \\
\hline 54 & G3 & & 196.00 & 185.00 & 5.102 & 5.405 \\
\hline 57 & $\mathrm{~A} 3$ & & 220.00 & 207. & 4.545 & 4.816 \\
\hline 59 & & & 246.94 & 233.06 & & \\
\hline 60 & & & $\begin{array}{l}261.63 \\
29367\end{array}$ & 277.18 & $\begin{array}{l}3.822 \\
3405\end{array}$ & 3.608 \\
\hline 64 & & & 329.63 & 311.13 & & 3.214 \\
\hline 65 & $\mathrm{~F}$ & & 349 & & 2.8 & \\
\hline 67 & $\mathrm{G}$ & & 392.00 & 369.99 & 2.551 & 2.703 \\
\hline 69 & & & 440.00 & & 2.273 & $\begin{array}{l}2.408 \\
2.145\end{array}$ \\
\hline & & & & & 2.023 & \\
\hline & & & & 5.5. & & 1 \\
\hline
\end{tabular}

Figura 2.4: Relação entre diversos domínios para representação de altura musical.

O protocolo MIDI possui mensagens bem definidas o que torna a tarefa de interpretar os eventos a menos trabalhosa. O principal papel do módulo pré-processador, portanto será modificar a sequência de eventos provenientes da entrada. Diversas heurísticas foram encontradas na literatura abordada com técnicas relativas a tal papel. Na próxima seção deste capítulo o leitor verá técnicas para rastreamento de partitura que consideram que a entrada seja de um instrumento monofônico. No entanto, uma das técnicas implementadas aceita entradas polifônicas, e por isso não queremos inibir a utilização de instrumentos MIDI polifônicos na entrada. Por isso, torna-se função do módulo pré-processador garantir a característica de monofonia nos eventos passados para o módulo rastreador, quando a técnica de rastreamento assim exigir.

O problema de lidar com entradas polifônicas foi abordado por Roger Dannenberg e Joshua Bloch em um artigo de 1985 [BD85]. Em um dos algoritmos propostos, os eventos da execução ao vivo são agrupados em eventos compostos. Tal algoritmo considera os intervalos de tempo entre as notas da entrada e as agrupa em um mesmo evento composto quando satisfizerem certas condições. A primeira delas consiste em verificar se o intervalo de tempo entre a nota atual e a anterior é menor do que um limiar arbitrariamente escolhido entre 90ms (intervalo máximo determinado empiricamente pelos autores entre notas de um mesmo acorde) e $125 \mathrm{~ms}$ (intervalo de tempo entre semicolcheias a 120BPM). A segunda condição tenta resolver ambiguidades em casos no qual a primeira condição falha: quando um músico toca um acorde em arpejo e os intervalos entre as notas desse acorde extrapolam o limiar fixado. Para resolver essas ambiguidades são consideradas as distâncias temporais entre a nota atual e as duas notas vizinhas (anterior e posterior): a nota atual é agrupada quando ela estiver mais próxima da anterior do que da posterior, conforme ilustrado na figura 2.5.

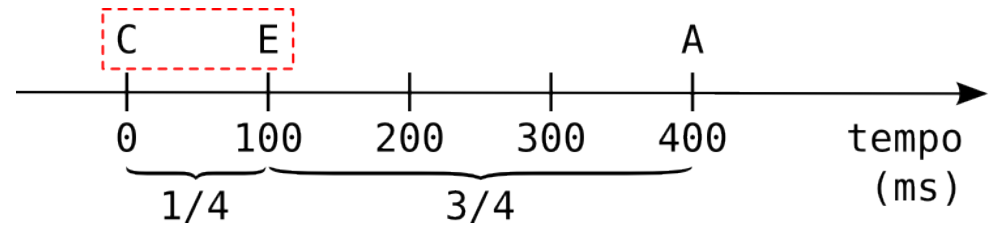

Figura 2.5: Segunda condição para agrupamento de notas em um evento composto.

Com isso, obtemos uma sequência monofônica de eventos e, usando rótulos especiais para esses eventos compostos, podemos passá-los para o módulo Rastreador comparar com o evento de rótulo correspondente na partitura.

Outras heurísticas foram sugeridas na literatura, como a de utilizar equivalência de oitavas nas notas da entrada [DM88], dando uma liberdade maior para o músico tocar na oitava que desejar. Isso pode ser implementado aplicando uma simples operação de módulo 12 nos valores de notas MIDI (conforme ilustrado na imagem 2.6). 


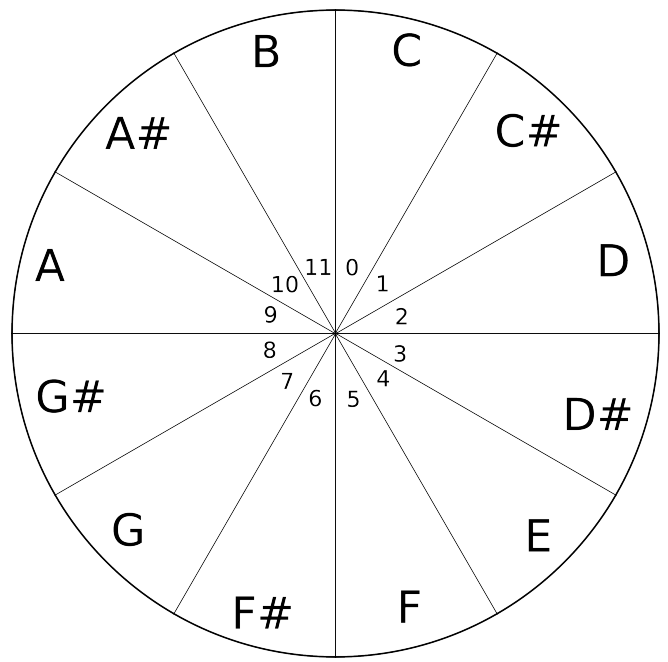

Figura 2.6: Equivalência de oitavas para os números de notas MIDI (mod 12).

\subsection{Métodos rastreadores}

O módulo rastreador é o responsável por casar os eventos provenientes do primeiro módulo com os eventos da partitura, assim detectando em tempo real as posições do músico na partitura e relatando-as para o próximo módulo. Nesta seção veremos detalhes sobre cinco algoritmos de rastreamento de partitura.

\subsubsection{Dannenberg (1984)}

O primeiro algoritmo de rastreamento de partitura apresentado é proveniente do artigo An OnLine Algorithm for Real-Time Accompaniment escrito por Roger Dannenberg no ano de 1984 [Dan84]. Ele faz uma simplificação das informações disponíveis nos eventos da entrada e utiliza apenas a altura musical de cada nota. Altura musical é uma das propriedades perceptuais mais importantes do som (junto com duração, intensidade e timbre) [Lac67]. Ela determina se uma nota é mais grave ou mais aguda e normalmente está associada a um nome de nota e sua oitava (Lá 4 ou Dó\# 1, por exemplo), e se relaciona com o atributo físico denominado frequência (a nota Lá 4 é frequentemente associada à frequência de $440 \mathrm{~Hz}$, por exemplo). Porém, conforme vimos anteriormente, utilizaremos MIDI como protocolo de entrada e, portanto, as alturas musicais das notas estarão em outro domínio: números de nota MIDI.

Podemos considerar para este primeiro algoritmo que a entrada é uma sequência de números inteiros ou, se quisermos abstrair mais ainda, uma sequência de dados primitivos (chamaremos deste ponto em diante de símbolos). Além disso, vimos que a partitura armazenada em memória também está no formato MIDI e podemos considerar que a partitura do solista também é uma sequência de símbolos. Símbolos são trivialmente comparados em qualquer linguagem de programação e, com tais suposições, o problema de comparar execução e partitura é reduzido ao de comparar duas sequências de símbolos (conforme ilustrado na figura 2.7). A ideia é casar o maior número possível de eventos da entrada com eventos da partitura e vice-versa.

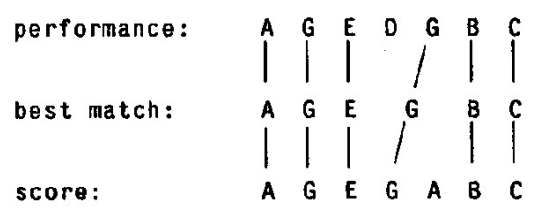

Figura 2.7: Exemplo de casamento entre símbolos da entrada com símbolos da partitura [Dan84]. 
O autor do artigo afirma que a comparação entre execução e partitura está intimamente relacionada com o problema de encontrar as diferenças entre dois arquivos de texto (problema resolvido tradicionalmente pelo comando diff). Para isso, o autor utiliza o clássico algoritmo de programação dinâmica para encontrar a maior subsequência comum entre duas sequências de símbolos.

Seguindo a mesma estratégia dos algoritmos de divisão e conquista, algoritmos de programação dinâmica resolvem um problema quebrando-o em subproblemas menores, resolvendo-os e combinando essas soluções. Tal método pode ser dividido em quatro passos [CLRS01]:

- caracterizar a estrutura da solução ótima;

- definir recursivamente o valor de uma solução ótima;

- calcular o valor de uma solução ótima de maneira bottom-up;

- construir a solução ótima a partir dos resultados obtidos.

O teorema abaixo [CLRS01] nos dá a estrutura da solução ótima para o problema da maior subsequência comum:

Teorema: Seja $X=x_{1}, x_{2}, \ldots, x_{m}$ e $Y=y_{1}, y_{2}, \ldots, y_{n}$ duas sequências e seja $Z=$ $z_{1}, z_{2}, \ldots, z_{k}$ uma maior subsequência comum de $\mathrm{X}$ e $\mathrm{Y}$.

- Se $x_{m}=y_{n}$, então $z_{k}=x_{m}=y_{n}$ e $Z_{k-1}$ é uma maior subsequência comum de $X_{m-1}$ e $Y_{n-1}$.

- Se $x_{m} \neq y_{n}$, então $z_{k} \neq x_{m}$ implica que Z é uma maior subsequência comum de $X_{m-1}$ e Y.

- Se $x_{m} \neq y_{n}$, então $z_{k} \neq y_{n}$ implica que $\mathrm{Z}$ é uma maior subsequência comum de $\mathrm{X}$ e $Y_{n-1}$.

Com tal estrutura podemos definir uma solução recursiva para encontrar a maior subsequência comum entre X e Y [CLRS01]:

- se $x_{m}$ é igual a $y_{n}$ devemos achar a maior subsequência comum entre $X_{m-1}$ e $Y_{n-1}$. E concatenando $x_{m}=y_{n}$ a essa subsequência temos a maior subsequência comum entre $\mathrm{X}$ e $\mathrm{Y}$.

- se $x_{m}$ é diferente de $y_{n}$ devemos achar a maior subsequência comum entre $X_{m-1}$ e Y, e entre $\mathrm{X}$ e $Y_{n-1}$. A maior delas será a maior subsequência comum de $\mathrm{X}$ e $\mathrm{Y}$.

A solução recursiva dada acima claramente possui cálculos repetidos (por exemplo, tanto a pilha de execução de $\mathrm{X}$ e $Y_{n-1}$, quanto a de $X_{m-1}$ e $\mathrm{Y}$ irão calcular a maior subsequência comum entre $X_{m-1}$ e $\left.Y_{n-1}\right)$. Para evitar recálculos dessa maneira pode-se encontrar o valor da maior subsequência comum entre $\mathrm{X}$ e $\mathrm{Y}$ utilizando uma implementação direta que computa em uma matriz $C$ os tamanhos $C_{i, j}$ das subsequências máximas entre $X_{i}$ e $Y_{j}$ [CLRS01].

A matriz resultante irá armazenar os tamanhos das soluções ótimas para os subproblemas, conforme ilustrado na figura 2.8 .

Voltando ao problema de comparar a execução com a partitura do solista, podemos aplicar esse algoritmo com a sequência $X$ sendo os eventos da partitura e a sequência $Y$ sendo os eventos da entrada, ambos referentes à parte do solista. Porém, não temos a sequência de eventos da entrada por completo na memória, ou seja, a sequência da entrada é gerada conforme a execução vai evoluindo. Assim, o algoritmo acima precisa passar por uma modificação para rodar em tempo real, na qual calcularíamos uma coluna inteira da matriz a cada nota que chega da entrada (conforme ilustrado na figura 2.9).

O autor ainda apresenta duas modificações para o algoritmo em tempo real acima. Para ficar mais eficiente, iremos olhar somente para uma janela em torno do evento atual na partitura e, 
performance:

$\begin{array}{lllllllll}\text { score : } & \text { A } & \text { G } & \text { E } & \text { D } & \text { G } & \text { B } & \text { C } \\ \text { A } & 1 & 1 & 1 & 1 & 1 & 1 & 1 \\ \text { G } & 1 & 2 & 2 & 2 & 2 & 2 & 2 \\ \text { E } & 1 & 2 & 3 & 3 & 3 & 3 & 3 \\ \text { G } & 1 & 2 & 3 & 3 & 4 & 4 & 4 \\ \text { A } & 1 & 2 & 3 & 3 & 4 & 4 & 4 \\ \text { B } & 1 & 2 & 3 & 3 & 4 & 5 & 5 \\ \text { C } & 1 & 2 & 3 & 3 & 4 & 5 & 6\end{array}$

Figura 2.8: Exemplo de matriz calculada para o problema da maior subsequência comum [Dan84].

performance:

$\begin{array}{llllllll} & & \text { A } & \text { G } & \text { E } & \text { D } & \text { G B C } \\ \text { score: } & \text { A } & 1 & 1 & 1 & 1 & & \\ \text { G } & 1 & 2 & 2 & 2 & \\ \text { E } & 1 & 2 & 3 & 3 \\ \text { G } & 1 & 2 & 3 & 3 \\ \text { A } & 1 & 2 & 3 & 3 \\ \text { B } & 1 & 2 & 3 & 3 \\ \text { C } & 1 & 2 & 3 & 3\end{array}$

Figura 2.9: Cálculo em tempo real das colunas da matriz conforme eventos da entrada são recebidos [Dan84].

\begin{tabular}{lllllllll} 
& performance: \\
score: & \multicolumn{1}{c}{ A } & G & E & D & G & B & C \\
A & 1 & 1 & & & & & \\
G & 1 & 2 & 2 & & & & \\
E & 1 & 2 & 3 & 3 & & & \\
G & & & 3 & 3 & 4 & 4 & \\
A & & & & 3 & 4 & 4 & 4 \\
B & & & & & 4 & 5 & 5 \\
C & & & & & & & 6
\end{tabular}

Figura 2.10: Utilização de janelas para cálculo das colunas da matriz [Dan84].

assim, não iremos comparar a nota recém chegada com todas as notas da partitura. Para economizar memória, não iremos guardar a matriz completa, mas somente as colunas atual e anterior.

A janela introduzida no parágrafo acima (ilustrada na figura 2.10) possui algumas rotinas para atualização de posição e tamanho.

A rotina de atualização de posição funciona assim: após o cálculo completo de todos os valores da coluna atual, verificamos se houve um aumento no valor da maior subsequência comum (queremos saber se a nova nota incrementou a subsequência comum). Se um novo valor máximo global foi detectado, iremos centralizar a janela ao redor do evento posterior ao recém casado. Caso contrário, iremos descer a janela uma linha apenas.

Observe que a decisão de descer uma linha mesmo que o valor da maior subsequência comum não seja incrementado é essencial para a dinâmica do algoritmo. Sem essa regra a janela ficaria estática até uma nota interna a ela chegar na entrada e, assim, um casamento futuro de uma nota externa a ela não seria detectado. A figura 2.11 mostra os comportamentos antagônicos de utilizar ou não tal regra.

Em relação ao tamanho da janela, ele é calculado como $(2 \times E)+1$, onde E é o número de erros cometidos pelo músico em um dado instante da performance. Aumentar o tamanho da janela de forma diretamente proporcional ao número de erros cometidos induz o algoritmo a considerar um conjunto maior de notas da partitura, com intuito de verificar mais possibilidades de casamentos 


\begin{tabular}{|c|c|c|c|c|c|}
\hline & B & B & B & $B$ & B \\
\hline C & 0 & 0 & 0 & 0 & 0 \\
\hline D & 0 & 0 & 0 & 0 & 0 \\
\hline$A$ & 0 & 0 & 0 & 0 & 0 \\
\hline$F$ & & & & & \\
\hline A & & & & & \\
\hline $\mathrm{E}$ & & & & & \\
\hline B & & & & & \\
\hline$\Delta$ & & & & & \\
\hline
\end{tabular}

(a)

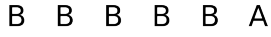

C 0

D $\quad 0 \quad 0$

A $\quad 0 \quad 0 \quad 0$

F $\quad 0 \quad 0 \quad 0$

A $\quad 0 \quad 0 \quad 0$

E $\quad 0 \quad 0 \quad 0$

B $\quad 1 \quad 1$

A $\quad$ (b) 2

Figura 2.11: Comportamentos do algoritmo de Dannenberg1984 com a janela estática (a) e dinâmica (b).

dado que as notas recém chegadas diferem das notas esperadas.

Os tipos de erros tratados pelo algoritmo são adições, deleções e substituições de notas. Tais erros são facilmente detectados pela técnica, pois símbolos extras, faltantes e diferentes ficam de fora da maior subsequência comum.

Por último, falta definir quando o algoritmo envia relatos para o próximo módulo. A técnica apresentada acima calcula apenas o tamanho da maior subsequência comum, porém não armazena quais foram as notas utilizadas. No entanto, isso não é necessário, pois apenas precisamos enviar a posição do músico na partitura. Isso é feito da seguinte maneira: toda vez que uma nota gerar um valor máximo global de tamanho de subsequência comum iremos relatar que aquela nota naquele ponto da partitura gerou um casamento (conforme podemos ver na figura 2.12). Caso esse valor global não aumente para a iteração atual, consideramos um erro e não produzimos relatos.

\section{performance :}

$\begin{array}{lllllllll} & & \text { A } & G & \text { E } & \text { D } & \text { G } & \text { B } & \text { C } \\ \text { score: } & A & 1 & 1 & 1 & 1 & 1 & 1 & 1 \\ \text { G } & 1 & 2 & 2 & 2 & 2 & 2 & 2 \\ \text { E } & 1 & 2 & 3 & 3 & 3 & 3 & 3 \\ \text { G } & 1 & 2 & 3 & 3 & 4 & 4 & 4 \\ \text { A } & 1 & 2 & 3 & 3 & 4 & 4 & 4 \\ \text { B } & 1 & 2 & 3 & 3 & 4 & 5 & 5 \\ \text { C } & 1 & 2 & 3 & 3 & 4 & 5 & 6\end{array}$

Figura 2.12: Atualizações da matriz que irão gerar relatos de casamentos [Dan84].

Sobre a qualidade da técnica, o autor do artigo deixa claro que a utilização da janela centralizada na nota esperada irá impedir o algoritmo de encontrar o melhor casamento global de fato entre entrada e partitura (que seria encontrado caso tivéssemos as duas sequências em memória e rodássemos o algoritmo em sua versão offline). Portanto, é essencial que o músico faça uma execução muito próxima da esperada.

\subsubsection{Lippe (1992)}

Uma outra técnica foi encontrada na literatura que utiliza as alturas musicais como única informação relevante dos eventos de entrada. No artigo Score Following in Practice de 1992 [LP92], Cort Lippe e Miller Puckette descrevem de forma bem prática um algoritmo que promete resolver o problema de rastreamento de partitura. Esse algoritmo foi considerado para ser implementado exatamente pela descrição clara e objetiva de seus processos internos. Inicialmente, o sistema recebe dois parâmetros de entrada, que irão condicionar todo o comportamento do rastreamento:

- N (skip number): um inteiro não-negativo que define um número de notas;

- T (skip time): um inteiro não-negativo que define um intervalo de tempo. 
O algoritmo, pelos mesmos motivos da técnica anterior, considera apenas um subconjunto de eventos da partitura para fazer comparações. No entanto, ele não trabalha com uma janela centralizada no evento esperado e não varre a vizinhança desse evento de forma linear e uniforme. $\mathrm{O}$ algoritmo analisa 4 regiões disjuntas (mostradas na figura 2.13).

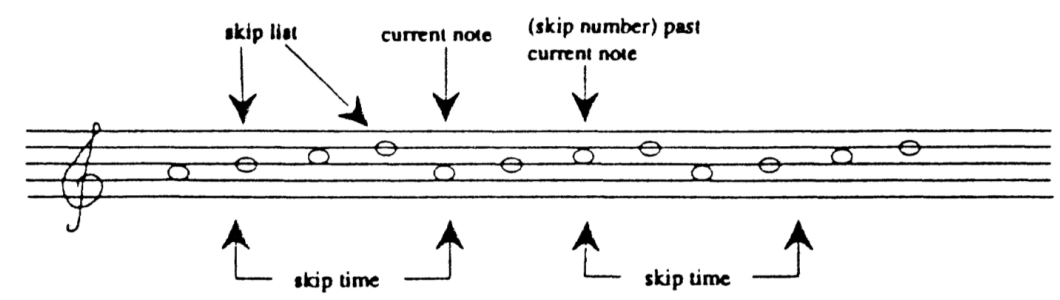

Figura 2.13: Regiões consideradas pelo algoritmo de Lippe92 [LP92].

O algoritmo utiliza um ponteiro para a nota atual (current note) e uma skip list que aponta para eventos anteriores à nota atual, com um intervalo de no máximo $\mathrm{T}$ unidades de tempo e que ainda não foram casados. Além disso, temos uma terceira região com N notas consecutivas após a nota atual e uma quarta região que é composta pelos eventos posteriores à última nota da terceira região, com um intervalo de tempo de no máximo $\mathrm{T}$ unidades.

Podemos observar que temos apenas duas estruturas de dados para manter - o ponteiro para a nota atual e a skip list - pois as regiões 3 e 4 são obtidas em relação à nota esperada varrendo a própria estrutura que armazena a partitura da esquerda para a direita e verificando se $\mathrm{N}$ notas foram alcançadas (para a terceira região) e se o intervalo de tempo $\mathrm{T}$ foi alcançado (para a quarta região).

O algoritmo é inicializado com o ponteiro current note na primeira nota da partitura e a skip list vazia. Para cada nota que chega da entrada é feita uma tentativa de casamento, comparando apenas a altura musical, com notas dessas 4 regiões seguindo a seguinte ordem. Primeiro, um casamento é solicitado na skip list. Se nenhum casamento for encontrado, daremos prosseguimento a partir da nota atual e das $\mathrm{N}$ notas na sequência da esquerda para a direita. Se ainda nenhum casamento for encontrado, iremos olhar as notas após essa sequência enquanto um intervalo de tempo T não for alcançado.

Caso alguma das notas a partir da atual gere um casamento, devemos atualizar todos os ponteiros. O ponteiro current note agora irá apontar para a nota imediatamente depois da recém casada. Enquanto a skip list irá ganhar as notas que ainda não foram casadas entre a esperada anterior e a esperada atual, e irá perder todas as notas mais velhas do que $\mathrm{T}$ em relação à nova nota esperada. Um exemplo de atualização é dado na imagem 2.14 (com N $=2$ e $\mathrm{T}=200)$.

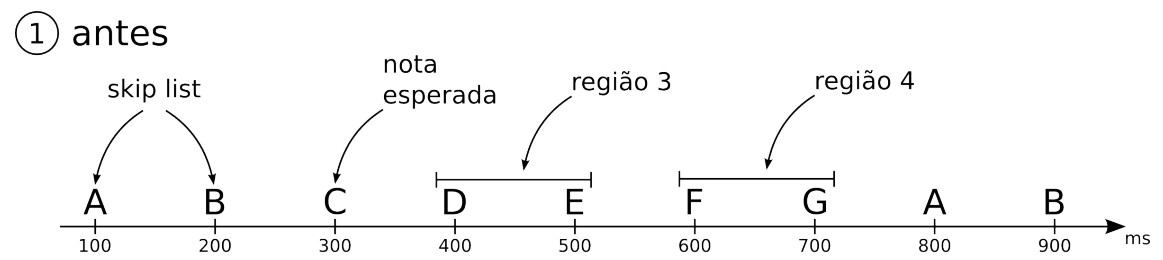

(2) chegou um D na entrada

(3) depois

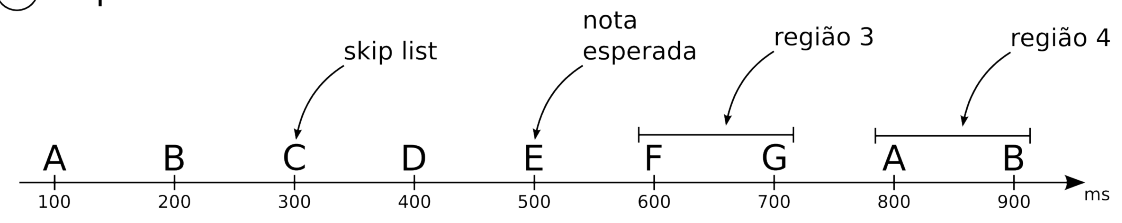

Figura 2.14: Exemplo de atualização das estruturas de dados após a detecção de um casamento.

No artigo, os autores discutem quais seriam bons valores para $\mathrm{N}$ e $\mathrm{T}$, oferecendo sugestões de 
valores específicos (bons valores para N são 1 ou 2 e um intervalo bom para T é de 100 até 300ms).

O skip number foi o parâmetro adotado para passagens musicais lentas nas quais duas notas podem estar mais distantes do que $\mathrm{T}$ entre si e, com a terceira região determinada por $\mathrm{N}$, temos garantia de que algumas notas (N no mínimo) serão verificadas após a esperada (conforme figura 2.15).

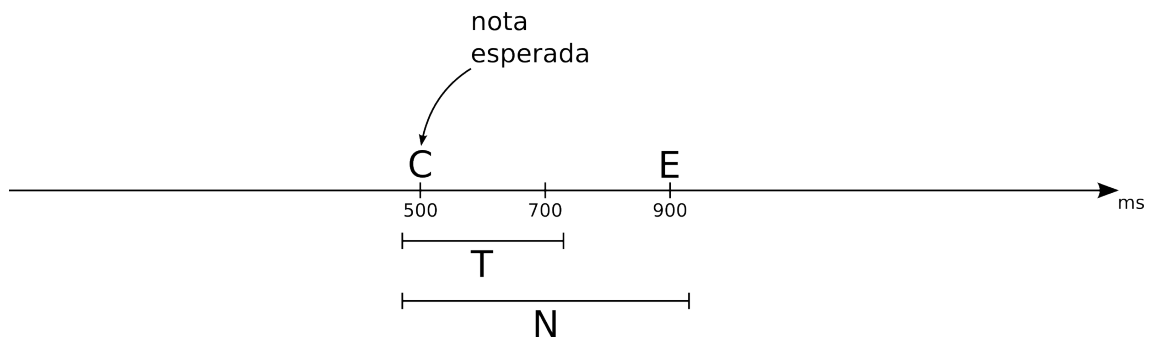

Figura 2.15: Exemplo de uma nota alcançada pelo parâmetro $N$ (em contraste ao parâmetro $T$ ).

Os autores afirmam que é melhor manter o valor de skip number pequeno, pois quanto maior esse número, maior a chance do algoritmo pular para frente, pois teríamos muitas notas possíveis a partir da atual (problema muito parecido com o controle do tamanho da janela no Dannenberg1984).

$\mathrm{Na}$ figura 2.16 temos o comportamento do algoritmo para dois valores de $\mathrm{N}$ diferentes. Caso $\mathrm{N}$ seja maior ou igual a 4, a sequência "E E G G" da entrada irá casar com a segunda ocorrência na partitura. Caso contrário, irá casar com a primeira.

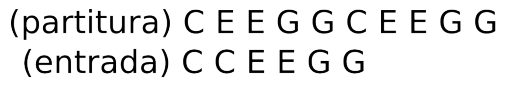

Figura 2.16: Diferentes comportamentos para diferentes skip numbers.

Diferentemente, o skip time foi o parâmetro adotado para a detecção de acordes, onde podemos ter um número grande (maior do que $\mathrm{N}$ ) de notas simultâneas e que não necessariamente serão tocadas na mesma ordem da partitura. Com a utilização desse parâmetro, o algoritmo irá tratar todas as notas que chegarem no intervalo de tempo T (conforme figura 2.17), garantindo a detecção de tais estruturas verticais.

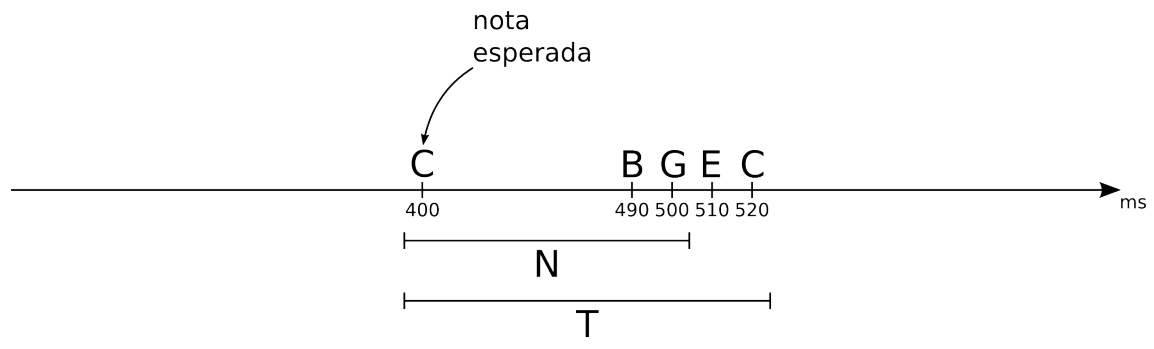

Figura 2.17: Exemplos de notas sendo consideradas pelo parâmetro $T$ (em contraste ao parâmetro $N$ ).

Os autores recomendam deixar o valor de skip time pequeno também, pois os tempos de ataques de notas de um acorde são muito próximos uns dos outros e as durações das notas não são relevantes para tal comparação (conforme ilustrado na figura 2.18).

Ao final do artigo, os autores comentam sobre as limitações do algoritmo. A primeira diz respeito à necessidade do músico manter uma execução bem próxima da que está sendo esperada, pois ao 
(1) acorde com $200 \mathrm{~ms}$

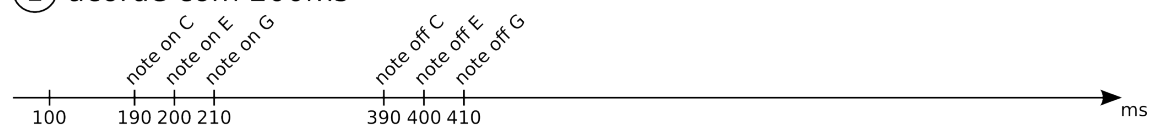

(2) acorde com $600 \mathrm{~ms}$

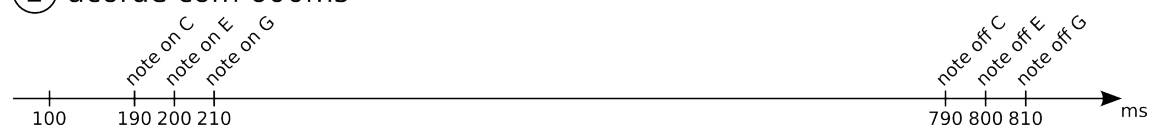

Figura 2.18: Exemplo de acordes de durações diferentes cujos tempos de ataques são próximos da mesma maneira.

utilizar um subconjunto de eventos e tomar decisões de forma local na partitura, o algoritmo não funcionará corretamente se o músico pular compassos ou cometer muitos erros consecutivos. Uma segunda questão está relacionada com passagens musicais nas quais os compositores exigem que os solistas toquem no máximo de suas capacidades. Tais passagens normalmente são executadas em alta velocidade e estão, conforme os autores, entre as mais difíceis de serem rastreadas.

Para lidar com essas dificuldades eles apresentam uma heurística que consiste em fazer uma subamostragem de eventos em trechos de alta densidade de notas e alta velocidade de execução (conforme figura 2.19). Ao modificar a partitura e deixar somente algumas notas mais relevantes, o algoritmo irá gerar menos relatos, porém com maior confiança e, assim, o sistema conseguirá acompanhar o músico mais facilmente.

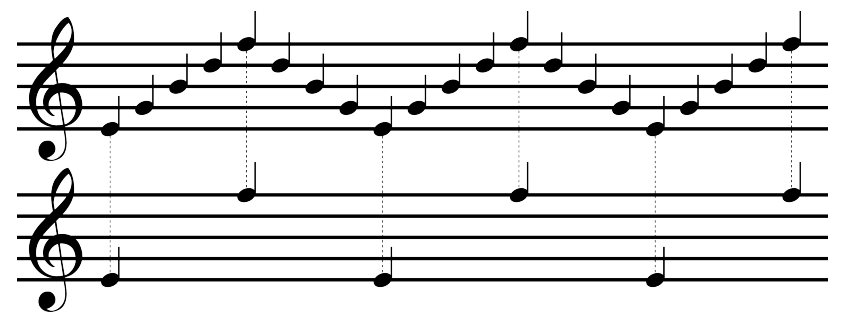

Figura 2.19: Exemplo de subamostragem de notas da partitura.

\subsubsection{Vercoe (1985)}

O próximo algoritmo de rastreamento de partitura selecionado está no artigo de 1985 escrito por Barry Vercoe e Miller Puckette, intitulado Synthetic Rehearsal: Training the Synthetic Performer [VP85]. Esse algoritmo leva em consideração também o tempo de ataque das notas, além da altura musical. Isso significa que o algoritmo irá, diferentemente das técnicas vistas anteriormente, considerar também o instante no qual um evento da entrada se iniciou para decidir se houve um casamento com o evento correspondente da partitura.

Comparar alturas musicais representadas simbolicamente é uma operação trivial, mas comparar tempos de ataque de duas notas é um problema mais complexo. Primeiramente, isso se deve ao fato de que os valores de tempo não são números inteiros ou quantizados em uma escala grosseira: uma nota da entrada que possui tempo de ataque $997 \mathrm{~ms}$ deveria casar com uma nota da partitura esperada aos 1000ms. Além disso, o tempo em uma execução musical via de regra não é metronômico, de onde não faz muito sentido comparar diretamente valores de tempo.

A técnica de rastreamento de partitura aqui apresentada, portanto, precisa manter uma estimativa de qual o andamento do músico. Para realizar essa tarefa o sistema mantém um histórico de tempos dos pares de notas que foram casados no formato $\left(s_{i}, t_{j}\right)$, onde $s_{i}$ é o tempo de ataque do i-ésimo evento na partitura e $t_{j}$ é o tempo de ataque do j-ésimo evento na entrada. A partir desse histórico é feita uma regressão linear, utilizando o método dos mínimos quadrados, e ponderando os pontos de maneira a dar mais peso para os casamentos mais recentes, para obter a reta $t=p \times s+q$. Finalmente, quando um novo evento da entrada chega no tempo $t_{j+1}$ e suspeitamos que ele deveria 
casar com um evento da partitura do tempo $s_{i+1}$, podemos calcular o desvio temporal desse novo ponto $\left(s_{i+1}, t_{j+1}\right)$.

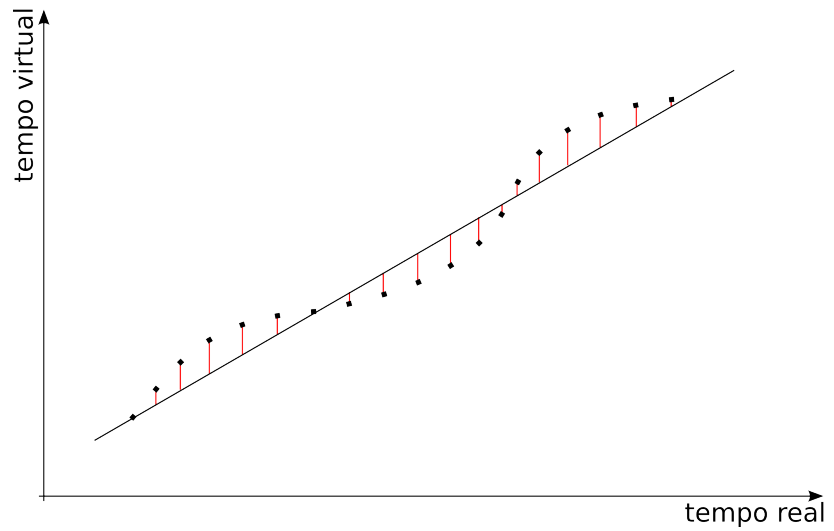

Figura 2.20: Regressão linear pelo método dos mínimos quadrados.

Podemos classificar os tipos de erros com os quais a técnica apresentada irá lidar em duas categorias: erros qualitativos (deleções, adições e substituições) e quantitativos (antecipações e atrasos). Os autores afirmam que o sucesso da técnica está limitado pela habilidade do sistema identificar (e, consequentemente, rejeitar) tais erros e ainda se manter sensível à informação útil disponível.

Para encontrar o casamento ótimo entre a entrada e a partitura essa técnica define uma medida de similaridade entre a entrada e a partitura. Essa similaridade é calculada a partir da teoria de maior valor dentre várias possibilidades de pareamento entre a sequência de eventos da entrada e a sequência de eventos da partitura, conforme descrito a seguir.

Um evento da partitura é um par $(s, x)$ que denota a nota x com tempo de ataque s e a partitura é uma sequência $\left(s_{1}, x_{1}\right),\left(s_{2}, x_{2}\right), \ldots,\left(s_{n}, x_{n}\right)$. Um evento da execução é um par $(t, y)$ que denota a nota y com tempo de ataque t e a entrada é uma sequência $\left(t_{1}, y_{1}\right),\left(t_{2}, y_{2}\right), \ldots,\left(t_{m}, y_{m}\right)$. Uma teoria de pareamento da entrada com a partitura é uma sequência $\left(a_{i}, b_{i}\right)$ estritamente crescente (onde $a_{i}<a_{j}$ e $b_{i}<b_{j}$ quando $\mathrm{i}<\mathrm{j}$ ) que denota que o evento $\left(t_{b_{i}}, y_{b_{i}}\right)$ da entrada corresponde ao (é mapeado no) evento $\left(s_{a_{i}}, x_{a_{i}}\right)$ da partitura, conforme a figura 2.21.

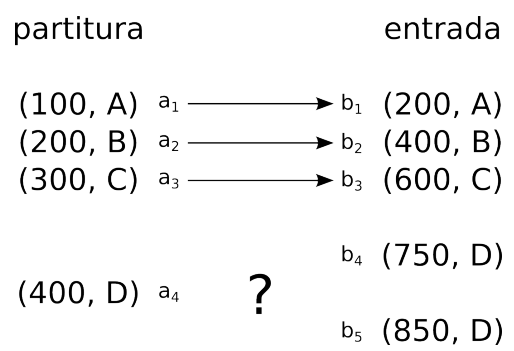

Figura 2.21: Mapeamento dos eventos da entrada nos eventos da partitura.

A cada nota que o músico emite, diversas teorias de pareamento entre a entrada e a partitura podem ser formadas. Podemos fazer diversas suposições em relação a como a entrada até o momento se relaciona com a partitura. Na figura anterior, por exemplo, podemos construir 2 teorias em relação ao evento D da partitura em $400 \mathrm{~ms}$ : ele corresponderia ao D da entrada em $750 \mathrm{~ms}$ ou ao D da entrada em $850 \mathrm{~ms}$. O autor do artigo formaliza tais suposições e sugere 4 tipos de teoria para parear os primeiros i eventos da execução com os primeiros j eventos da partitura:

1. o par $(i, j)$ pode ser um ponto de real correspondência entre a entrada e a partitura;

2. o par $(i, j)$ pode ser uma correspondência de altura cujo tempo nós desejamos ignorar;

3. a i-ésima nota da execução pode ser uma nota extra; 
4. a j-ésima nota da partitura pode ter sido omitida.

Dessas 4 possíveis teorias consideradas precisamos decidir qual delas é a melhor, conforme um critério definido pelos autores em relação ao que seria considerado uma boa execução. Para determinar a distância de uma teoria para a execução ideal são dadas penalidades para cada tipo de erro citado anteriormente, sendo 3 penalidades para erros combinatórios e 3 penalidades para erros de métrica:

- $p_{m}$ : para cada erro de deleção;

- $p_{e}$ : para cada erro de adição;

- $p_{w}$ : para cada erro de substituição;

- $p_{l} \times d$ : para notas cujo tempo será considerado, onde d é o desvio temporal do ponto;

- $p_{t r}$ : para notas certas cujo tempo será ignorado;

- $p_{t w}$ : para notas erradas cujo tempo será ignorado.

O custo total de uma teoria é a soma de todas as penalidades descritas acima:

1. o custo combinatório da melhor teoria $(i-1, j-1)$, somado a $p_{w}$ se a nota atual for errada, somado ao custo do ajuste linear de $(i, j)$;

2. o custo combinatório da melhor teoria $(i-1, j-1)$, somado ao custo $p_{t r}$ se a nota estiver certa ou $p_{t w}$ se a nota estiver errada;

3. o custo da melhor teoria $(i-1, j)$ somado a $p_{e}$;

4. o custo da melhor teoria $(i, j-1)$ somado a $p_{m}$.

Finalmente, o problema de rastrear uma execução se resume a encontrar a teoria de menor custo. Isso é feito em tempo real, calculando os custos das quatro teorias para cada nota que chega, escolhendo localmente a de menor custo e, assim, construindo de forma combinatória a teoria de menor custo global.

Por último, vale a pena enfatizar que os autores afirmam, de maneira idêntica aos outros artigos estudados, que o músico precisaria tocar a partitura sem muitos erros e sem mudar drasticamente o seu andamento, em outras palavras, que a técnica não é robusta para lidar com situações relativamente comuns em execução. Isso parece ser uma característica comum a todas as técnicas determinísticas que tomam decisões locais, olhando uma janela temporal pequena, para encontrar o casamento ótimo.

\subsubsection{Baird (1993)}

O quarto algoritmo é apresentado no artigo de 1993 chamado Artificial Intelligence and Music: Implementing an Interactive Computer Performer [BBZ93], onde os autores Bridget Baird, Donald Blavins e Noel Zahler apresentam um método supostamente baseado na cognição musical humana. Segundo os autores, seres humanos reconhecem composições por padrões musicais. Tais padrões são constituídos por notas musicais e suas durações e, mais ainda, por pausas musicais e suas durações. O algoritmo aqui apresentado, portanto, considera as durações dos eventos da entrada e é o primeiro a fazer isso. Mais ainda, é o primeiro a considerar a ausência de notas na entrada.

A técnica apresentada irá simular esse processo de reconhecimento de padrões casando blocos de eventos musicais entre a entrada e a partitura, ao invés de casar notas isoladas. Tais blocos são constituídos por unidades musicais (notas ou pausas com suas respectivas durações) que formam um padrão musical. Na sequência o padrão da entrada é comparado com mais de um padrão da 

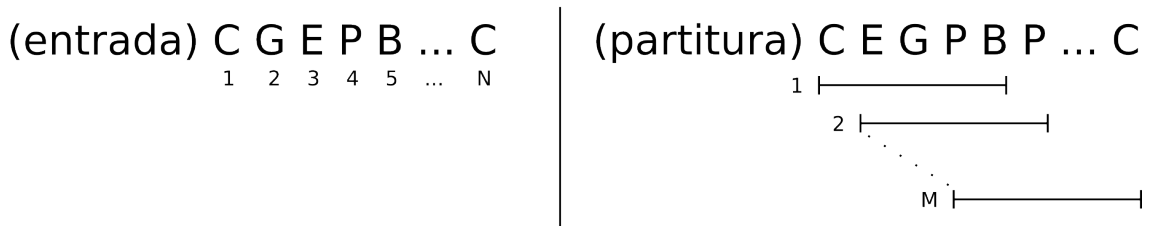

Figura 2.22: Padrão com $N$ eventos da entrada e sua comparação com $M$ padrões da partitura.

partitura (conforme figura 2.22) dentro de uma janela temporal centralizada no último ponto da partitura onde ocorreu algum casamento de padrões.

Quando dois padrões são comparados, o algoritmo verifica exaustivamente diversas possibilidades de pareamento entre as unidades do padrão da entrada com as do padrão da partitura. Os autores escolheram 4 modelos de casamentos entre unidades dos padrões, baseados em julgamentos próprios sobre os tipos de situações mais comuns em execuções musicais.

O primeiro modelo de casamento é chamado de literal e consiste em um casamento entre todas as notas da entrada e da partitura. O modelo literal foi criado para lidar com uma execução na qual o músico executa todas as alturas e durações de forma idêntica à esperada.

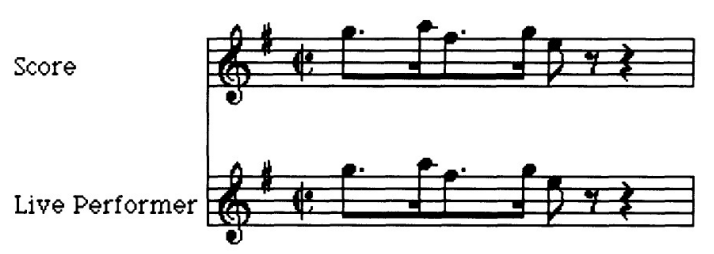

Figura 2.23: Modelo literal de casamento [BBZ93].

O segundo modelo é chamado de amalgamado e nele duas notas da entrada são casadas com uma da partitura. Esse modelo foi criado para tratar situações onde o músico adiciona uma nota extra para em seguida retornar à nota prevista na partitura sem sair do andamento. Tais situações poderiam ser propositais (ornamentações) ou acidentais (notas erradas ou "esbarradas"). Nesses casos, o casamento é feito considerando a altura da segunda nota e duração total das duas.

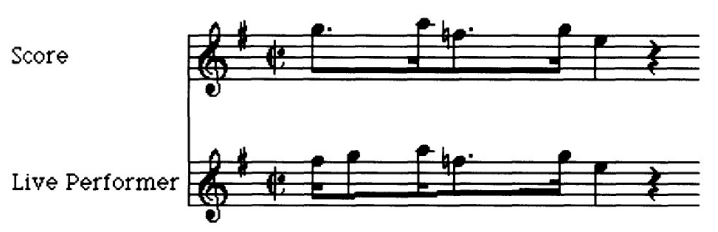

Figura 2.24: Modelo amalgamado de casamento [BBZ93].

O terceiro modelo é chamado de sem interrupções e nele uma nota da entrada é casada com duas da partitura. Esse modelo foi criado para tratar situações onde o músico deixa de executar uma nota da partitura, mantendo a nota anterior por mais tempo. Nesses casos, o casamento é feito com a altura da primeira nota e duração total das duas.

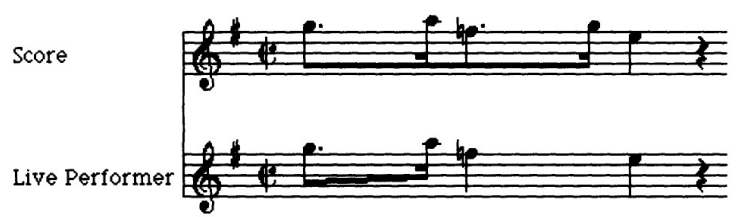

Figura 2.25: Modelo sem interrupções de casamento [BBZ93]. 
O quarto e último modelo é chamado de modelo de pausas e nele uma nota da entrada seguida de uma pausa são casadas com uma única nota da partitura. Esse casamento é feito com a altura da nota da entrada e a duração total da nota e da pausa.

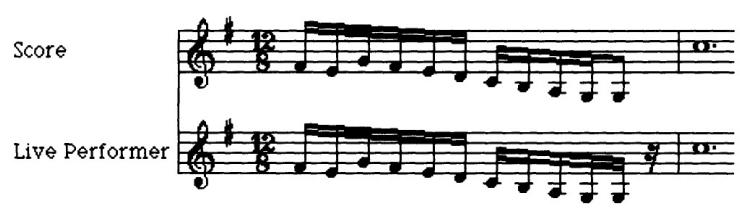

Figura 2.26: Modelo de pausas de casamento [BBZ93].

Os autores do artigo diferenciam pausas intencionais de pausas acidentais. Eles chamam de pausas intencionais os intervalos de silêncio da entrada previstos na partitura (tradicionalmente, chamados de pausas musicais) e que foram criados pelo compositor por razões estéticas. Já as pausas acidentais são intervalos de silêncio não definidos na partitura, introduzidos entre notas por razões diversas (expressividade, adaptação à acústica de um espaço ou por necessidade mecânica na execução ${ }^{9}$.

A cada padrão de entrada formado, inicializamos a comparação com alguns padrões da partitura seguindo os modelos descritos acima. Precisamos decidir qual deles é o mais adequado para encontrar o melhor pareamento entre entrada e partitura. Para isso, penalidades são atribuídas para diferenças entre alturas e durações de unidades, e a soma destas penalidades define um custo para cada casamento. Os modelos de casamento que tiverem seus custos abaixo de um limiar predefinido serão os candidatos a gerar o casamento daquela iteração, sendo escolhido o candidato de menor custo.

Devemos observar que cada modelo (exceto o literal) irá gerar mais de uma possibilidade de casamento para um mesmo par de padrões. O modelo amalgamado, conforme podemos observar nas 3 figuras abaixo, considera todos os pares de notas da entrada que serão agrupados para casar com uma nota da partitura.

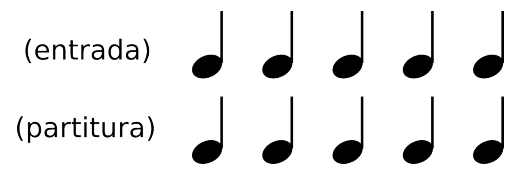

Figura 2.27: Exemplo de dois padrões a serem comparados com 5 notas fictícias cada.
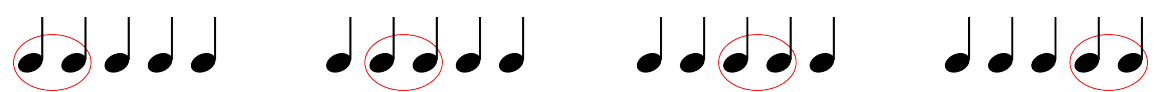

Figura 2.28: Possibilidades de agrupamento de pares de notas no padrão da entrada.

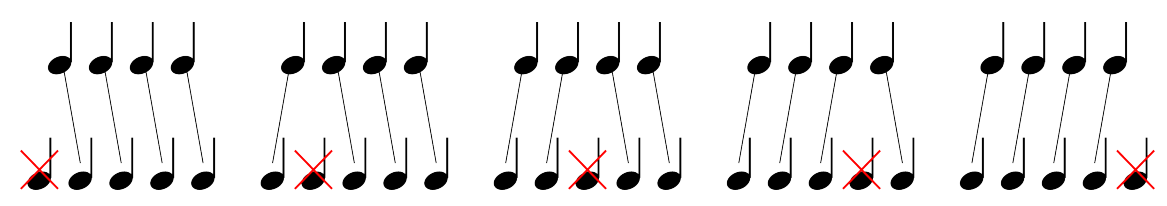

Figura 2.29: Possiveis pareamentos com as 5 unidades do padrão da partitura (o padrão de entrada possui agora 4 unidades).

Por trabalhar com padrões este é o algoritmo que mais faz comparações por nota de entrada de todos os escolhidos para implementação. Podemos verificar a complexidade de cada modelo

\footnotetext{
${ }^{9} \mathrm{Um}$ exemplo disso ocorre em instrumentos de cordas (violão, violino, etc) quando uma nota grave no início da última corda é seguida imediatamente de uma nota aguda no final da primeira corda, exigindo um deslocamento considerável da mão esquerda. Esse tipo de deslocamento pode gerar um intervalo de alguns milissegundos entre as duas notas e isso não deve ser considerado uma pausa musical para efeito de casamento de padrões.
} 
em função do tamanho do padrão N. O modelo literal irá percorrer os padrões uma única vez, comparando altura e duração de cada par de notas. O número de comparações será, portanto, $\mathcal{O}(N)$. O modelo amalgamado irá agrupar pares de notas do padrão da entrada ( $\mathrm{N}-1$ possibilidades) e, para obter N - 1 notas no padrão da partitura terá que escolher uma das notas para exclusão (N possibilidades). O número de comparações de todas as combinações (cada par agrupado no padrão da entrada e cada nota excluída do padrão da partitura) será portanto $\mathcal{O}\left(N^{2}\right)$. Os modelos sem interrupções e de pausas são análogos ao amalgamado; em ambos iremos agrupar unidades de um padrão e casar com N - 1 unidades do outro. Os números de comparações dos dois últimos modelos, portanto, terão a mesma ordem de grandeza do amalgamado: $\mathcal{O}\left(N^{2}\right)$.

\subsubsection{Vantomme (1995)}

O quinto e último artigo sobre rastreamento de partitura é o Score Following by Temporal Pattern do ano de 1995 por Jason Vantomme [Van95]. O algoritmo apresentado nesse artigo foi escolhido para ser estudado e implementado por apresentar uma técnica bastante diferente das anteriores: o autor sugere fazer rastreamento de partitura utilizando os tempos de inícios de notas como as informações mais importantes da entrada. Vantomme afirma que as alturas musicais (cruciais em todas as técnicas vistas até o momento) podem até mesmo nem serem consultadas, dependendo da peça e da execução do músico.

$\mathrm{O}$ artigo tem como ponto de partida aplicações musicais que tentam inferir o andamento de uma música, e afirma que um sistema de acompanhamento musical apresenta uma vantagem em relação àquelas por conhecer a partitura da entrada. Portanto, ao invés de construir uma representação rítmica da música a partir do zero, o sistema irá reconstruir um padrão já conhecido a partir da comparação das informações temporais da entrada com as da partitura.

A técnica irá, portanto, rastrear uma execução a partir de padrões temporais detectados na entrada, na tentativa de explorar a hipótese de que notas com alturas erradas provavelmente teriam sido tocadas no tempo certo. O método de predição de padrões temporais do músico segue os seguintes passos, ilustrados na figura 2.30 .

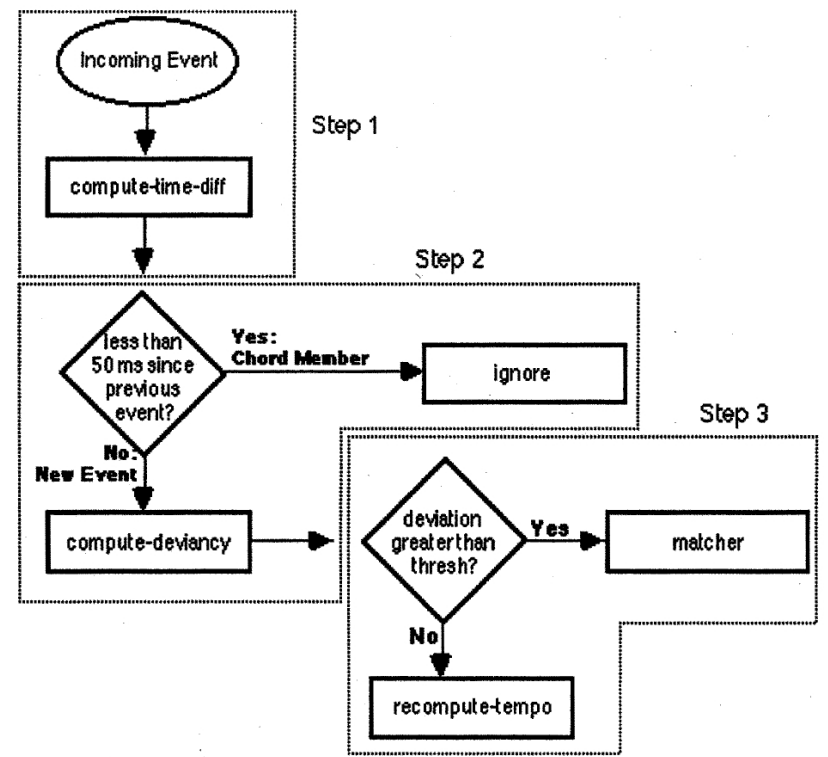

Figura 2.30: Passos do algoritmo de Vantomme1995 [Van95].

O primeiro passo é decidir se a nota recém chegada pode ser agrupada com a anterior em um mesmo acorde: se o intervalo de tempo entre ela e a nota anterior for menor ou igual a um limiar predefinido, elas serão consideradas simultâneas. O intervalo adotado, arbitrariamente fixado em 50ms, está relacionado tanto ao fato de que é frequente em execuções musicais que notas de um mesmo acorde não sejam executadas simultaneamente (devido a recursos expressivos como arpeggiato ou 
inexatidões inerentes à execução humana), quanto ao fato de que representações simbólicas como o MIDI frequentemente impõem a seriação de eventos simultâneos, causando pequenas diferenças entre seus respectivos timestamps.

Caso a nota recém chegada não seja agrupada com a anterior, iremos executar o segundo passo que consiste em decidir se existe correspondência entre a nota recém chegada da entrada e nota esperada da partitura: se o tempo de início da nota for menor ou igual a um outro limite predefinido, ela será considerada um casamento. O limite adotado é determinado a partir de um refinamento do modelo de Rosenthal [Ros92]. Em 1992, David Rosenthal observou a tolerância de ouvintes a desvios em tempos de inícios de notas e desenvolveu um modelo que determinava uma porcentagem de confiança dado um intervalo de tempo.

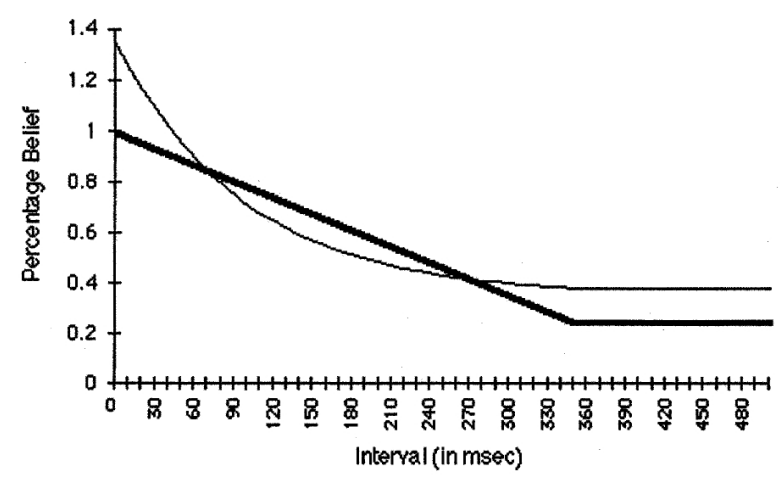

Figura 2.31: Curvas original e modificada do modelo de Rosenthal [Van95].

Como toda técnica determinística apresentada nesta seção, a descrita acima também está sujeita a falhas. Se diversas notas sequenciais possuírem desvios temporais não toleráveis pelo modelo, o algoritmo não irá gerar relatos. Para contornar isso, o autor decide acoplar ao sistema um rastreador baseado em alturas para determinar a posição mais provável do músico nos casos onde os padrões temporais só geram erros. Tal rastreador de backup será consultado toda vez que o desvio temporal de uma nota for maior do que o tolerável.

Para habilitar a utilização de um rastreador por alturas musicais, o sistema irá manter um histórico dos eventos da entrada e isso irá permitir a chamada do rastreador reserva a qualquer instante da execução.

$\mathrm{O}$ autor faz algumas observações sobre os dois rastreadores de diferentes naturezas. O rastreador que considera as alturas musicais poderá provar que o músico estava mesmo na posição esperada e nesse caso o músico simplesmente tocou a nota certa, mas com tempo grosseiramente errado. Além disso, execuções com diversas alturas incorretas, mas tempos toleráveis poderão ser inteiramente acompanhadas sem o rastreador reserva nunca ser chamado. Porém, o sistema irá falhar completamente quando o músico cometer um erro temporal e o rastreador substituto for consultar um histórico com notas completamente erradas.

Outros algoritmos determinísticos foram encontrados na literatura abordada, no entanto, os cinco apresentados acima são suficientemente abrangentes para nossas necessidades. Temos algoritmos que consideram alturas musicais, tempos de ataques e durações de notas em combinações diversas conforme a tabela abaixo:

$\begin{array}{rccc} & \text { alturas } & \text { ataques } & \text { durações } \\ \text { Dannenberg1984 } & \mathrm{X} & & \\ \text { Lippe1992 } & \mathrm{X} & & \\ \text { Vercoe1985 } & \mathrm{X} & \mathrm{X} & \\ \text { Baird1993 } & \mathrm{X} & \mathrm{X} & \mathrm{X} \\ \text { Vantomme1995 } & & \mathrm{X} & \end{array}$

É de se esperar que os comportamentos desses algoritmos sejam discrepantes para uma mesma entrada. Os algoritmos de Dannenberg1984 e Lippe1992, por exemplo, provavelmente irão ter pouca 
mudança no comportamento caso o músico toque todas as alturas certas, mas todas as durações erradas; eles só terão variação no comportamento se a duração de uma nota ultrapassar o tempo de ataque da próxima e, por mais que eles não considerem ataques para fazer rastreamento, a emissão de uma nota atrasada poderá influenciar o cálculo do andamento.

Outro comportamento previsto pelos autores, no caso do algoritmo de Vantomme1995, é que esse algoritmo irá produzir um rastreamento perfeito de notas tocadas no tempo certo mesmo se a altura musical de todas estiverem erradas.

Tais características sugerem que uma técnica híbrida poderia mesclar os pontos fortes de cada algoritmo. No entanto, não é simples criar um algoritmo novo que combine todas as técnicas apresentadas. Em particular, o que determina esses comportamentos individuais é o fato dos algoritmos considerarem informações parciais ou disjuntas da entrada, ignorando as demais. Em outras palavras, não poderíamos criar um algoritmo que considera e ignora a mesma informação ao mesmo tempo (por exemplo, as durações das notas da entrada).

$\mathrm{Na}$ seção 3.2.3 iremos introduzir um algoritmo novo que chamaremos de MetaRastreador. Ele será, essencialmente, a combinação de $\mathrm{N}$ instâncias de algoritmos de rastreamento de partitura sendo executados simultaneamente.

\subsection{Acompanhador}

O terceiro módulo integrante de um sistema de acompanhamento musical é o Acompanhador. Suas habilidades incluem inferir o andamento do músico a partir da sequência de relatos das posições temporais do músico na partitura e gerar o acompanhamento de maneira musicalmente apropriada. Partimos do pressuposto que o acompanhamento já está predefinido e armazenado em memória, e portanto, as técnicas apresentadas nesta seção irão apenas decidir o momento de enviar cada evento do acompanhamento para a saída.

Roger Dannenberg em seu artigo clássico de 1984 [Dan84] apresenta uma solução para tal tarefa fazendo um paralelo com um sistema convencional que toca uma partitura em tempo real. Em tal sistema, os tempos dos eventos da partitura são comparados com um relógio para decidir quando cada um deve ser executado.

Para o sistema de acompanhamento musical precisamos de duas propriedades extras. A primeira é poder variar a velocidade desse relógio (para permitir a execução da partitura armazenada de maneira mais rápida ou mais devagar do que a padrão). A segunda é poder redefinir o valor do relógio a qualquer instante (para dar pulos para trás ou para frente na execução da partitura). Porém, o relógio do sistema operacional do computador (chamado deste ponto em diante de relógio real) não pode ter sua velocidade alterada e não pode ter seu valor restabelecido. Iremos implementar um relógio lógico (referido deste ponto em diante como relógio virtual) que terá seus valores definidos em função do relógio real.

A figura abaixo apresenta uma possível curva de evolução do tempo virtual (eixo y) em relação ao tempo real (eixo x). Interpretando os trechos do ponto de vista do Acompanhador, temos que os que possuem a derivada maior do que 1 representam andamentos maiores que o original definido na partitura, e os que possuem derivada menor do que 1, andamentos menores que o original.

Em um caso real de execução, o módulo Acompanhador irá iniciar sua execução com o andamento original da partitura (a não ser que seja determinado um andamento inicial alternativo) e, após a chegada de alguns relatos, deverá recalcular o andamento real da execução e controlar o relógio virtual de acordo com o andamento atualizado dinamicamente.

Um relato será um ponto ( $R, V)$, onde $\mathrm{R}$ é o tempo (real) do evento emitido pelo músico na entrada e $\mathrm{V}$ é o tempo (virtual) do evento casado correspondente da partitura.

Se tivéssemos todos os relatos do futuro em mãos, poderíamos inseri-los no gráfico de tempo real versus virtual e, com alguma técnica de interpolação, poderíamos determinar valores não definidos da função do tempo virtual entre os pontos de relato. Porém, numa execução em tempo real não temos todos os relatos quando o sistema começa a ser executado. A definição do problema se resume, então, ao seguinte: dados os últimos $\mathrm{N}$ pontos do histórico de relatos e os últimos M pontos 


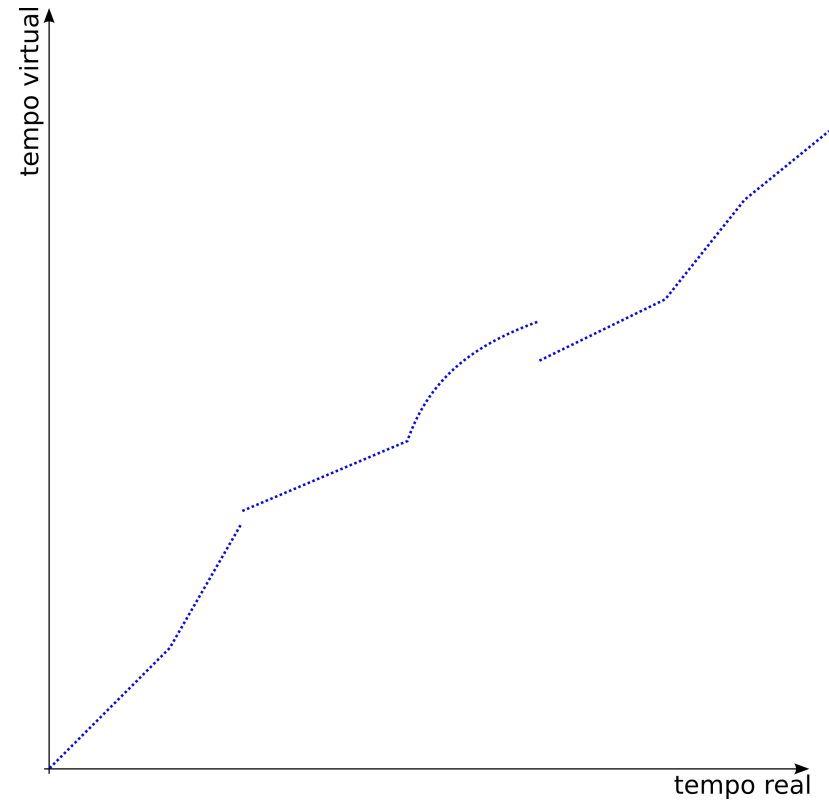

Figura 2.32: Curva de evolução do tempo virtual em relação ao tempo real.

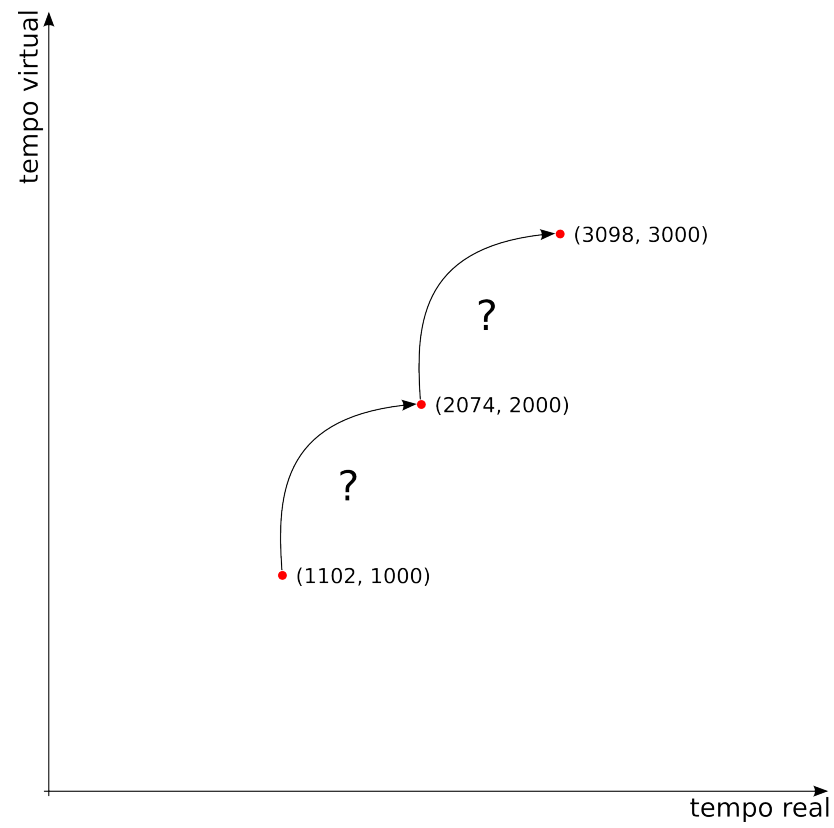

Figura 2.33: Pontos de relatos no gráfico de tempo real versus virtual.

do histórico da evolução do relógio virtual, devemos encontrar uma função que determina um novo valor para o tempo lógico dado um tempo real. Abaixo veremos técnicas selecionadas da literatura que lidam com esse problema.

Para a representação do andamento instantâneo do acompanhador, utilizaremos um valor percentual relativo ao andamento original denotado na partitura. Assim, se o músico estiver tocando em um andamento de 60 BPM e na partitura estiver definido o andamento de 120 BPM, nosso sistema irá representar esse andamento por 0,5 .

\subsubsection{Gerenciamento do relógio virtual}

A primeira técnica selecionada [Dan84] possui duas rotinas separadas para alterar a velocidade do acompanhamento e para atualizar o valor do relógio virtual. A primeira rotina utiliza apenas os dois últimos pontos do histórico e define a velocidade do acompanhamento como a inclinação do 
segmento de reta que une esses dois pontos. Considera-se que cada relato recebido pode indicar uma alteração de andamento, e assim a velocidade do relógio é imediatamente alterada. Seja $\left(R_{r e f}, V_{\text {ref }}\right)$ o último ponto do histórico e $(R, V)$ o relato recém chegado. A nova velocidade $\mathrm{S}$, então, será calculada com a seguinte fórmula:

$$
S=\frac{V-V_{r e f}}{R-R_{r e f}}
$$

A segunda rotina, que incrementa o relógio virtual, é chamada também após cada relato recebido e a cada intervalo fixo de 50ms (valor arbitrariamente escolhido pelo autor). O valor do relógio virtual será extrapolado de forma linear utilizando a nova velocidade calculada (conforme figura 2.34). A fórmula acima, invertida, nos dá um novo valor para o relógio virtual V como $\left(R-R_{r e f}\right) \times S+V_{\text {ref }}$, onde $\mathrm{R}$ é o tempo real do sistema operacional, $R_{\text {ref }}$ é o tempo real da última vez que o relógio virtual foi atualizado, S é a velocidade e $V_{r e f}$ é o último tempo atribuído ao relógio virtual.

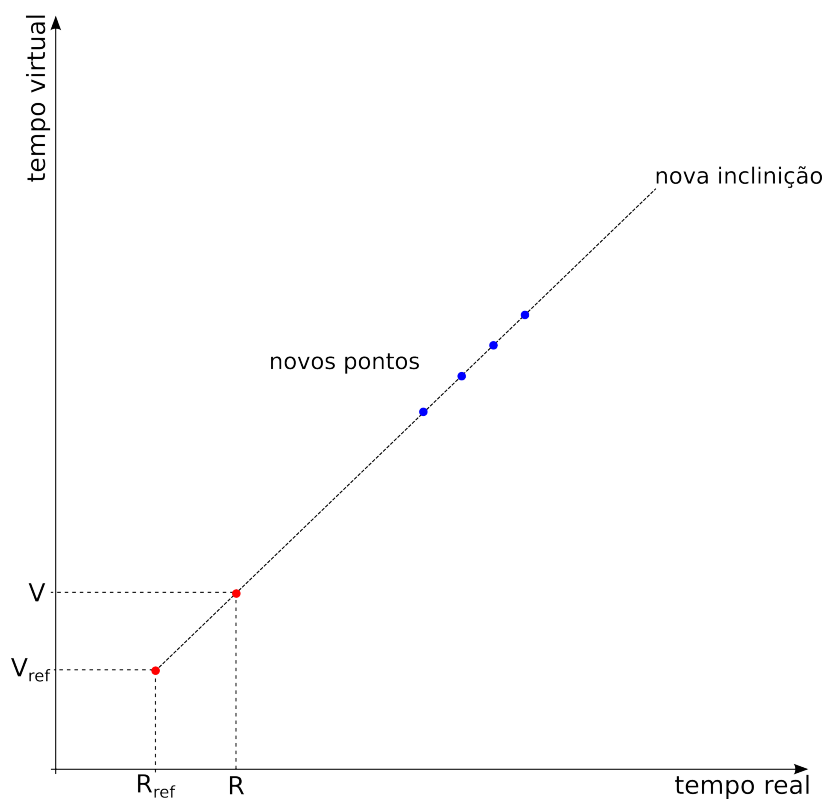

Figura 2.34: Extrapolação do relógio virtual a partir da inclinação dos dois últimos pontos.

É importante observarmos que essa técnica é sensível a pequenas flutuações de andamento do músico e que a velocidade pode oscilar drasticamente a cada relato recebido (principalmente se o relato foi errado por parte do Rastreador). Isso é considerado nocivo à geração do acompanhamento, pois o Acompanhador irá gerar variações na velocidade de execução do acompanhamento sem que haja qualquer intenção por parte do músico de variar o andamento global da peça. Isso ocorre normalmente em fraseados e acentuações musicais que possuem pequenas variações locais de tempo.

Podemos minimizar as influências dessas microestruturas da execução no andamento global filtrando relatos da seguinte maneira. A ideia é comparar a diferença de tempo entre os dois últimos relatos e, se o intervalo for menor do que um limite predefinido (100ms, por exemplo), o último relato é descartado. Assim o sistema evita fazer diversas atualizações de andamento em trechos com densidade alta de notas (exatamente os que têm mais propensão a variações locais de tempo).

A segunda técnica selecionada da literatura [BD85] também possui rotinas separadas para cada tarefa. Porém, o algoritmo proposto agora mantém uma tabela com os últimos 4 pontos do histórico. Ao invés de utilizar o segmento de reta dos 2 últimos pontos, eles utilizam o dos pontos de índices 1 e 4 dessa tabela. Com isso os autores afirmam que obtém uma suavização da execução do acompanhamento. Considerando os 4 pontos armazenados em uma tabela $\mathrm{T}$, a nova velocidade $\mathrm{S}$ é calculada com a seguinte fórmula:

$$
S=\frac{T[3] \cdot v-T[0] \cdot v}{T[3] . r-T[0] . r}
$$


Nela ".v" e ".r" representam os tempos virtual e real, respectivamente. De maneira análoga à técnica anterior, a rotina de atualização do andamento também é chamada a cada recebimento de um novo relato.

A política de gerenciamento dessa tabela é a seguinte: junto com o relato, os autores pedem para o módulo Rastreador enviar uma flag que determina se o evento que gerou o casamento atual está na sequência do evento que gerou o casamento do relato anterior. Se o casamento for detectado fora da sequência da partitura, a tabela é esvaziada por completo e somente o ponto recém chegado é inserido nela. Caso contrário, o ponto mais antigo é descartado, os pontos que restaram são deslocados uma posição para a esquerda e o novo ponto é inserido no final da tabela.

A abordagem acima, de zerar a tabela quando o casamento for fora de sequência, possui um ponto negativo. Se o solista estiver tocando uma passagem muito lenta, iremos demorar para preencher a tabela novamente e, consequentemente, o andamento da execução pode ficar desatualizado. Para isso foi criada uma heurística que irá alterar o valor de andamento quando dois pontos já estiverem disponíveis na tabela (com os mesmos cálculos da técnica anterior) se o intervalo de tempo entre eles ultrapassar o limite de 1 segundo.

Outra heurística foi criada para tratar casos de passagens muito rápidas nas quais os pontos da tabela são descartados rapidamente. A heurística diz que devemos comparar o tempo do relato recém-chegado com o do último ponto da tabela. Se o intervalo for menor do que $200 \mathrm{~ms}$ não devemos inserí-lo na tabela. Os autores afirmam que essa heurística foi criada para "as amostras que modificam o andamento se estenderem além de grupos de rápida execução".

A segunda rotina que trata da evolução do relógio virtual possui exatamente a mesma função de atualização da técnica anterior e é chamada a cada recebimento de relato e em intervalos fixos de tempo.

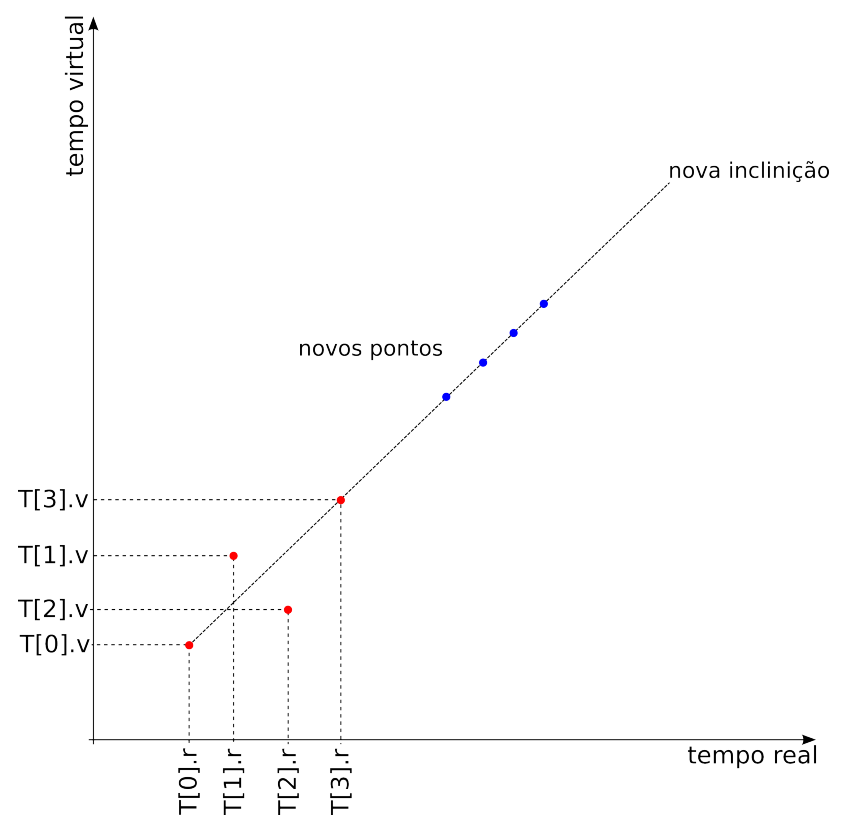

Figura 2.35: Extrapolação do relógio virtual a partir da inclinação dos pontos $(N-1)$ e $(N-4)$.

Podemos observar que essa estratégia produz uma evolução mais suave do tempo lógico, porém ainda temos diversos pontos de descontinuidade, e tal curva (diversos segmentos de retas conectados) ainda irá produzir repostas quase instantâneas para mudanças de andamento do solista. Podemos minimizar esse efeito utilizando um número consideravelmente maior de pontos do histórico e alguma técnica de valores médios para o cálculo do andamento.

Diversos autores sugerem a utilização de regressão linear dos pontos do histórico de relatos [BD85, VP85, BBZ93]. Barry Vercoe e Miller Puckette sugere explicitamente a utilização do método dos mínimos quadrados para tal tarefa [VP85]. O processo consiste em encontrar uma equação de reta que melhor se encaixa nos últimos pontos recebidos de relato, dando um peso maior 
para os últimos pontos a fim de priorizar informações mais recentes.

Os autores afirmam que essa reta é utilizada tanto para fazer rastreamento da execução, calculando e penalizando o desvio temporal das notas (conforme vimos na seção anterior), quanto para agendar os eventos do acompanhamento. A cada recebimento de relato, o histórico é incrementado e uma nova regressão é calculada. Os coeficientes da reta serão utilizados para determinar o andamento do músico. Mais explicitamente, se a reta obtida for $t=p \times s+q$, podemos utilizar o coeficiente $\mathrm{p}$ diretamente como medida relativa entre andamento real da execução e andamento esperado da partitura.

A rotina de evolução do relógio virtual não é determinada explicitamente pelos artigos que sugerem a utilização de regressão linear, porém nada nos impede de chamá-la a todo relato e em intervalos fixos de tempo. Nesse caso, não precisamos mais utilizar a fórmula das técnicas anteriores que considera a relação entre as diferenças de tempos e a velocidade atual. Podemos aplicar o tempo real do instante da atualização na equação de primeiro grau acima e obter o novo valor para o tempo virtual.

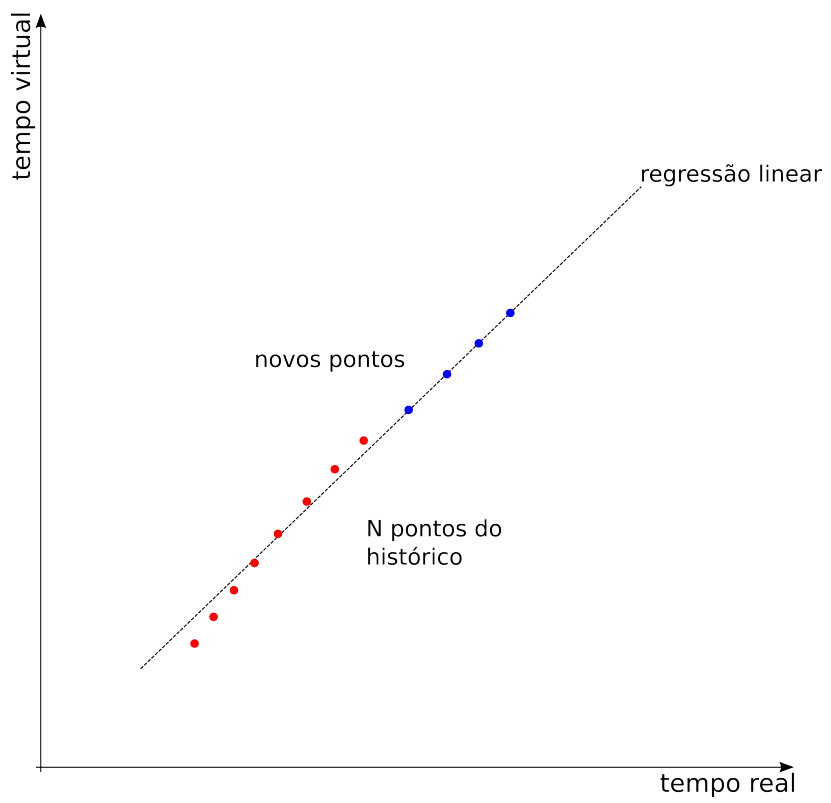

Figura 2.36: Extrapolação do relógio virtual a partir de regressão linear.

A técnica anterior, nitidamente, nos fornece uma curva de evolução de tempo mais suave do que as técnicas anteriores. No entanto, por utilizarem modelos lineares, todas irão produzir curvas que são a concatenação de segmentos de retas e isso irá produzir uma função do tempo lógico cheia de descontinuidades. Tais descontinuidades são impossíveis de serem evitadas, pela própria natureza do problema de acompanhamento musical, pois é permitido que o relógio virtual dê pulos (tanto para frente, quanto para trás) para corrigir um erro de posicionamento, caso o sistema constate que estava fora de sincronia com o músico. Técnicas para tratar assincronia serão apresentadas mais adiante, porém, no caso de uma execução mais previsível (sem pulos) podemos testar a utilização de outros métodos de regressão para obter funções mais suaves de evolução do tempo virtual.

Para isso, utilizaremos uma regressão quadrática, pois estamos interessados em tratar trechos da composição marcados com ritardando ou accelerando. Com tal objetivo, é natural tentar ajustar a curva por uma quadrática, considerando que além da velocidade de atualização do tempo também pode existir momentaneamente uma aceleração na atualização do tempo.

As equações de segundo grau obtidas pela utilização da regressão quadrática realmente se encaixam muito bem em pontos de variação de andamento (conforme ilustrado na figura 2.37). Porém, percebemos que em trechos de andamento fixo, a utilização de modelos lineares apresentam melhores resultados, mesmo que as parábolas sejam extremamente suaves (com coeficientes associados ao termos quadráticos bem baixos) por considerarmos diversos relatos do passado. Então, pensamos em uma heurística para alterar o método de regressão de linear para quadrático, por exemplo, se a 


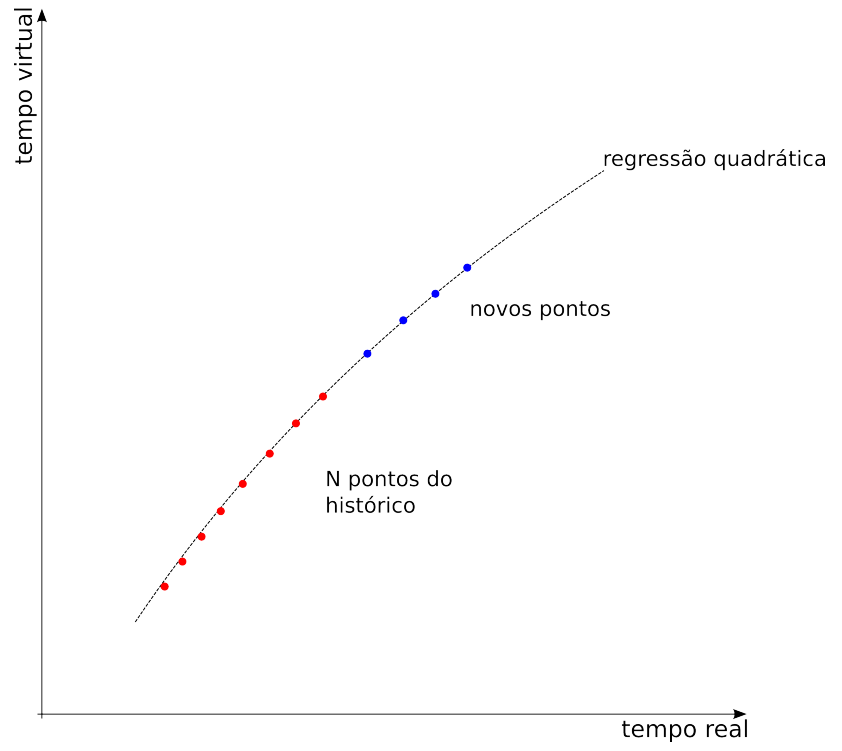

Figura 2.37: Extrapolação do relógio virtual a partir de regressão quadrática.

sequência de relatos estivesse consistentemente chegando antecipados em relação à previsão linear (que sugeriria um accelerando) ou consistentemente atrasados em relação à previsão linear (típico de um ritardando). Após a regularização do andamento, o sistema voltaria para o modelo linear.

Até este ponto do texto mencionamos apenas técnicas para gerar o acompanhamento a partir dos relatos emitidos de maneira puramente reativa, ou seja, após o recebimento de um relato as informações sobre a execução são atualizadas e o sistema muda seu comportamento como resposta à entrada. Nenhum mecanismo de sincronismo, essencial para a qualidade da geração do acompanhamento e para a satisfação do músico, foi abordado ainda.

\subsubsection{Evolução preditiva do relógio virtual}

Existe uma latência inerente ao processo completo que engloba o recebimento de um evento da entrada, a deteç̧ão de um casamento, a emissão de um relato e a atualização das informações sobre o relógio virtual (ilustrado na figura 2.38). Técnicas que possuem uma abordagem puramente reativa irão fazer com que o sistema sempre chegue em um ponto específico da partitura depois do músico. Desse modo, notas do acompanhamento que estavam definidas na partitura para soar simultaneamente à entrada (ver figura 2.39) serão executadas com um certo atraso.

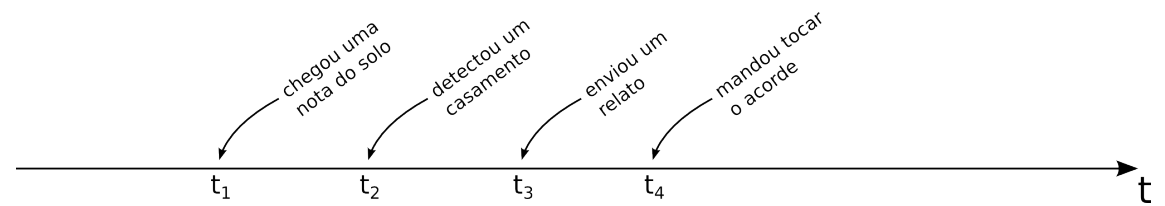

Figura 2.38: Tempos do processo para emissão de um evento na saída $\left(t_{4}-t_{1}\right.$ deveria ser zero).

Christopher Raphael afirma no artigo Current Directions With Music Plus One [Rap09] que em teoria poderíamos construir um sistema puramente responsivo cujo atraso seja musicalmente insignificante, porém que é essencial construir um sistema cujo comportamento seja apoiado em predições.

Um dos sistemas mais avançados desenvolvidos nos últimos anos - Music Plus One - possui técnicas de predição na geração do acompanhamento musical para tratar a latência inevitável descrita acima. No artigo Musical Accompaniment Systems [Rap04], Christopher Raphael se baseia no comportamento humano para fornecer ao sistema a capacidade de prever a execução de sua parte. Ele afirma que "o músico humano entende essa latência de escuta como parte do problema básico de tocar em grupo e responde continuamente prevendo a evolução musical futura baseado no que 


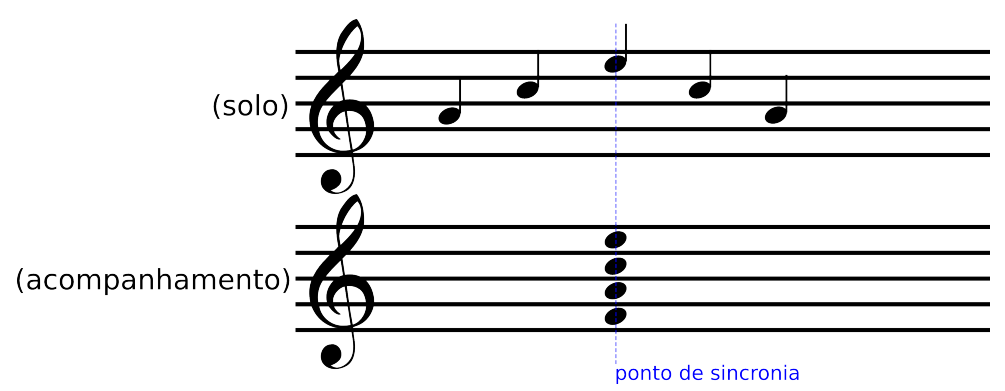

Figura 2.39: Exemplo de um ponto da partitura no qual eventos do solo e do acompanhamento devem soar sincronizados.

ouviu até o momento e, de uma maneira ou de outra, o computador deve abordar esse problema fundamental do mesmo jeito" [Rap04].

Para isso, o autor enumera o que é esperado de um músico profissional atuando dentro de um grupo. Primeiramente, ele deve ter conhecimentos básicos teóricos e práticos para conseguir tocar uma música a primeira vista caso isso seja requisitado. Em segundo lugar, ele deve ter a capacidade de se afastar do que está rigorosamente determinado na partitura a fim de executar a música conforme a interpretação do grupo. Por último, ele deve ter a habilidade de aprender como o grupo executa a peça de maneira particular, após diversos ensaios, para se antecipar em momentos em que essa interpretação difere muito da partitura.

Apoiando-se nessas habilidades, o autor desenvolve um modelo estatístico com centenas de variáveis aleatórias gaussianas para mesclar diversas fontes de informação sobre a execução: a partitura, a análise em tempo real do que o solista está tocando, a interpretação demonstrada pelo solista em ensaios e execuções humanas do acompanhamento. Com tais variáveis, o autor deseja adicionar uma variedade rítmica na interpretação do acompanhamento. Os tempos de cada evento originais da partitura do acompanhamento são redefinidos a partir de variáveis para mudanças globais de andamento, para acentuações agógicas, entre outras, modeladas a partir da análise das diversas fontes de informação consideradas. Após essa modelagem, a tarefa do Acompanhador agora é somente agendar os eventos.

Um artigo posterior ao de Christopher Raphael afirma explicitamente que tal técnica, apesar de utilizar modelos probabilísticos bem sofisticados, possui restrições quanto a generalidade de gêneros musicais aplicáveis [AW10a]. Andreas Arzt e Gerhard Widmer afirmam que o sistema enfoca o repertório ocidental clássico, que possui um ritmo mais regular e que exige uma sincronização mais rígida entre solo e acompanhamento. Em busca de uma solução mais simples e mais ampla, os autores introduzem uma técnica robusta para antecipação na geração do acompanhamento musical. Essa técnica também utiliza dados coletados de outras execuções da mesma peça musical como detalhado a seguir.

Inicialmente, são armazenadas informações de diversas execuções diferentes para uma mesma música. Os dados de entrada dessas execuções são, na sequência, fornecidos como entrada para uma versão offline do rastreador do sistema. Executar o algoritmo de rastreamento de partitura no modo offline aumenta a qualidade do pareamento entre entrada e partitura, pois o algoritmo poderá enxergar os eventos do futuro e isso garante a detecção do casamento global ótimo entre os dois.

Com os pareamentos ótimos detectados para todas as execuções armazenadas, temos diversas curvas de evolução do tempo virtual por diversos músicos que são fornecidas para o rastreador online as utilizarem como informações adicionais para calcular uma melhor estimativa do andamento. Isso é feito através dos seguintes passos.

O rastreador mantém um histórico com as últimas 50 notas da curva de andamento da execução atual. A cada iteração do algoritmo, as $\mathrm{N}$ curvas armazenadas são normalizadas para representar o mesmo andamento da execução atual. Na sequência, são calculadas medidas de similaridade entre a curva de andamento atual e cada uma das $\mathrm{N}$ curvas armazenadas no intervalo que corresponde ao trecho com as últimas 50 notas. 

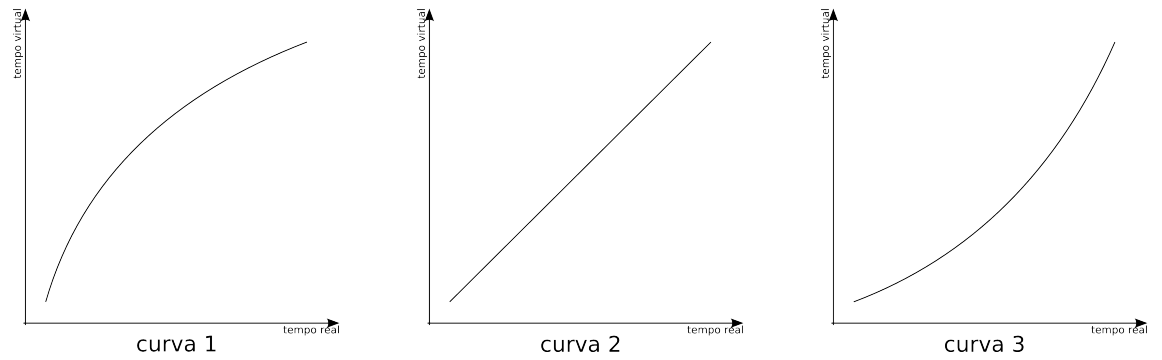

Figura 2.40: Exemplo de possíveis curvas armazenadas no histórico para um dado trecho da música.

Os autores utilizam os seguintes cálculos como medida de similaridade entre duas curvas: são calculadas as distâncias euclidianas entre elas e os valores obtidos são invertidos e normalizados para que pertençam ao intervalo $[0,1]$.
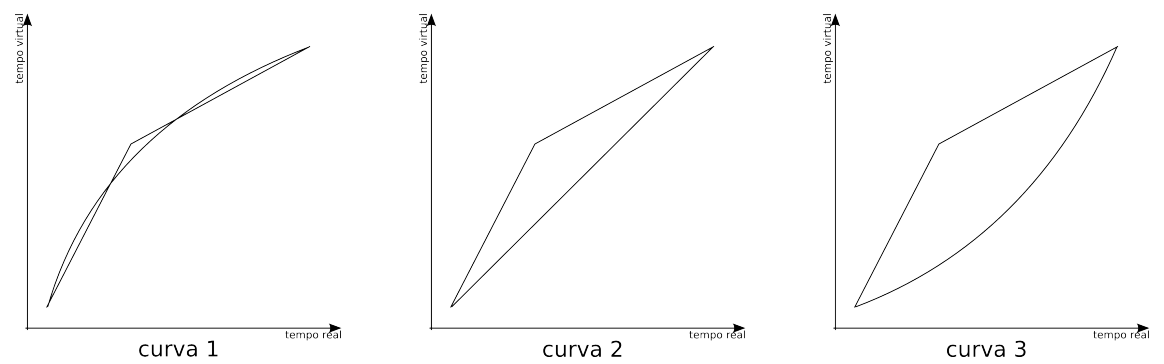

Figura 2.41: Sobreposição das curvas do histórico com a curva da execução atual em um dado trecho da música.

Com os valores de similaridades entre a curva de andamento atual e as curvas armazenadas, podemos estimar o andamento da execução no ponto atual. Os autores afirmam que a posição atual sempre estará entre dois eventos $o_{j}$ e $o_{j+1}$ da partitura (podendo incluir um deles ou não). Portanto, o andamento atual é calculado com a seguinte fórmula:

$$
\frac{\sum_{i=1}^{N}\left(t_{i, o_{j}}+t_{i, o_{j+1}}\right) \times s_{i}}{2}
$$

Onde $t_{i, o_{j}}$ e $t_{i, o_{j+1}}$ são os andamentos normalizados da curva i para os inícios de notas $o_{j}$ e $o_{j+1}$, respectivamente, e $s_{i}$ é a similaridade entre a curva i e a curva atual da execução.

Um fato importante de ser observado é que a técnica apresentada aqui não necessariamente utiliza como histórico as execuções de um mesmo músico. Esse fato a diferencia das técnicas de outros artigos que, normalmente, consideram as execuções de um solista para as execuções futuras dele mesmo. Isso é possível pela utilização da medida de similaridade que aumenta a influência de execuções de solistas que interpretaram a música de maneira mais parecida com a execução atual. Inclusive, trechos com interpretações diferentes terão seus andamentos influenciados por diferentes execuções do histórico. Em outras palavras, o músico pode tocar a primeira metade da peça tendo o acompanhamento previsto por uma execução do histórico como a mais similar (e consequentemente a mais influente) e a segunda metade por outra execução do histórico.

Ao final do artigo, os autores apresentam os resultados medidos no sistema com e sem a técnica de predição apresentada acima e tais resultados demonstram que ela é robusta, apesar de simples.

Em relação à sincronia, existem casos nos quais os relatos não são gerados de forma sequencial. Isso se deve ao fato do músico não tocar de forma linear (e dar pulos na partitura) ou do Rastreador emitir relatos errados (por erros de deteç̧ão) e corrigir-se em seguida. Em ambos os casos, o Acompanhador estará se baseando em um histórico que, com a chegada de um relato conflitante, pode ser considerado inválido. Alguns artigos da literatura que tratam a detecção de assincronia serão apresentados a seguir. 


\subsubsection{Detecção e tratamento de assincronia}

Roger Dannenberg [Dan84] apresenta a técnica mais simples para tratar assincronia. Nela o Acompanhador se sincroniza imediatamente com os relatos que chegam, isto é, o valor do relógio virtual recebe diretamente o valor do tempo lógico do relato. Um único tratamento dado em prol de uma execução mais suave é diminuir um pouco a velocidade do Acompanhador quando o relógio virtual dá um pulo para trás e aumentar um pouco a velocidade quando o pulo é para frente. Porém, nenhuma informação mais explícita é dada em relação a quanto devem ser esses ajustes de velocidade.

Em outro artigo [BD85], o mesmo autor apresenta um algoritmo mais robusto para tratar a detecção de assincronia. Ele afirma que pular para os novos valores de tempos virtuais dos relatos pode gerar notas com dois ou mais ataques (conforme ilustrado na figura 2.42) e deseja que o sistema imite o comportamento de um músico humano acelerando quando se percebe atrasado e desacelerando quando se percebe adiantado.

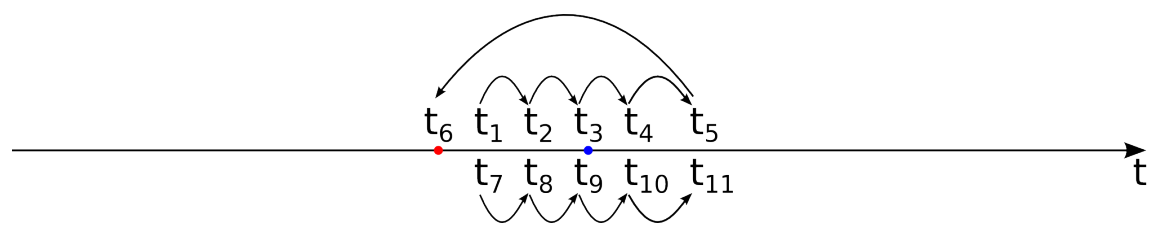

Figura 2.42: Duas execuções do mesmo evento note on em $t_{3}$ e $t_{9}$. Considere $t_{i}$ tempos reais, $t_{i}<t_{j}$ quando $i<j$ e um relato em $t_{6}$.

O algoritmo apresenta comportamentos alternativos para obter sincronização conforme é detectado se o Acompanhador está muito (ou pouco) adiantado (ou atrasado) em relação ao músico. Para obter esse comportamento o autor incrementa o conjunto de dados contidos em um relato. As seguintes informações são enviadas do Rastreador para o Acompanhador:

- o tempo real do evento de entrada;

- o tempo virtual do evento casado na partitura;

- uma flag indicando se o evento atual era o próximo na sequência após o último evento casado;

- o tempo virtual do próximo evento da partitura.

O algoritmo apresentado também possui duas rotinas separadas para atualizar o valor do relógio virtual e mudar o andamento da execução. Porém, temos algumas tarefas extras para cada uma dessas rotinas. $\mathrm{O}$ autor divide o comportamento do Acompanhador em dois casos globais: se o casamento for na sequência ou não.

Se o casamento for na sequência, consideramos que o Acompanhador recebeu um relato de alta confiança e ele só precisa verificar qual o grau de sincronia com o músico. Para isso ele faz um teste no intervalo de tempo entre o último valor do relógio virtual e o tempo lógico do relato. Caso esse valor seja menor do que um limite superior de 2 segundos, o Acompanhador continua tocando os eventos da partitura em sequência, se acelerando para alcançar o músico ou desacelerando para ser alcançado pelo músico. Caso contrário, segundo o autor é melhor "saltar diretamente para a posição do acompanhamento", ao invés de "correr desesperadamente para alcançar" ou "praticamente parar e esperar".

Se o casamento não for na sequência, o Acompanhador considera que a sua hipótese anterior em relação à posição do músico não era muito confiável. Portanto, ele se sincroniza imediatamente com o solista. Para isso, além de atribuir o valor do relógio para o valor do relato, o Acompanhador precisa garantir que todas as notas que deveriam estar soando naquele ponto fiquem ativas. Isso é feito através da seguinte rotina.

Em uma análise prévia da partitura, o Acompanhador irá guardar quantas notas do acompanhamento devem estar soando para cada evento do solista. Além disso, a estrutura de dados que 
armazena um evento da partitura terá agora um ponteiro para o evento anterior. A rotina, então, é a seguinte: quando um relato chegar para o evento $\mathrm{X}$, sabemos que $\mathrm{N}$ eventos do acompanhamento deveriam estar soando naquele instante e, portanto, basta percorrer a partitura de trás para frente ativando as primeiras $\mathrm{N}$ notas encontradas (conforme ilustrado na figura 2.43).

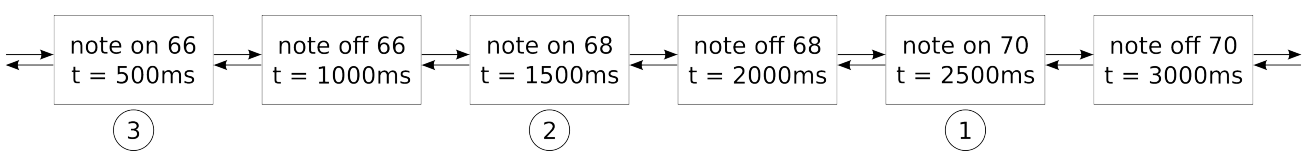

Figura 2.43: Rotina para ativar notas percorrendo a partitura de trás para frente.

\subsubsection{Detecção e tratamento de fuga}

Por último, precisamos tratar um detalhe que poucos artigos citam, mas que é de extrema importância: o que fazer quando o Rastreador não envia nenhum relato.

O problema foi chamado em um dos artigos da literatura de detecção de fuga do músico, pois um dos principais motivos de tal problema ocorrer é quando o músico para de tocar de fato. Porém, sabemos também que isso pode ocorrer quando o músico continua tocando e o Rastreador não consegue encontrar casamentos na partitura. Independentemente dos motivos, o problema é que o Acompanhador para de receber relatos.

Roger Dannenberg, no mesmo artigo de 1985 citado na seção anterior, apresenta a seguinte solução. Em todo relato, o Rastreador irá repassar o valor esperado para a próxima nota da partitura do solista. Se um limite de tempo (o limite sugerido no artigo é de 2 segundos) se passar após esse valor sem nenhum novo relato, o Acompanhador declara a fuga do músico. Na sequência, ele silencia todas as notas e para a evolução do relógio virtual. Quando o Rastreador emitir um relato novamente no futuro (seja porque o músico voltou a tocar ou porque o Rastreador se localizou no processo de rastreamento), o Acompanhador deve voltar a produzir o acompanhamento a partir do tempo recebido nesse novo relato.

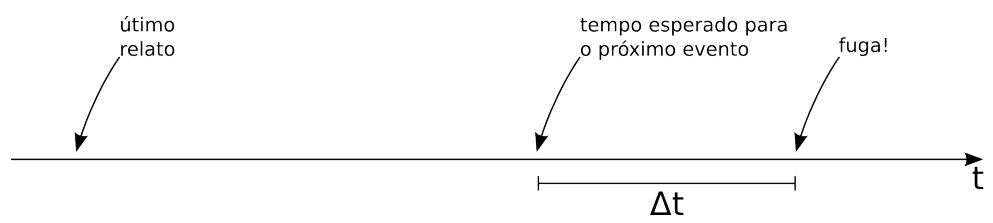

Figura 2.44: Detecção de fuga do músico por inatividade na execução solo.

Essa heurística é de grande importância ao permitir que o músico faça uma pausa no meio da execução e volte ao ponto em que parou. Em sua ausência o Acompanhador iria tocar o acompanhamento até o final com a última velocidade calculada.

\subsection{Sintetizador}

A saída de nosso sistema deve ser o áudio relativo ao acompanhamento gerado conforme a dinâmica de tempo detectada da entrada. A geração do acompanhamento pode ser obtida de diversas maneiras utilizando técnicas de síntese de áudio (como aditiva, subtrativa, FM, granular, etc) ou fazendo reproduções de áudio com mudança de escala temporal do acompanhamento [DPZ02]. Tais técnicas entretanto não têm quase nada em comum com as questões relativas ao rastreador e ao acompanhador; a fim de manter claros o escopo e o foco do trabalho iremos terceirizar a síntese de áudio, ou seja, o módulo Acompanhador irá enviar comandos MIDI para um sintetizador externo. Esse sintetizador precisa ter algumas características para dar suporte às instruções desejadas. A primeira é suprir todos os requisitos de implementação definidos pela especificação General $M I D I\left[\mathrm{~A}^{+} 96\right]$. Entre tais requisitos, temos: 
- ter a capacidade de tocar até 24 vozes simultaneamente, sendo 16 para sons melódicos e 8 para percussivos;

- reproduzir 16 canais MIDI polifônicos, sendo o décimo canal reservado para percussão;

- possuir sons para os 128 instrumentos definidos no General MIDI Sound Set;

- responder aos valores de velocity das mensagens note on e note off;

- aceitar as mensagens do tipo aftertouch e pitch bend.

A segunda característica desejada no sintetizador é a aceitação de comandos de controles contínuos (MIDI continuous controllers); essa característica não é imprescindível (como a primeira), porém aumenta a qualidade do áudio final, permitindo um ajuste melhor de parâmetros relacionados à expressividade. A seguir temos uma lista de algumas mensagens que deveriam ser aceitas pelo sintetizador e o que elas forneceriam para o sistema.

- Continuous Controller \#11: Expression Controller

Alternativa para realizar modificações nas amplitudes das notas em tempo real. Ideal para controlar mudanças na dinâmica marcadas na partitura com crescendo ou diminuendo dentro de cada nota.

- Continuous Controller \#68: Legato Pedal

Aplica o efeito de legato entre notas. Ideal para emular sequências melódicas tocadas com um único ataque (por exemplo, no mesmo sopro ou na mesma arcada).

- Continuous Controller \#72: Release Time

Define o tempo de finalização no envelope ADSR das notas.

- Continuous Controller \#73: Attack Time

Define o tempo de ataque no envelope ADSR das notas.

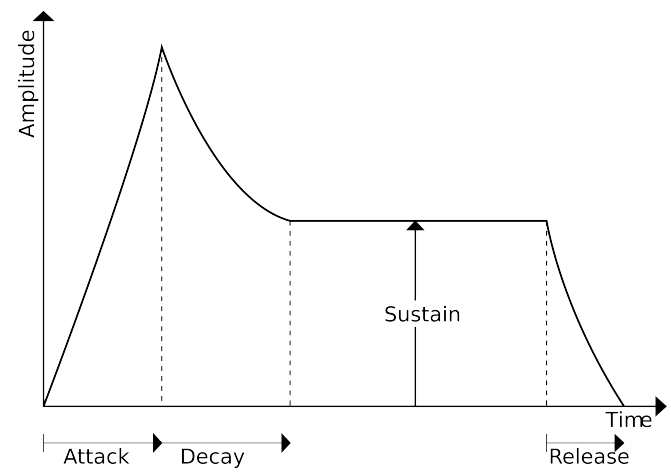

Figura 2.45: Envelope ADSR (Attack Decay Sustain Release) que representa as fases da amplitude de uma nota.

Diversas opções de sintetizadores que satisfazem os requisitos acima foram encontradas: Discovery $^{10}$, FluidSynth ${ }^{11}$, Hexter ${ }^{12}$, TiMidity $++{ }^{13}$ e ZynAddSubFX ${ }^{14}$. O sintetizador FluidSynth foi escolhido por trabalhar com SoundFonts permitindo a utilização de todos os instrumentos do $G e-$ neral MIDI Sound Set, além da utilização de filtros, envelopes ADSR, efeitos de reverberação e chorus, cujos parâmetros são controlados por mensagens MIDI [Hen11].

\footnotetext{
${ }^{10} \mathrm{http}: / /$ www.discodsp.com/discovery/

${ }^{11} \mathrm{http}: / /$ sourceforge.net/projects/fluidsynth/

${ }^{12}$ http://dssi.sourceforge.net/hexter.html

${ }^{13}$ http://timidity.sourceforge.net/

${ }^{14}$ http://zynaddsubfx.sourceforge.net/
} 


\section{Capítulo 3}

\section{Desenvolvimento}

Após apresentarmos toda a base teórica e explicitarmos o funcionamento das técnicas de cada módulo iremos, neste capítulo, tratar de todo o processo de desenvolvimento do sistema. Iniciaremos com as escolhas técnicas essenciais para a implementação do mesmo, como linguagem de programação, APIs para a leitura de instrumentos MIDI, para a criação de interface gráfica, entre outras.

\subsection{Escolhas técnicas}

A linguagem de programação escolhida para o desenvolvimento do sistema proposto foi a linguagem C, por ser uma linguagem adequada à implementação de sistemas em tempo real, devido ao fato de ser uma linguagem compilada, possuir tipagem estática, permitir o gerenciamento da memória e possuir um compilador com rotinas internas de otimização.

A necessidade de acesso direto aos dispositivos de entrada e saída de som tornam a opção por um desenvolvimento multiplataforma bastante difícil e, por essa razão, fomos obrigados a priorizar o desenvolvimento em uma plataforma: os sistemas operacionais baseados em Linux. Para lidarmos com a comunicação de dispositivos MIDI na entrada e com sintetizadores MIDI na saída, precisamos de APIs de áudio que supram essas necessidades.

Flávio Schiavoni e coautores [SGQ12] discutem o impacto no desenvolvimento de uma aplicação a partir da API de áudio escolhida. O artigo apresenta um levantamento de diversas APIs e escolhemos ALSA e JACK para o nosso sistema, segundo os seguintes critérios:

- a utilização da linguagem C;

- a compatibilidade com sistemas Linux;

- o suporte ao protocolo MIDI;

- o suporte aos dois principais padrões de mercado para comunicação com dispositivos MIDI: USB e FireWire.

ALSA $^{1}$, acrônimo de Advanced Linux Sound Architecture, é um arcabouço integrante do núcleo do Linux desenvolvido com objetivo principal de dar suporte a diversas placas de som de forma automática, sendo classificada como uma API de áudio do sistema operacional [SGQ12]. O principal motivo da escolha do ALSA é o fato de sua API possuir suporte nativo a dispositivos MIDI com portas USB (principal padrão do mercado recentemente). Devido ao seu alto grau de acoplamento com o SO, a escolha dessa API implica na necessidade de reescrever partes do código, caso decidamos futuramente dar suporte a outros sistemas operacionais além do Linux. No entanto, esse problema de compatibilidade é minimizado ao utilizarmos a API do JACK como camada adicional no desenvolvimento.

\footnotetext{
${ }^{1}$ http://alsa-project.org/
} 
JACK $^{2}$, acrônimo de JACK Audio Connection Kit, é um servidor de som [SGQ12]. Isso significa que temos uma camada a mais entre a aplicação e o hardware, facilitando o desenvolvimento de aplicações multiplataforma, pois o uso do JACK não requer a comunicação direta das aplicações com drivers ou com a API do sistema operacional [SGQ12]. O JACK fornece comunicação em tempo real tanto de áudio quanto de MIDI com latências muito baixas. Sua API possui compatibilidade com os drivers do projeto $\mathrm{FFADO}^{3}$ possibilitando a comunicação também com dispositivos MIDI que usam portas FireWire.

Mais duas bibliotecas foram utilizadas na implementação de nosso sistema, GSL e OpenGL, que merecem destaque pela importância que tiveram no desenvolvimento, pela facilidade de utilização, pela agilidade na implementação de algumas tarefas e pela qualidade de seus resultados.

GSL $^{4}$ (GNU Scientific Library) é uma biblioteca numérica com diversos métodos matemáticos que englobam geração de números aleatórios, solução de equações polinomiais, criação e manipulação de combinações e permutações, execução das transformadas de Fourier, Hankel e Wavelet discretas, entre muitos outros métodos matemáticos e estatísticos. Estes últimos foram particularmente úteis no desenvolvimento do nosso sistema. Além de auxiliar nas medidas de qualidade dos algoritmos extraídas nos experimentos (conforme veremos no próximo capítulo), a implementação de algumas técnicas de rastreamento e acompanhamento utilizou as seguintes funções desta biblioteca: gsl_stats_mean: para cálculo de média; gsl_stats_sd: para cálculo de desvio padrão; gsl_stats_median_from_sorted_data: para cálculo de mediana (vide seção 3.2.3); e gsl_fit_linear: para cálculo de regressão linear (essencial para a evolução do tempo virtual).

OpenGL ${ }^{5}$ (Open Graphics Library) é uma biblioteca multi-plataforma para renderização gráfica, ideal para a criação de aplicações com interfaces dinâmicas e interativas. Ela inclui diversas rotinas desde a renderização de primitivas simples em 2D (pontos, linhas, polígonos, etc), até funções complexas de texturização e outros efeitos especiais.

A interface desenvolvida utilizando OpenGL mostra para o usuário a evolução do relógio virtual em função do relógio real (pontos em azul na figura 3.1) e também os relatos emitidos pelo Rastreador (pontos em vermelho na figura 3.1). Essas informações tiveram bastante importância para o desenvolvimento, não como feedback da execução propriamente dita, mas como uma forma de registro do comportamento do sistema para análise e depuração.

Essa interface possui dois modos de visualização alternáveis por comandos de teclado. O primeiro, chamado de modo estático global, mostra a performance toda, evidenciando visualmente o andamento inferido pelo Acompanhador, de maneira mais perceptível do que seria pela audição, através de guias em segundo plano dos andamentos de referência em 50, 75, 100, 125 e 150 por cento do andamento original. O segundo modo, chamado de modo dinâmico local, oferece mais detalhes sobre a evolução do relógio virtual, ampliando a visualização em torno de uma janela centralizada no último relato.

Como última escolha técnica a ser apresentada nesta seção, discutiremos a solução para paralelismo através de threads (vide seção 3.2.3). Mais especificamente, utilizamos uma implementação para a interface definida pelo padrão IEEE POSIX 1003.1c chamada de POSIX threads ou, mais comumente, de Pthreads.

Threads apresentam as seguintes vantagens sobre o uso de processos independentes: threads duplicam apenas dados essenciais para rodar independentemente e trabalham com memória compartilhada. Uma thread possui seus próprios registradores, contadores e pilhas, porém compartilha a sequência de instruções e o contexto com a thread mãe. Toda a sobrecarga está na inicialização, o que torna a thread em si mais leve do que um processo independente. Além disso, a utilização de processos exigiria uma camada de implementação a mais para tratar a comunicação entre eles: seja via pipes (mão única) ou sockets (mão dupla) iríamos introduzir um atraso extra na troca de dados.

\footnotetext{
${ }^{2}$ http://jackaudio.org/

${ }^{3}$ http://www.ffado.org/

${ }^{4}$ http://www.gnu.org/software/gsl/

${ }^{5}$ https://www.opengl.org/
} 


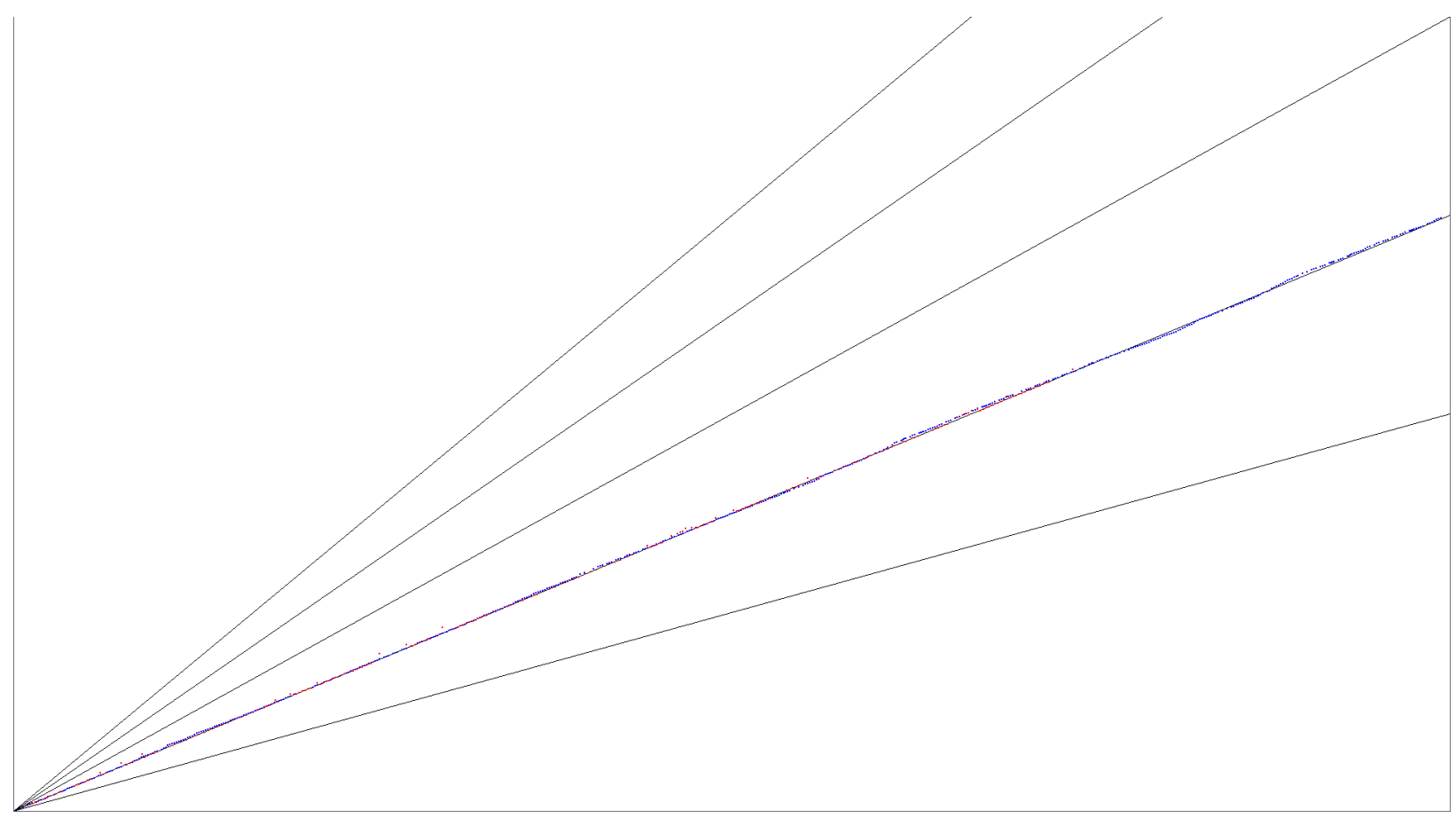

Figura 3.1: Interface gráfica do sistema no modo estático global.

\subsection{Implementação do sistema principal}

Conforme foi visto no capítulo anterior, nosso sistema possui dois tipos de entrada: a execução em tempo real do músico e a partitura. Após a escolha das APIs de áudio, a implementação do código de leitura do instrumento de entrada foi consideravelmente simples. No entanto, a implementação do código que carrega a partitura teve um processo mais extenso. Criamos uma biblioteca para ler um arquivo MIDI e carregar seus eventos em memória de uma maneira que permita uma fácil manipulação no futuro. Para isso fizemos um pré-processamento dos dados originais em etapas descritas a seguir.

\subsubsection{Etapas de desenvolvimento do carregador de partitura}

Primeiramente, modificamos os tempos dos eventos MIDI. Originalmente eles são armazenados de forma relativa, isto é, o tempo do evento $\mathrm{N}$ no arquivo MIDI é a diferença de tempo entre ele e o evento $\mathrm{N}-1$. Portanto, para obter o tempo exato do evento $\mathrm{N}$ precisamos somar todos os tempos do evento 1 ao $\mathrm{N}$ de forma acumulativa.
4, 0, Note_on_c, 2, 64, 119
4, 0, Note_on_c, 2, 64, 119
4, 500, Note_off_c, 2, 64, 64
4,500 , Note_off_c, $2,64,64$
4, 500, Note_on_c, 2, 65, 126
4, 1000, Note_on_c, 2, 65, 126
4, 500, Note_off_c, 2, 65, 64
4, 1500, Note_off_c, 2, 65, 64
4, 500, Note_on_c, 2, 69, 110
4, 2000, Note_on_c, 2, 69, 110
4, 500, Note_off_c, 2, 69, 64
4, 2500, Note_off_c, 2, 69, 64

A segunda etapa está relacionada com o fato de que os eventos do arquivo MIDI possuem uma unidade (ticks) diferente da unidade obtida no relógio do sistema operacional (milissegundos). Ainda, o tick é uma unidade relativa e, para ser convertida, depende de outras duas informações referentes ao andamento da música:

- time division:

Este campo é encontrado no cabeçalho inicial do arquivo MIDI e define a taxa de ticks por pulso (beat). 
- set tempo:

Este meta-evento simboliza uma mudança de andamento e pode ser encontrado diversas vezes durante o decorrer da partitura. Usualmente, eventos desse tipo ficam isolados na primeira faixa (track) do arquivo chamada de mapa de andamento (tempo map) e definem a taxa de microssegundos por pulso.

Para converter um timestamp de ticks para milissegundos, dado um valor de divisão de tempo e um valor de andamento, temos a seguinte fórmula:

$$
t_{m s}=t_{\text {ticks }} \times \frac{1}{\text { time_division }} \times \text { set_tempo } \times \frac{1}{1000}
$$

Porém, a conversão não é tão simples assim. O evento set tempo pode aparecer diversas vezes no decorrer da música e, portanto, temos que considerar as diversas mudanças de andamento ocorridas entre dois eventos, dado que estamos acumulando ticks e o valor de 1 tick muda com o tempo. O tempo de um evento $\mathrm{N}$ será calculado, então, conforme a seguinte fórmula:

$$
t(N)_{m s}=\sum_{i=1}^{N-1}\left(t(i+1)_{t i c k s}-t(i)_{t i c k s}\right) \times C, \text { onde } C=\frac{1}{t_{i m e} \text { division }} \times \text { set_tempo } \times \frac{1}{1000} .
$$

\subsubsection{Alterações nas implementações dos algoritmos rastreadores}

O processo de implementação dos algoritmos do módulo Rastreador passou por diversas fases de tomada de decisão (pela ausência de alguma informação mais explícita da qual a implementação dependia) ou de adaptação (pela necessidade de modificar a técnica para nossas necessidades) e também será detalhado nesta seção. Abaixo iremos listar todas as alterações feitas durante esse processo.

\section{Dannenberg (1984)}

No artigo original [Dan84] existe uma sugestão de guardar apenas as colunas anterior e atual ao invés da matriz inteira de programação dinâmica. Com tal modificação, temos que fazer uma cópia da coluna atual na coluna anterior para a próxima execução, ao final do processo de cálculo dos valores das linhas. Porém, após tal processo sempre teremos valores indefinidos nas colunas (pelo menos os valores que estariam na matriz abaixo da coluna anterior e acima da coluna atual, conforme ilustrado na figura 3.2).

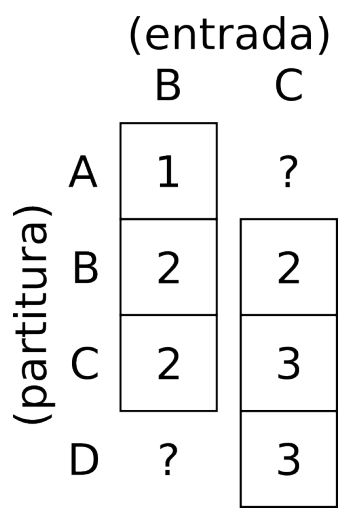

Figura 3.2: Valores indefinidos ao redor das colunas anterior e atual para um deslocamento de janela de tamanho 1.

A solução adotada foi preencher os dois valores com zeros e em ambos os casos a integridade dos valores calculados até o momento será mantida. O zero colocado acima da coluna atual será utilizado para calcular o valor da primeira posição da coluna atual somente se as alturas não casarem e, nesse caso, será descartado na chamada de $\max (N, 0)=N$. O zero colocado abaixo da coluna 
anterior será utilizado para calcular o valor da última posição da coluna atual no mesmo cenário e será descartado pelo mesmo motivo. É garantido que o valor da máxima subsequência comum até o instante esteja armazenado na coluna anterior e que ele será utilizado no cálculo dos próximos valores. Tal afirmação ainda vale para deslocamentos de janela maiores do que 1 (conforme ilustrado na figura 3.3).

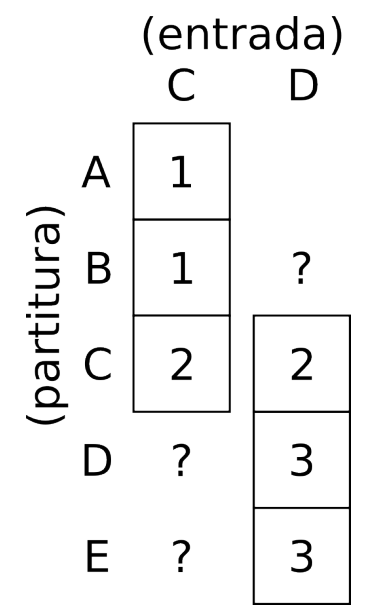

Figura 3.3: Valores indefinidos ao redor das colunas anterior e atual para um deslocamento de janela de tamanho 2.

\section{Lippe (1992)}

No processo de implementação deste algoritmo [LP92] foi necessário determinar quando casamentos irão gerar relatos. Os autores afirmam que casamentos encontrados da nota esperada para frente irão gerar atualização das estruturas de dados. Achamos conveniente gerar relatos nesses casamentos em primeira instância. Além disso, consideramos gerar relatos para casamentos encontrados na skip list também. Gerar relatos para casamentos à esquerda da nota esperada teria a consequência de gerar pulos na geração do acompanhamento (pois teríamos relatos em eventos passados). Porém, é crucial permitir que o Rastreador perceba e se recupere de um erro. Se realmente o músico cometeu um erro e voltou na partitura para uma nota da skip list ela deve gerar um relato. Mais ainda, iremos atualizar as estruturas de dados quando casamentos ocorrerem na skip list também.

Outra decisão tomada foi em relação a como varrer a skip list. Todas as regiões da nota atual para frente são percorridas da esquerda para a direita. Seguir a mesma estratégia para a skip list seria dar privilégio para relatos em notas mais antigas. Tal comportamento poderia gerar pulos muito bruscos no acompanhamento e, portanto, parece mais prudente olhar para as notas da skip list da direita para a esquerda.

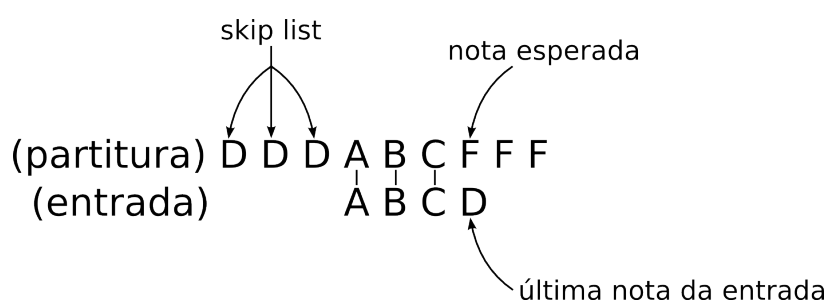

Figura 3.4: Diferentes possibilidades de casamentos na skip list para a nota $D$ recém chegada.

\section{Vercoe (1985)}

Ao implementarmos este algoritmo [VP85] foi necessário determinar quando iremos emitir relatos. Para isso foi feito um paralelo entre o algoritmo de Vercoe1985 com o de Dannenberg1984, 
pois ambos constroem a solução ótima global de forma incremental. Porém, no algoritmo de Vercoe1985 não existe nenhuma medida (nenhum número) que cresce conforme bons casamentos são encontrados (como acontece com o tamanho da maior subsequência comum de Dannenberg1984).

O algoritmo de Dannenberg1984 gera relatos apenas quando a nota recém chegada é incorporada à maior subsequência comum. No algoritmo de Vercoe1985 temos duas teorias que consideram que existe correspondência com alguma nota da partitura; portanto nossa implementação gera relatos quando tais teorias forem escolhidas, isto é, quando as respectivas notas forem incorporadas no pareamento global.

Outro ponto importante na implementação foi a medida de desvio temporal de uma nota recém chegada em relação à regressão linear das notas anteriores. Os autores sugerem utilizar dois parâmetros cujos valores não estão definidos no artigo e, assim, não puderam ser utilizados na nossa implementação. Porém, o algoritmo depende da definição de uma medida de desvio temporal e, para suprir essa necessidade, escolhemos o módulo da distância vertical entre o ponto e a reta.

\section{Baird (1993)}

Nossa implementação para este algoritmo [BBZ93] passou por diversas modificações em relação ao que estava proposto originalmente no artigo. A principal delas está no núcleo do algoritmo e diz respeito à representação de pausas. No nosso caso, isso é especialmente relevante pelo fato do MIDI não considerar pausas musicais em seu protocolo e possuir apenas eventos para início e fim de notas (note on e note off, respectivamente) provenientes da entrada. Teríamos, portanto, que criar novos eventos (rest on e rest off) ou utilizar eventos pré-existentes (note on e note off com nota MIDI igual a zero, por exemplo) para representar eventos de pausas. Mais ainda, o instrumento de entrada não iria gerar esses eventos de pausa e, assim, o sistema teria que criar um processo de análise da entrada para identificar pausas e gerar tais eventos por conta própria.

Um possível método para gerar eventos de pausa seria contabilizar quantos eventos note on estão ativos a cada momento. Assim podemos gerar um rest on quando nenhum note on estiver ativo e um rest off assim que o próximo note on aparecer. Tal abordagem, porém, é muito simplista por não diferenciar pausas acidentais das intencionais. O próprio artigo sugere trabalhar com um limiar de tempo para fazer essa diferenciação. Se uma pausa ultrapassar esse limiar podemos gerar o rest on. Caso contrário, consideramos que era uma pausa acidental.

Os autores afirmam que tal limiar varia de obra para obra e ainda que ele deve ser determinado por uma análise da partitura anterior à execução, porém não dão detalhes sobre essa análise; apenas mencionam que ela deve considerar a métrica e o andamento. Essa questão é complicada do ponto de vista musical, pois o final de uma nota não é tratado na execução exatamente do mesmo jeito que o início; assim por exemplo um trecho em staccatto (seja este indicado na partitura ou não) terá todos os finais de nota antecipados em relação à representação original.

Essa discussão está intimamente ligada com a penalização de notas por durações menores do que as previstas. Porém, nesse ponto em particular os autores já tomaram a decisão de estender o fim de uma nota até o início da próxima quando sua duração executada for menor do que a especificada na partitura. Assim, só serão penalizadas notas cuja duração ultrapassar o início da próxima (conforme ilustrado na figura 3.5).

A modificação final, portanto, consiste em implementar o sistema sem representação de pausas fazendo assim uma versão consideravelmente diferente da do artigo. Assim, toda vez que nos referenciarmos à implementação de Baird1993 neste texto devemos considerar que o algoritmo é inspirado nas técnicas do artigo e não uma versão totalmente fiel (como foi a intenção para os artigos anteriores).

Uma outra modificação ficou a cargo do implementador. O artigo determina explicitamente quando devemos emitir um relato: assim que o casamento de menor custo for escolhido. Porém, não é claro qual ponto da partitura devemos relatar, pois não temos mais uma nota sozinha sendo casada; temos um padrão formado por diversas notas. É necessário, então, determinar qual a posição interna ao padrão que o músico está. Inicialmente, utilizamos a posição da última nota que formou o padrão 
(1) não haverá penalidade

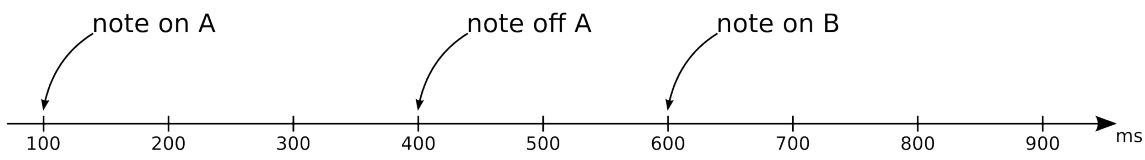

(2) haverá penalidade

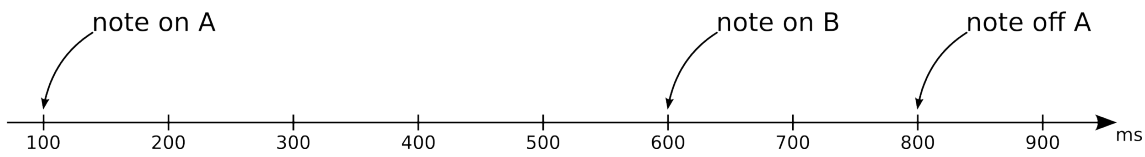

Figura 3.5: Casos de penalização de notas por durações diferentes.

da partitura. Porém, a figura 3.6 mostra que tais notas podem ficar de fora do emparelhamento. Então, iremos verificar quais notas foram utilizadas e relatar a posição da última delas.

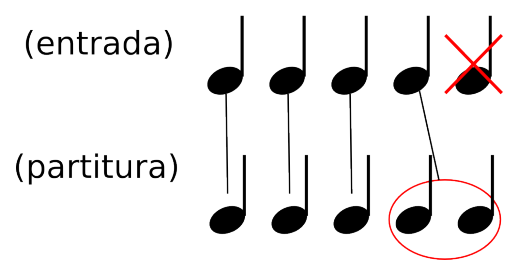

Figura 3.6: Exemplo no qual a última nota emitida na entrada foi excluída do pareamento.

\section{Vantomme (1995)}

Para a implementação desta técnica [Van95] apenas um item extra precisou ser abordado: a geração de relatos. No fluxograma da imagem 2.30 temos dois pontos onde podemos decidir se houve o casamento de uma nota ou não. Consideramos que tanto o agrupar de um evento em um acorde, quanto o detectar de um evento com tempo de ataque tolerável são pontos candidatos a relatos de casamento entre entrada e partitura. Dentre esses dois pontos, o autor diz que devemos ignorar eventos agrupados em acordes para o recálculo do andamento, pois diversas notas emitidas em intervalos tão pequenos não deveriam gerar vários relatos, mesmo quando corretas. Portanto, ao implementar esse algoritmo iremos gerar relatos apenas no segundo tipo de casamento descrito acima (que inclusive trata a primeira nota de um acorde).

\subsubsection{MetaRastreador}

A fim de mesclar os pontos fortes dos cinco algoritmos rastreadores implementados introduzimos um novo método que denominamos MetaRastreador. A concepção do nosso MetaRastreador está diretamente conectada com dois artigos que utilizam diversas instâncias de um mesmo algoritmo de rastreamento em conjunto paralelamente [DM88, AW10b], o que sugere a possibilidade de se criar um rastreador que combine ou pondere os relatos e opiniões de diversos rastreadores diferentes.

Roger Dannenberg e Hirofumi Mukaino [DM88] propõem a utilização de dois rastreadores iguais rodando em paralelo para solucionar o seguinte problema: caso o músico pare de tocar, não sabemos se ele irá voltar na posição em que ele parou de tocar, ou na posição atual do acompanhamento (que evolui de forma autônoma). O primeiro rastreador fica centralizado na nota após a última tocada pelo músico e o segundo rastreador acompanha a execução do Acompanhador (conforme ilustrado na figura 3.7) e, conforme as próximas notas chegarem, cada algoritmo irá procurar por casamentos na região correspondente da partitura. O rastreador que encontrar casamentos com maior confiabilidade envia suas informações para o módulo Acompanhador e o outro é descartado.

Andreas Arzt e Gerhard Widmer [AW10b] apresentam a utilização de diversos rastreadores em paralelo para possibilitar que o músico toque os compassos da música na ordem em que desejar. Isso permite que ele pule alguns compassos ou até mesmo que toque compassos de forma repetida para 


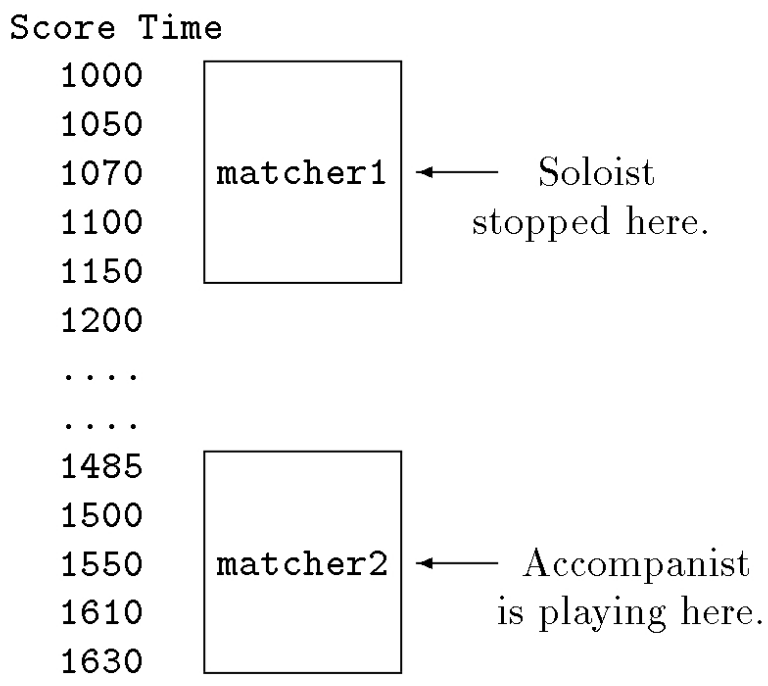

Figura 3.7: Dois rastreadores sendo executados em paralelo [DM88].

ensaiar melhor um trecho de maior dificuldade, sem avisar explicitamente o sistema que a partitura será tocada em uma ordem alternativa. Para obter esse comportamento de forma automática eles sugerem espalhar uniformemente pela partitura $\mathrm{N}$ rastreadores idênticos (conforme ilustrado na figura 3.8) que irão calcular diversas hipóteses de onde o músico pode estar na partitura. Um outro componente chamado de Decision Maker irá decidir qual dessas hipóteses será aceita, caracterizando uma repetição ou um reinício de trecho.

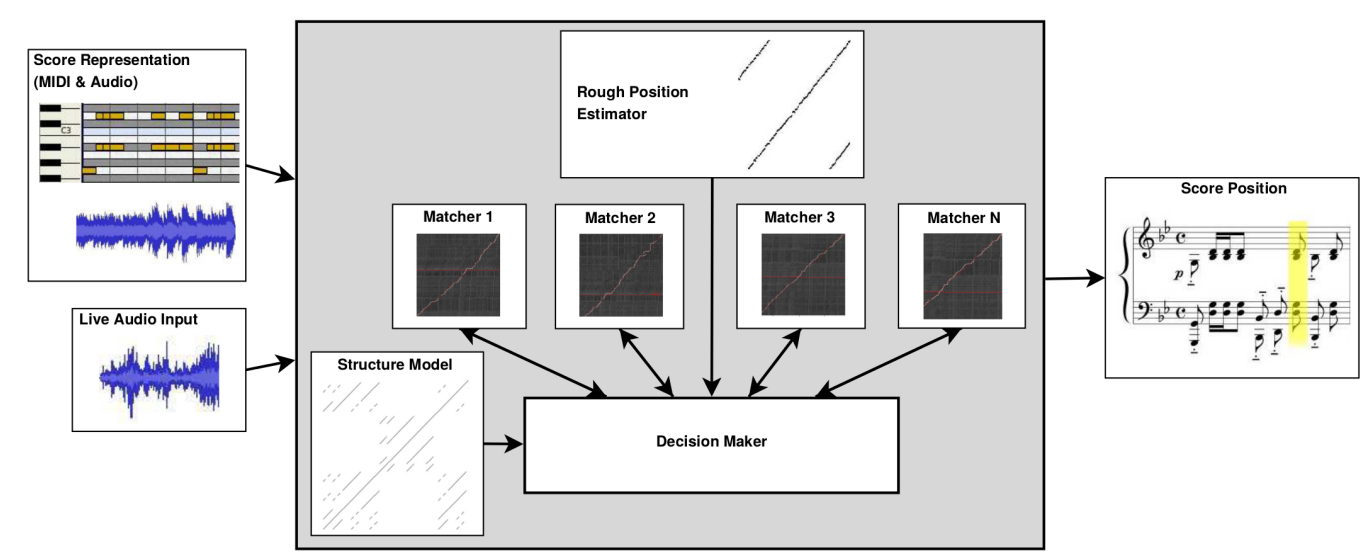

Figura 3.8: $N$ rastreadores sendo executados em paralelo [AW10b].

Diferentemente dos dois artigos citados acima, que utilizavam instâncias de um mesmo algoritmo de rastreamento em pontos diferentes da partitura, o que estamos propondo é rodar várias instâncias de algoritmos diferentes em uma mesma região da partitura para aumentar a confiança sobre a localização do músico. Tais instâncias não são necessariamente de $\mathrm{N}$ técnicas diferentes, o que permite também o uso de uma mesma técnica com parâmetros diferentes. Por exemplo, podemos rodar o algoritmo de Dannenberg1984 com mais de um tamanho de janela (permitindo alcances diferentes na partitura), ou o algoritmo de Vercoe1985 com custos de penalidades variados (apresentando rigor diferenciado para classes de erros diferentes), ou ainda o algoritmo de Baird1993 com diferentes limites de custo para casamentos de padrões (variando a tolerância em relação ao que o algoritmo considera uma execução perfeita). 
Dados $\mathrm{N}$ algoritmos sendo executados em paralelo, teremos a possibilidade de $\mathrm{N}$ relatos serem emitidos para um mesmo evento de entrada. Isso iria nos indicar até $\mathrm{N}$ posições diferentes (alguns algoritmos irão provavelmente relatar a mesma posição) para um mesmo evento, conforme ilustra a imagem abaixo.

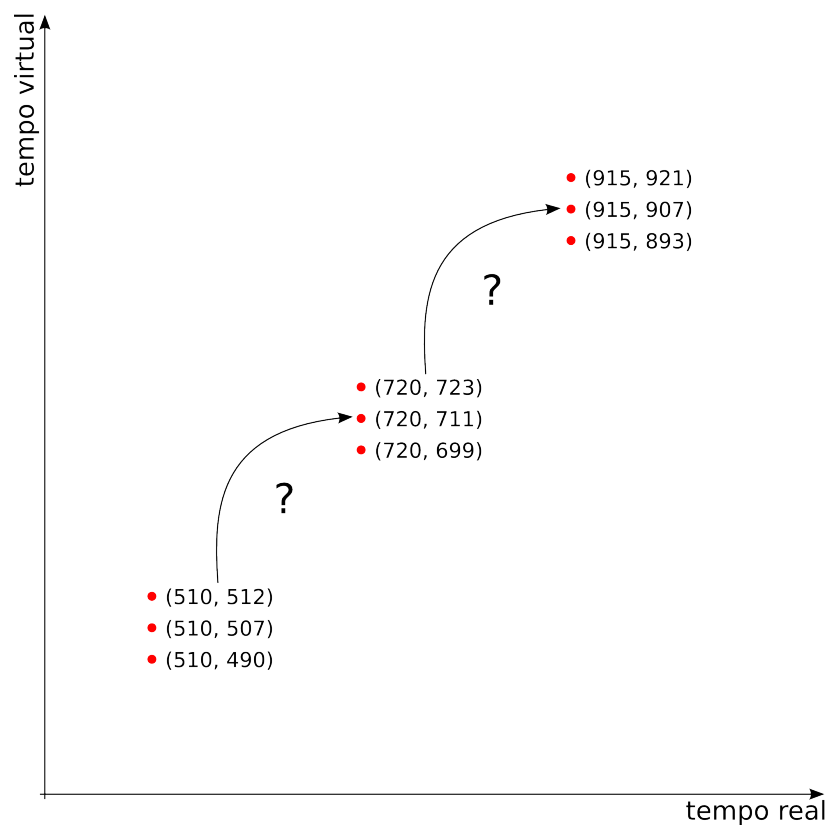

Figura 3.9: Diversos pontos de relatos para um mesmo tempo real de recebimento de uma nota.

A presença de relatos diversos é considerada positiva, pois permite mais de uma opinião sobre a posição do músico para cada nota recebida, aumentando a chance de que uma destas opiniões corresponda à posição correta. Porém, o problema agora é decidir qual posição relatar para o módulo Acompanhador. O caso mais simples seria se a maioria dos rastreadores relatasse a mesma posição, pois teríamos maior confiança em tal valor. Entretanto, temos que considerar o caso mais geral no qual todos os $\mathrm{N}$ rastreadores irão relatar posições diferentes.

Uma primeira possibilidade de combinação dos relatos seria usar a média das posições relatadas. Porém a média dá peso igual para todos os relatos, mesmo aqueles que poderiam ser descartados como outliers por se encontrarem muito afastados de todos os demais. A alternativa escolhida é considerar a mediana das posições relatadas pelos $\mathrm{N}$ rastreadores, o que privilegia os valores centrais da distribuição e ignora os outros, como podemos ver na figura 3.10.

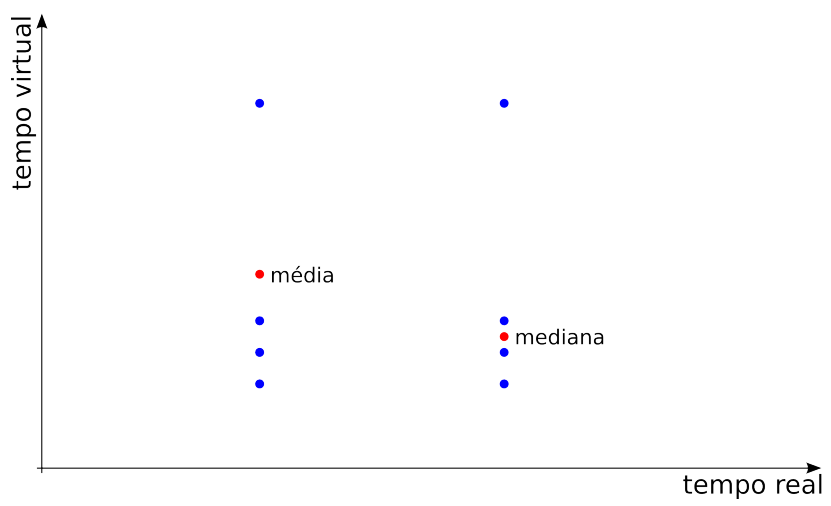

Figura 3.10: Comparação entre média e mediana.

Uma outra dificuldade encontrada está relacionada ao fato de que cada algoritmo demora um tempo diferente para gerar seu relato, ou seja, não temos todos os relatos entregues de forma sincronizada para calcular a mediana imediatamente. Para resolver esse problema, criamos uma estrutura de dados que irá armazenar todos os relatos emitidos para cada nota recebida na entrada. 
Conforme pode ser visto na figura 3.11 iremos armazenar os relatos em uma lista ligada. Quando um algoritmo emitir seu relato, iremos armazená-lo nessa lista e, além disso, iremos atualizar a mediana dos pontos.

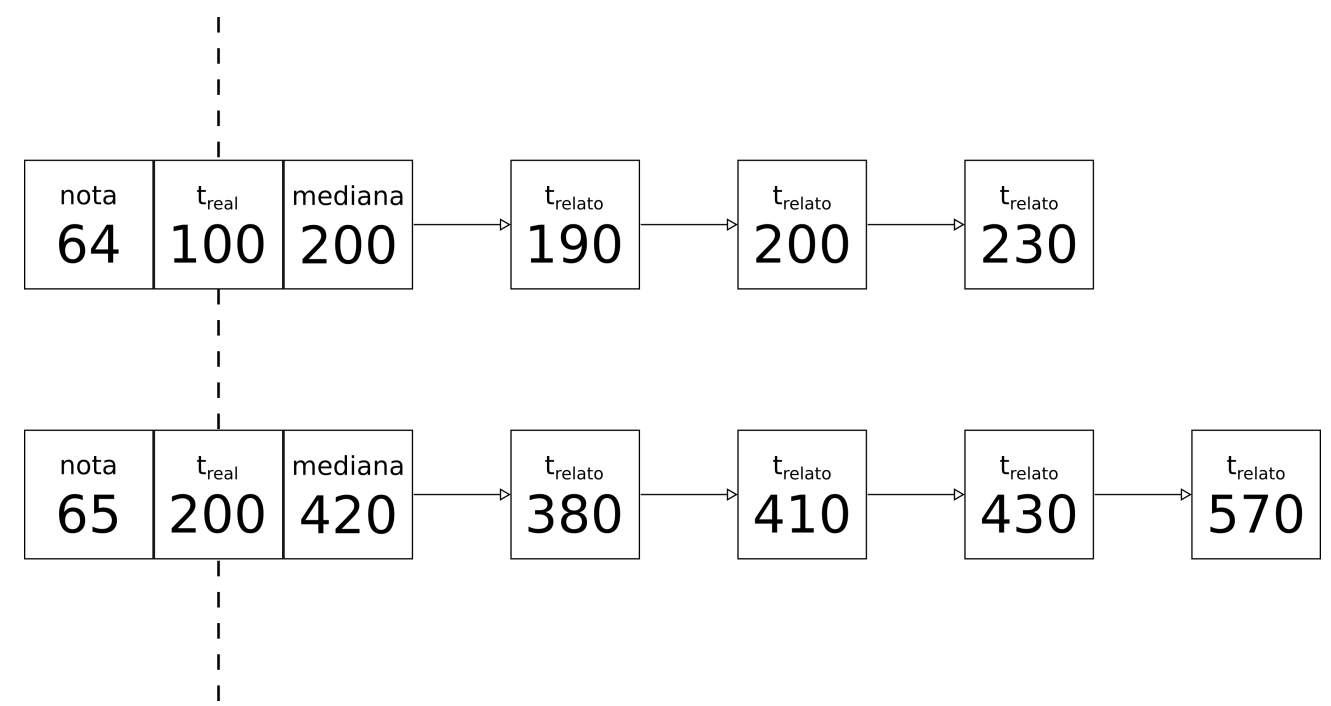

Figura 3.11: Estrutura de dados que armazena os relatos emitidos para uma nota e a respectiva mediana.

Essa atualização iterativa da mediana produz uma tendência no MetaRastreador de replicar os relatos do rastreador que produz os relatos primeiro, mas nada garante que esses relatos sejam corretos. Para aproveitar as diversas opiniões dos diferentes rastreadores sobre uma mesma nota da entrada, o MetaRastreador espera ao menos 3 relatos de algoritmos diferentes antes de calcular a mediana (desse modo temos a opinião de mais da metade dos rastreadores e a mediana desses valores não é necessariamente igual à média).

\subsection{Sistemas periféricos}

Com todas as técnicas implementadas temos o nosso sistema pronto para ser executado. No entanto, para fazermos uma avaliação robusta do mesmo identificamos algumas necessidades que foram supridas pela implementação de três sistemas periféricos que serão descritos a seguir.

\subsubsection{Tocador de MIDI}

O primeiro sistema auxiliar implementado foi um tocador de MIDI com velocidade variável, com a finalidade de permitir a avaliação do sistema sem a dependência de um intérprete musical humano. Para alcançar tal objetivo, reutilizamos alguns códigos do sistema de acompanhamento musical que lidam com MIDI, com certas modificações.

O carregador de partitura foi alterado para carregar em memória apenas a faixa do solista. O agendador de eventos MIDI para a saída foi modificado para receber a razão entre o tempo virtual e o real (0.7, por exemplo, para $70 \%$ do andamento original). Além disso, o leitor de dispositivos MIDI da entrada foi reaproveitado, considerando apenas eventos do tipo controller para variar o parâmetro de andamento em tempo real (entre $50 \%$ e $150 \%$ do original).

A utilização conjunta do tocador com nosso sistema foi útil na primeira fase de depuração para estimarmos objetivamente a qualidade dos algoritmos implementados, através da variação do andamento em tempo real e observação simultânea da curva de evolução do tempo virtual.

Tais experimentos entretanto duram o tempo real (total) das músicas testadas, o que foi considerado um ponto negativo para uma avaliação experimental mais abrangente. Em particular, desejamos que uma grande bateria de testes seja executada de forma rápida a fim de permitir a obtenção de estatísticas dos vários algoritmos. Esse objetivo foi alcançado através do mecanismo de execução em lote descrito a seguir. 
1. substituição;

Nessa alteração iremos trocar as alturas musicais das notas sorteadas por um outro valor aleatório dentro do intervalo [0, 127].
4, 1276, Note_on_c, 2, 64, 119
4, 1276, Note_on_c, 2, 64, 119
4, 1460, Note_off_c, 2, 64, 64
4, 1460, Note_off_c, 2, 64, 64
4, 1515, Note on c, 2, 72, 126
4, 1515, Note on c, 2, 85, 126
4, 1739, Note_off_c, 2, 72, 64
4, 1739, Note off c, 2, 85, 64
4, 1756, Note on c, 2, 69, 110
4,1756 , Note on c, 2, 69, 110
4, 1888, Note_off_c, 2, 69, 64
4, 1888, Note_off_c, 2, 69, 64

2. deleção;

Nessa alteração iremos simplesmente remover as notas sorteadas da faixa do solista para simular deleções de notas por parte do músico solista.
4,6555, Note_on_c, 2, 63, 114
4, 6555, Note_on_c, 2, 63, 114
4, 6668, Note_off_c, 2, 63, 64
4, 6668, Note_off_c, 2, 63, 64
4, 6795, Note_on_c, 2, 71, 120
4, 7019, Note_off_c, 2, 71, 64
4, 7036, Note_on_c, 2, 66, 119
4, 7036, Note_on_c, 2, 66, 119
4, 7220, Note_off_c, 2, 66, 64
4, 7220, Note_off_c, 2, 66, 64

3. adição (antes);

Nessa alteração iremos adicionar notas extras na faixa do solista para simular ornamentos ou erros adicionados durante a execução. Para realizar tal tarefa, no entanto, precisamos abrir espaço para essas novas notas sem alterar a duração total do evento (o que seria uma modificação quantitativa e não qualitativa). Para cada nota sorteada, então, será gerado um outro número aleatório dentro do intervalo [0.0, 1.0] para definir a fração da duração da nota original que iremos dar para a nova nota, colocando-a antes da nota original (encurtada da mesma fração).
4, 555, Note_on_c, 2, 65, 111
4, 555, Note_on_c, 2, 65, 111
4, 667, Note_off_c, 2, 65, 64
4, 667, Note_off_c, 2, 65, 64
4, 796, Note_on_c, 2, 35, 120
4, 831, Note_off_c, 2, 35, 64
4, 796, Note_on_c, 2, 64, 120
4, 832, Note_on_c, 2, 64, 120
4, 940, Note_off_c, 2, 64, 64
4, 940, Note_off_c, 2, 64, 120
4, 1035, Note_on_c, 2, 65, 127
4, 1035, Note_on_c, 2, 65, 127
4, 1259, Note_off_c, 2, 65, 64
4, 1259, Note_off_c, 2, 65, 64

4. adição (depois);

Essa alteração é análoga à anterior, porém iremos adicionar a nota extra depois da nota original.
4, 555, Note_on_c, 2, 65, 111
4, 555, Note_on_c, 2, 65, 111
4, 667, Note_off_c, 2, 65, 64
4, 667, Note_off_c, 2, 65, 64
4, 796, Note_on_c, 2, 64, 120
4, 796, Note on c, 2, 64, 120
4, 940, Note_off_c, 2, 64, 64
4, 831, Note_off_c, 2, 64, 120
4, 832, Note_on_c, 2, 35, 120
4, 940, Note_off_c, 2, 35, 64
4, 1035, Note_on_c, 2, 65, 127
4,1035 , Note_on_c, 2, 65, 127
4, 1259, Note_off_c, 2, 65, 64
4, 1259, Note_off_c, 2, 65, 64

5. antecipações nos ataques de notas;

Nessa alteração iremos variar os ataques das notas para simular antecipações realizadas pelo músico. Para cada nota sorteada pelo parâmetro de destruição, geraremos um número aleatório 
dentro do intervalo $[0.9,1.0]$ para criar variações de até $10 \%$ antecipando o tempo de ataque, e alterando correspondentemente o tempo dos eventos note on e note off da nota sorteada para preservar sua duração.
4, 2715, Note_on_c, 2, 64, 120
4, 2715, Note_on_c, 2, 64, 120
4, 2860, Note_off_c, 2, 64, 64
4, 2860, Note_off_c, 2, 64, 64
4, 2955, Note_on_c, 2, 72, 123
4, 2869, Note_on_c, 2, 72, 123
4, 3179, Note_off_c, 2, 72, 64
4, 3093, Note_off_c, 2, 72, 64
4, 3496, Note_on_c, 2, 69, 119
4, 3496, Note_on_c, 2, 69, 119
4, 3680, Note_off_c, 2, 69, 64
4, 3680, Note_off_c, 2, 69, 64

6. atrasos nos ataques de notas;

Essa alteração é análoga à anterior, porém as variações são de até $10 \%$ de atraso nos instantes de ataque.
4, 2715, Note_on_c, 2, 64, 120
4, 2715, Note_on_c, 2, 64, 120
4, 2860, Note_off_c, 2, 64, 64
4, 2860, Note_off_c, 2, 64, 64
4, 2955, Note_on_c, 2, 72, 123
4, 3102, Note_on_c, 2, 72, 123
4, 3179, Note_off_c, 2, 72, 64
4, 3326, Note_off_c, 2, 72, 64
4, 3496, Note_on_c, 2, 69, 119
4, 3496, Note_on_c, 2, 69, 119
4, 3680, Note_off_c, 2, 69, 64
4, 3680, Note_off_c, 2, 69, 64

7. encurtamentos nas durações das notas.

Nessa alteração iremos modificar as durações das notas para simular encurtamentos realizados pelo músico. Para cada nota sorteada pelo parâmetro de destruição, geraremos um número aleatório dentro do intervalo $[0.9,1.0]$ para criar variações de até $10 \%$ a serem subtraídos do tempo do evento note off da nota sorteada. É importante observar que esta alteração não afeta as notas subsequentes à nota encurtada.
4, 5596, Note_on_c, 2, 66, 110
4, 5596, Note_on_c, 2, 66, 110
4, 5728, Note off c, 2, 66, 64
4, 5728, Note_off_c, 2, 66, 64
4, 6075, Note_on_c, 2, 63, 127
4, 6075, Note_on_c, 2, 63, 127
4, 6300, Note_off_c, 2, 63, 64
4, 6273, Note_off_c, 2, 63, 64
4, 6515, Note_on_c, 2, 64, 111
4, 6515, Note_on_c, 2, 64, 111
4, 6727, Note_off_c, 2, 64, 64
4, 6727, Note_off_c, 2, 64, 64

8. prolongações nas durações das notas.

Essa alteração é análoga à anterior, porém até $10 \%$ da duração da nota será acrescentado ao tempo do evento note off. Isso será feito apenas quando houver espaço antes do evento note on da próxima nota, a fim de não propagar a alteração para notas futuras.
4, 5596, Note_on_c, 2, 66, 110
4, 5596, Note_on_c, 2, 66, 110
4, 5728, Note_off_c, 2, 66, 64
4, 5728, Note_off_c, 2, 66, 64
4, 6075, Note_on_c, 2, 63, 127
4, 6075, Note_on_c, 2, 63, 127
4, 6300, Note_off_c, 2, 63, 64
4, 6435, Note_off_c, 2, 63, 64
4, 6515, Note_on_c, 2, 64, 111
4, 6515, Note_on_c, 2, 64, 111
4, 6727, Note_off_c, 2, 64, 64
4, 6727, Note_off_c, 2, 64, 64

Com os sistemas periféricos descritos acima podemos gerar e testar a execução de diversos arquivos diferentes para diversas peças musicais. Com isso surge o cenário de experimentações que será apresentado com detalhes no próximo capítulo. 


\section{Capítulo 4}

\section{Experimentos}

\subsection{Experimentos}

O processo experimental teve início com a seleção das obras musicais. Utilizamos como critério abranger diversos estilos e épocas do repertório erudito ocidental, ao mesmo tempo escolhendo peças representativas e razoavelmente bem conhecidas. Para isso selecionamos uma lista de compositores entre o período Barroco e o início do século XX: Bach, Mozart, Schubert, Chopin, Liszt, Debussy, Stravinsky, Bartók, Schoenberg e Stockhausen. Além disso, procuramos cobrir o repertório popular, selecionando compositores e grupos como Astor Piazzolla, Tom Jobim, John Coltrane, Pink Floyd, Radiohead, entre outros. Para cada compositor ou grupo buscamos no mínimo duas peças (uma mais lenta e outra mais rápida), a fim de submeter o sistema a entradas de diferentes graus de exigência.

Alguns requisitos técnicos também foram considerados para a escolha das peças. O primeiro é que a faixa do instrumento solo deve ser monofônica. Para isso selecionamos peças para instrumentos originalmente monofônicos (como flauta, trompete, clarinete, etc.) e peças para instrumentos polifônicos (como violino, piano, bandoneon, etc) cuja parte possui poucos trechos com polifonia que foram removidos usando um editor de partitura.

O próximo requisito possui relação com o formato do arquivo MIDI em si. Existe um campo no cabeçalho de um arquivo MIDI chamado tipo do formato (format type), que determina se as informações estarão todas em uma faixa (track) só ou se estarão divididas em diversas faixas [A+96]. Se o arquivo MIDI possuir todas as informações na primeira faixa, nosso sistema irá considerá-lo inválido, por diversos motivos, que incluem a impossibilidade do músico escolher a faixa do solista, e a falta de uma organização que permita ao usuário visualizar as partes separadas em um editor de partituras. Por esta razão todas as peças selecionadas para os experimentos possuem faixas separadas.

Outro requisito relacionado ao formato do arquivo MIDI está no campo do cabeçalho do arquivo que se chama divisão de tempo (time division). O protocolo permite que esse campo esteja em duas unidades: ticks por beat ou quadros por segundos [A+96]. Em nosso sistema aceitamos apenas arquivos com a primeira unidade, pois a segunda é utilizada para sincronismo de vídeos, que não é nosso escopo de utilização.

Com o repositório pronto de arquivos MIDI, podemos gerar as entradas com variações dentro das classes de erros definidas anteriormente. Isso irá gerar um grupo de entradas de tamanho 20.000 vezes maior do que o repositório de peças. Estamos utilizando cada uma das 8 classes de erro com 5 parâmetros de destruição diferentes $(2 \%, 4 \%, 6 \%, 8 \%$ e 10\%) e, além disso, geramos 500 lotes de arquivo para cada classe de erro e cada parâmetro de destruição.

Para obter uma avaliação objetiva e quantitativa, precisamos estabelecer uma medida a ser extraída do sistema que reflita o quanto sua resposta está distante de uma resposta ideal ou esperada. Todos os arquivos de entrada que refletem a execução do solista foram gerados com andamento fixo ( $75 \%$ do original da partitura), de onde se espera que a evolução do relógio virtual siga o mesmo andamento. Para medir a acurácia do acompanhador serão usados os erros dos instantes atribuídos 
ao relógio virtual. Para cada ponto gerado na função que descreve o tempo virtual em relação ao tempo real, utilizaremos o valor absoluto da diferença vertical em relação à reta $y=0.75 \times x$. O erro total da execução será definido como a média dos erros de todos os valores atribuídos ao relógio virtual. Utilizaremos essa medida de erro como principal métrica de qualidade do acompanhamento: quanto menor o desvio do relógio virtual em relação à meta, melhor o resultado do sistema.

Cada técnica de rastreamento de partitura possui uma série de parâmetros que influenciam fortemente o comportamento dos algoritmos. Os resultados preliminares nos mostraram que variar tais parâmetros pode influenciar fortemente os resultados obtidos para uma determinada peça. Dada essa observação, decidimos fazer uma fase de otimização de parâmetros para cada peça e cada algoritmo de acompanhamento, processo esse que pode ser utilizado também pelo usuário para calibrar o sistema para cada música e cada método de acompanhamento que desejar. Veja abaixo a lista desses parâmetros e o conjunto de valores utilizados.

- Dannenberg1984

1. window_size: $\{3,5,7,11,13\}$

- Lippe1992

1. skip_number: $\{1,2,3,4,5\}$

2. skip_time: $\{100,200,300,400,500\}$

- Vercoe1985

1. $p_{m}:\{3,5,7,11,13\}$

2. $p_{e}:\{3,5,7,11,13\}$

3. $p_{w}:\{3,5,7,11,13\}$

4. $p_{l}:\{3,5,7,11,13\}$

5. $p_{t r}:\{3,5,7,11,13\}$

6. $p_{t w}:\{3,5,7,11,13\}$

- Baird1993

1. pattern_size: $\{3,5,7,11,13\}$

2. points_threshold: $\{0.5,0.75,1.0,1.25,1.5\}$ (em relação ao pattern_size)

A otimização de parâmetros foi feita algoritmo por algoritmo e o processo de testar todas as combinações de parâmetros para um lote de arquivos de uma peça do repositório era realizado em poucos minutos para a maioria dos algoritmos. Porém, com o algoritmo de Vercoe1985, tivemos que fazer algumas simplificações. O conjunto com todas as combinações tem cardinalidade 15.625 $\left(=5^{6}\right)$. Rodar todos esses parâmetros para um lote de arquivos tomava um tempo de 6 horas em média (dependendo do número de notas da partitura), o que gerou a necessidade de utilizar um subconjunto dos parâmetros.

Além disso, lidamos com um outro problema no processo de otimização de parâmetros. Inicialmente, estávamos escolhendo os parâmetros que maximizavam a qualidade do sistema para todas as classes de erro de forma conjunta, motivados pelo fato de que não conhecemos a priori quais tipos de erro são mais frequentes para um músico genérico. No entanto, os resultados obtidos não eram satisfatórios. Resolvemos testar a otimização de parâmetros para cada classe de erro separadamente a fim de melhor compreender quais os principais desafios apresentados em cada cenário. Isso produziu uma melhora considerável nos resultados.

Uma última observação a ser feita em relação aos experimentos realizados é que seu processo de criação não se utilizou de nenhum modelo de performance musical, sendo as entradas geradas a partir de uma perspectiva puramente matemática, com intuito de cobrir diversos cenários relativos às classes de erro estudadas. 


\subsection{Resultados e Discussões}

Para cada lote de arquivos de uma música em particular foram gerados 240 valores numéricos ( 8 classes de erro; 5 parâmetros de destruição; 6 algoritmos de acompanhamento) que representam as medidas de erro do sistema para as entradas do lote.

Como foram gerados 500 lotes para cada música, os 120 mil valores serão omitidos deste texto. Para uma melhor análise, foram gerados diversos gráficos com o intuito de observarmos os resultados de forma resumida.

Duas discussões importantes serão feitas. A primeira será sobre os valores estimados para os parâmetros de cada técnica de rastreamento no processo de otimização. A segunda será sobre os erros médios do sistema ao acompanhar as entradas utilizando o MetaRastreador.

Considerando o fato do MetaRastreador se valer dos relatos dos outros algoritmos rastreadores implementados e melhorar a robustez desses relatos, apresentaremos e analisaremos apenas as execuções do sistema com o MetaRastreador. Nos casos em que o MetaRastreador apresenta bons resultados para uma classe de erro em particular, poderemos atribuir seu sucesso à utilização conjunta das várias técnicas de rastreamento; nos demais casos, poderemos concluir que mais da metade dos algoritmos não conseguiu obter bons resultados individuais, afetando o resultado geral do MetaRastreador.

\subsubsection{Discussão sobre os valores estimados para os parâmetros}

Em relação à estimação de parâmetros para cada algoritmo podemos fazer algumas observações. Cada algoritmo e cada classe de erro serão estudados separadamente: por exemplo, para o algoritmo de Dannenberg1984 e para erros de substituição serão estimados os parâmetros ótimos para a coleção de todas as músicas, a fim de minimizar o erro total da evolução do relógio virtual nesse algoritmo na presença de erros desse tipo. Cada música gera um valor ótimo diferente para cada parâmetro, produzindo uma distribuição estatística dos valores daquele parâmetro para aquela classe de erro. Cada distribuição será resumida através de gráficos do tipo boxplot onde poderemos ver as médias (triângulos verdes), medianas (linhas laranjas) e valores mínimos e máximos de cada parâmetro.

Para Dannenberg1984 temos apenas um parâmetro - window_size - que determina o tamanho da janela do algoritmo de rastreamento (baseado no problema da maior subsequência comum). Podemos observar na figura 4.1 que em classes de erro nas quais o número de notas das entradas é igual ao número de notas da partitura (por exemplo, para substituições e variações nas durações) o parâmetro escolhido foi, em média, o menor dentro do conjunto das possibilidades dadas. Nos casos de adições (antes e depois), o número de notas da entrada é maior do que o número de notas da partitura e, em média, o tamanho escolhido da janela foi maior. Isso se deve ao fato de que com janelas maiores o algoritmo tem em mãos um número maior de notas da partitura para conseguir classificar a nota recém chegada da entrada como uma adição.

Para Lippe1992, temos dois parâmetros - skip_number e skip_time (quantidade de notas e intervalo de tolerância de tempo) - que determinam quantas comparações o algoritmo irá realizar. Podemos observar, pela figura 4.2, que os tipos de erro que tiveram os maiores skip_numbers foram atraso e deleção. Esses são os casos nos quais as notas chegam com tempos avançados ou nem chegam e, por isso, a otimização de parâmetros obteve melhores resultados considerando um maior número de notas à frente (optando por utilizar um skip_number maior em contraste com skip_time maior). Em relação ao skip_time, a classe de erro que apresentou maior valor em média foi a adição depois. Nesse caso temos um número maior de notas na entrada do que na partitura e, além disso, as notas extras são inseridas entre outras duas, ocupando parte da duração da anterior. Isso aumenta a densidade de notas em um trecho de tempo fixo, o que explica a necessidade de um skip_time maior para essa classe (pois o skip_number sozinho deixaria algumas notas de fora).

O algoritmo de Vercoe1985 possui seis parâmetros que são pesos de penalidades para diversos erros considerados pelo algoritmo em questão. Ficam bem evidentes algumas correlações entre os valores escolhidos pelo processo de otimização e as classes de erro testadas. Observe na figura 4.3 que o parâmetro $p_{l}$ possui maiores valores de penalidade para as classes de substituição, antecipação 


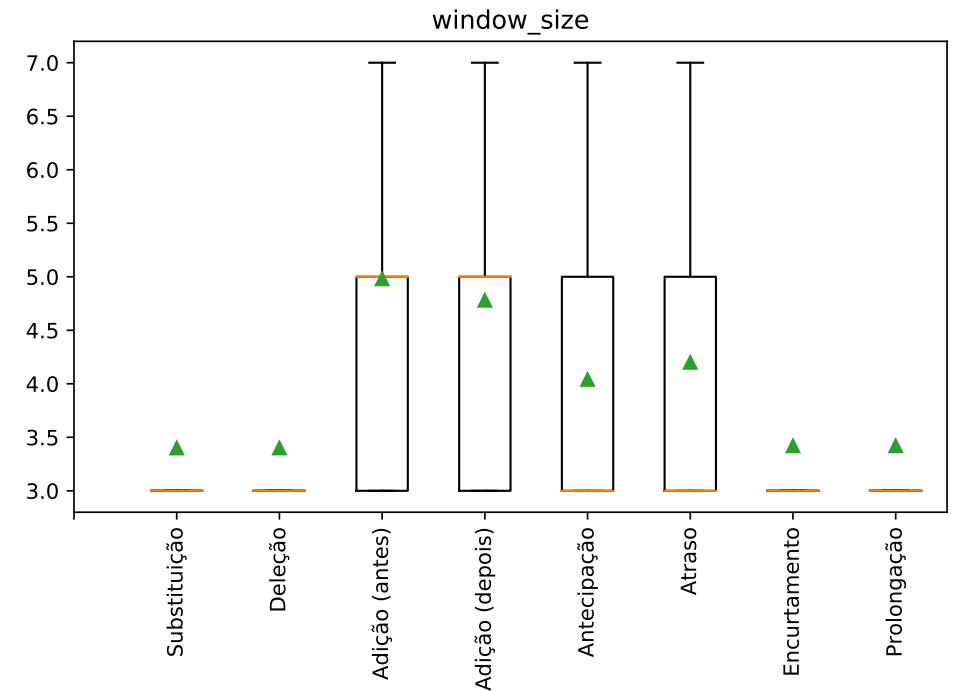

Figura 4.1: Estatísticas de estimação de parâmetros de Dannenberg1984.
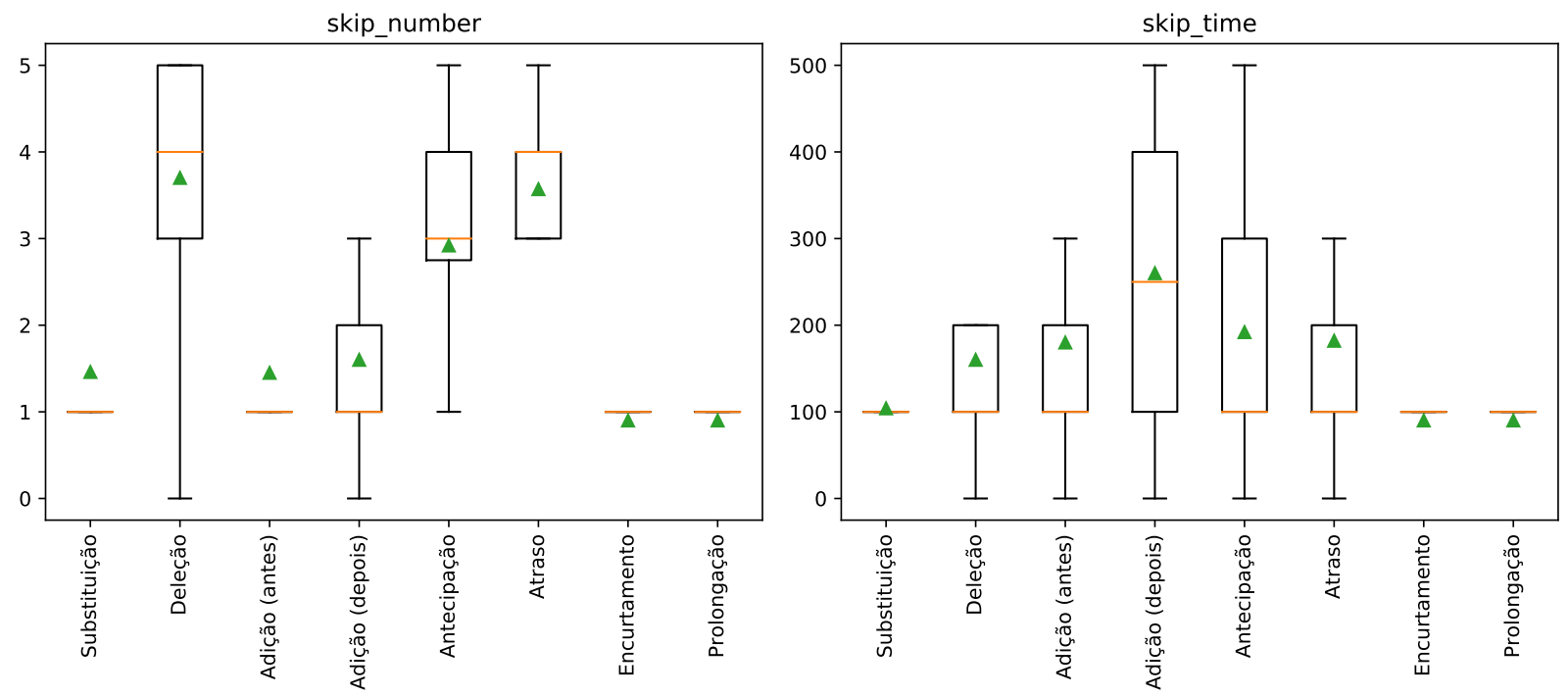

Figura 4.2: Estatísticas de estimação de parâmetros de Lippe1992.

e atraso. O parâmetro $p_{l}$ lida com o caso de quando a nota está errada (ou pela altura, ou pelo tempo), porém será considerada pelo algoritmo para a estimativa de andamento do músico. As três classes destacadas acima são exatamente as que representam esses erros. Observe que $p_{t r}$ e $p_{t w}$ possuem valores altos nas classes de antecipação e atraso. Os dois parâmetros tratam de penalidades para notas cujos tempos serão descartados e tal característica nos explica porque $p_{t r}$ e $p_{t w}$ tiveram valores altos. Por último, desejamos destacar uma diferença entre os dois: $p_{t w}$ possui, na média, valores maiores para erros de substituição e isso condiz com sua finalidade de ignorar tempos de notas com alturas erradas (em contraste com $p_{t r}$ que ignora tempos de notas com alturas certas).

Por último, o algoritmo de Baird1993 apresenta dois parâmetros - pattern_size e points_threshold - que determinam o tamanho dos padrões a serem comparados e o valor limite de qualidade dessas comparações. Dentre as classes de erro que tiveram as menores médias para o parâmetro pattern_size, temos as adições (antes e depois), como se pode ver na figura 4.4. Nessas classes de erro temos, sistematicamente, notas extras na entrada, e isso torna possível que o algoritmo gere relatos falsos ao utilizar padrões muito grandes para os casamentos (pois a nota extra pode estar na partitura em uma vizinhança próxima). Consequentemente, o processo de otimização encontrou melhores resultados utilizando padrões menores para os erros de adição. Em relação ao points_threshold, gos- 

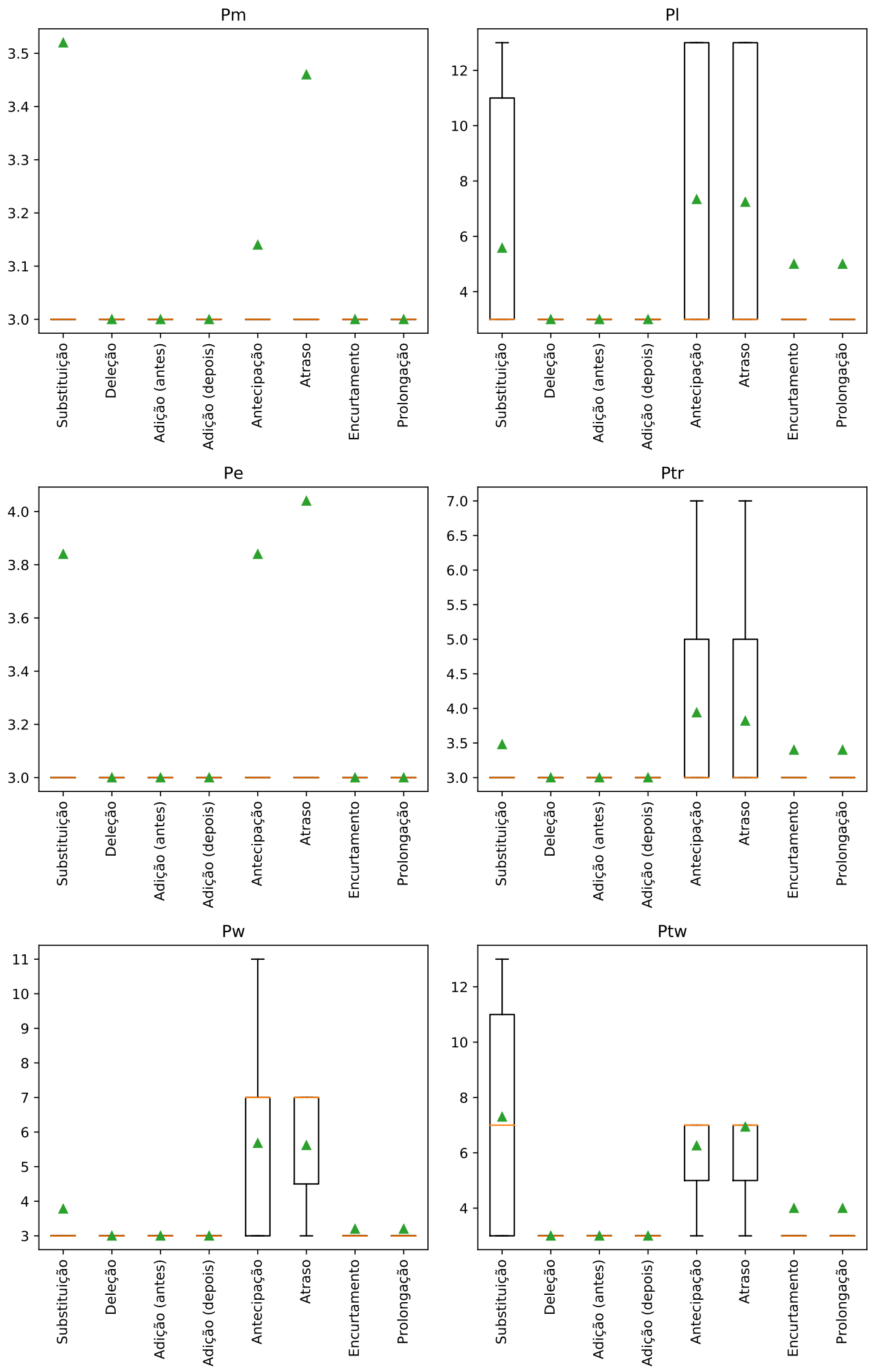

Figura 4.3: Estatísticas de estimação de parâmetros de Vercoe1985. 
taríamos de lembrar ao leitor que o algoritmo de Baird1993 é o único, dentre os selecionados, que considera variações nas durações ao fazer rastreamento de partituras. Assim, é compreensível que os erros de encurtamentos e prolongações tenham apresentado as menores médias desse parâmetro. Interpretamos que, para garantir uma melhor performance, a otimização de points_threshold determinou que flexibilizar erros de duração irá garantir melhores resultados.
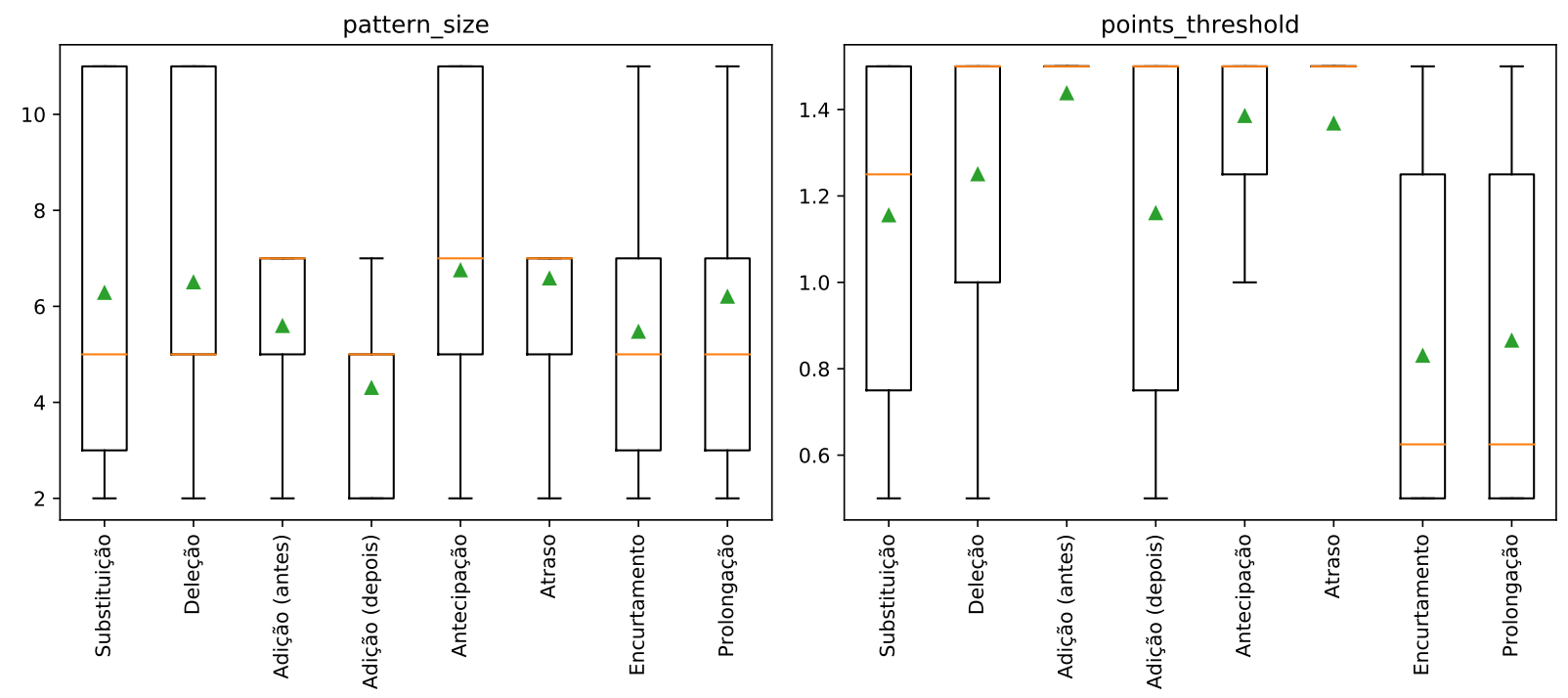

Figura 4.4: Estatísticas de estimação de parâmetros de Baird1993.

A análise do processo de estimação de parâmetros foi considerada satisfatória, pois os valores estimados refletiram o funcionamento esperado de cada um dos algoritmos. Na sequência, iremos discutir os erros médios obtidos com o MetaRastreador.

\subsubsection{Discussão sobre os erros médios do MetaRastreador}

Iniciaremos nossa análise observando os gráficos das médias ${ }^{1}$ dos desvios para cada classe de erro para todos os lotes das músicas executadas com cada um dos 5 valores do parâmetro de destruição.

Pelos 8 gráficos apresentados nesta seção (figuras 4.5 a 4.12), podemos observar que as classes de erro que apresentaram os melhores resultados foram substituição, encurtamento e prolongação. Nos três casos temos o mesmo número de notas na entrada e na partitura, o que é considerado um cenário positivo para os algoritmos de rastreamento que compõem o MetaRastreador. Inclusive este é o cenário ótimo para o algoritmo de Vantomme1995: todas as notas foram tocadas no tempo certo mesmo havendo diversas alterações nas alturas musicais e durações.

Os erros de substituição pouco atrapalham a geração do acompanhamento, pois um evento de altura musical trocada será detectado e simplesmente não irá gerar um relato, não afetando a evolução do relógio virtual e permitindo que o sistema permaneça alinhado com o solista. Um caso levemente mais complicado é quando o evento de altura trocada pertence à partitura em uma vizinhança próxima, o que poderia gerar um relato e uma alteração errônea no andamento. Porém, a probabilidade do sorteio de uma altura de 0 a 127 devolver uma das notas posteriores é muito baixa e tal caso foi pouco observado nos experimentos.

\footnotetext{
${ }^{1}$ Nos experimentos realizados cerca de $6 \%$ das execuções apresentavam ou erros exatamente iguais a zero ou valores de erro muito altos (da ordem de $10^{16} \mathrm{~ms}$ ). Inspecionando tais casos particulares observamos que poucos relatos iniciais determinavam um andamento fixo até o final da música. Imagine que os dois primeiros relatos coincidem com o andamento exato e depois nenhum outro relato é produzido até o final da música: nesse caso o erro será zero, porém não é razoável considerar essa uma execução válida. No outro caso, imagine que os dois primeiros relatos sejam quase simultâneos porém casem com eventos distantes na partitura, e mais nenhum relato seja produzido: nesse caso o andamento estimado será muito alto, gerando um erro gigantesco em uma execução também considerada inválida. Para eliminarmos esses casos extremos fizemos uma remoção simples dos outliers dos resultados. Os dados apresentados nesta seção, então, são de cerca de $94 \%$ das execuções dos experimentos.
} 


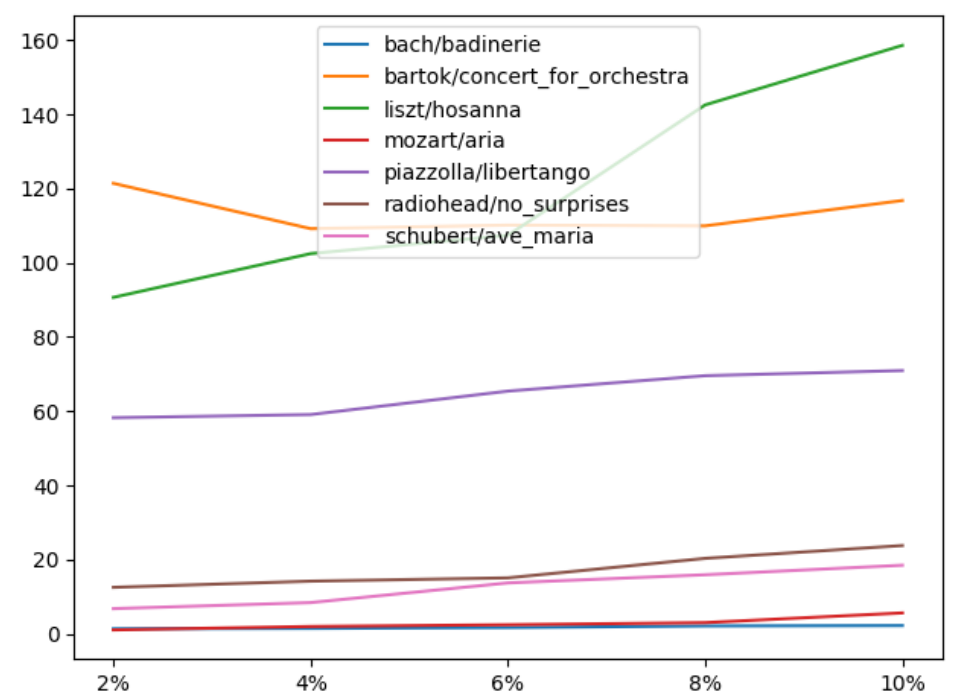

Figura 4.5: Médias de valores para erros de Substituição

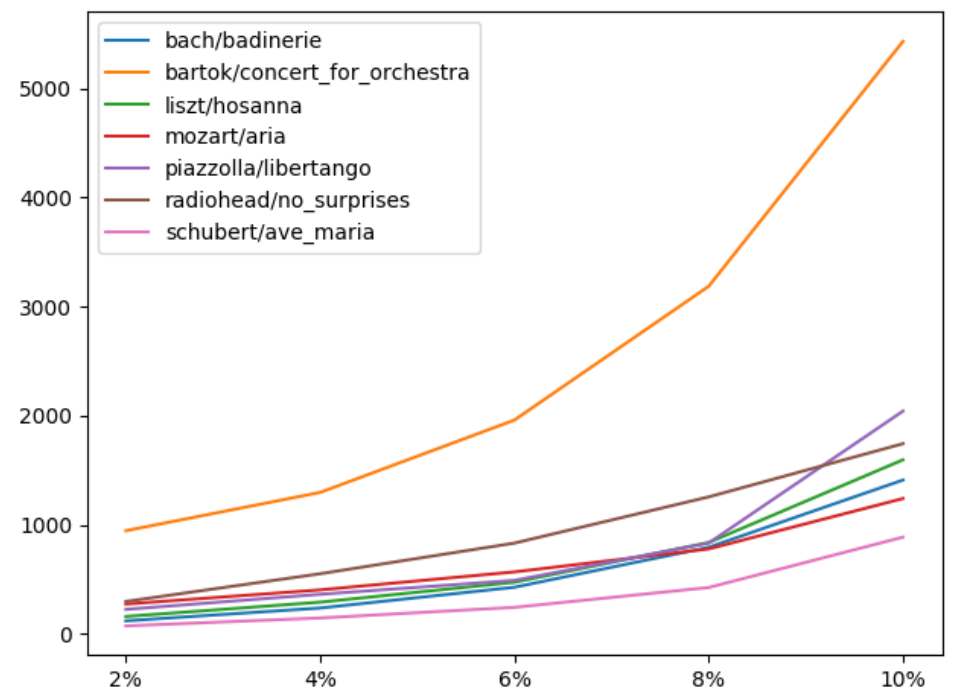

Figura 4.6: Médias de valores para erros de Deleção

As duas classes de variações de durações (encurtamento e prolongação) tiveram bons resultados, pois quatro dos cinco algoritmos de rastreamento não consideram as durações (simplesmente as ignoram). Logo, com alturas musicais e tempos de ataques corretos na entrada, tais algoritmos possuem comportamento inalterado com quaisquer variações de durações. Por consequência, o MetaRastreador obteve bom comportamento para os experimentos dessas duas classes de erro.

Por último, podemos observar nesses três gráficos (figuras 4.5, 4.11 e 4.12) que diversas músicas possuem pouca variação no erro total (desvio do relógio virtual) em função da porcentagem de destruição (principalmente nos erros de encurtamento). Concluímos, então, que os algoritmos implementados são bem robustos em relação a esses erros.

Em relação aos erros de precisão temporal dos ataques (erros de antecipação e atraso), (figuras 4.9 e 4.10) podemos observar que embora a quantidade de notas na entrada e na partitura seja a mesma, os resultados são inferiores aos dos erros de substituição e duração. Isso ocorre porque cada nota produz um relato correspondente ao seu tempo de ataque, que flutua (em relação ao tempo fixo da partitura) devido às antecipações e atrasos, afetando o andamento estimado e acumulando erros no relógio virtual.

Diferentemente das classes anteriores, podemos observar que os erros aumentam proporcional- 


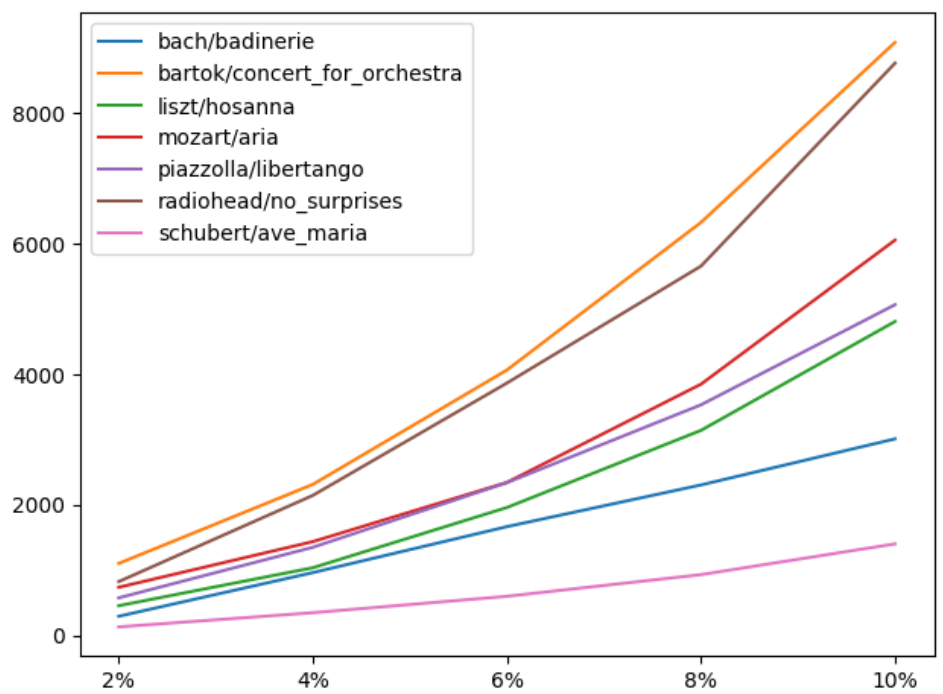

Figura 4.7: Médias de valores para erros de Adição (antes)

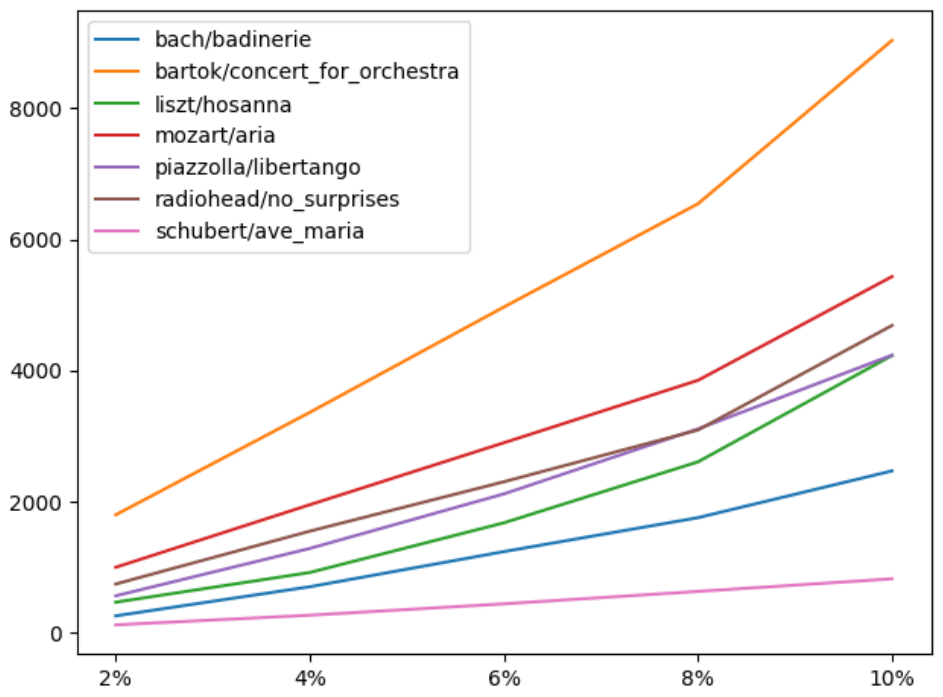

Figura 4.8: Médias de valores para erros de Adição (depois)

mente aos parâmetros de destruição para todas as músicas, o que explicita que maiores desvios nos tempos de ataque irão gerar maiores desvios de andamento. No entanto, vimos que os parâmetros testados (de até 10\%) não irão gerar consequências catastróficas. Isso se deve ao fato de utilizarmos regressão linear de muitos pontos e os pontos relativos a essas variações aleatórias não conseguem influenciar tão fortemente a evolução global do relógio virtual.

Na sequência devemos olhar a classe de erro de deleção (figura ??). Temos, pela primeira vez, experimentos cujas entradas possuem um número de notas diferente da partitura. Mais especificamente, um número menor de notas. Um dos cinco algoritmos de rastreamento - Vantomme1995 se baseia totalmente nos tempos de ataques das notas e, caso uma nota seja omitida na entrada, a nota correspondente na partitura será casada com a próxima nota da entrada, independentemente de sua altura musical (isso se seu tempo de ataque estiver dentro de um limiar aceitável).

Isso significa que teremos um efeito cascata, pois os relatos consecutivos estarão sempre deslocados desse ponto para frente (se os tempos de ataque forem todos dentro do esperado). Músicas que possuem alta densidade de notas e baixas durações estão mais sujeitas a tal erro cumulativo. O comportamento do Vantomme1995 explica o motivo da qualidade ter caído tanto para essa classe de erro. Os quatro algoritmos restantes de rastreamento possuem tratamentos para deleção de notas, 


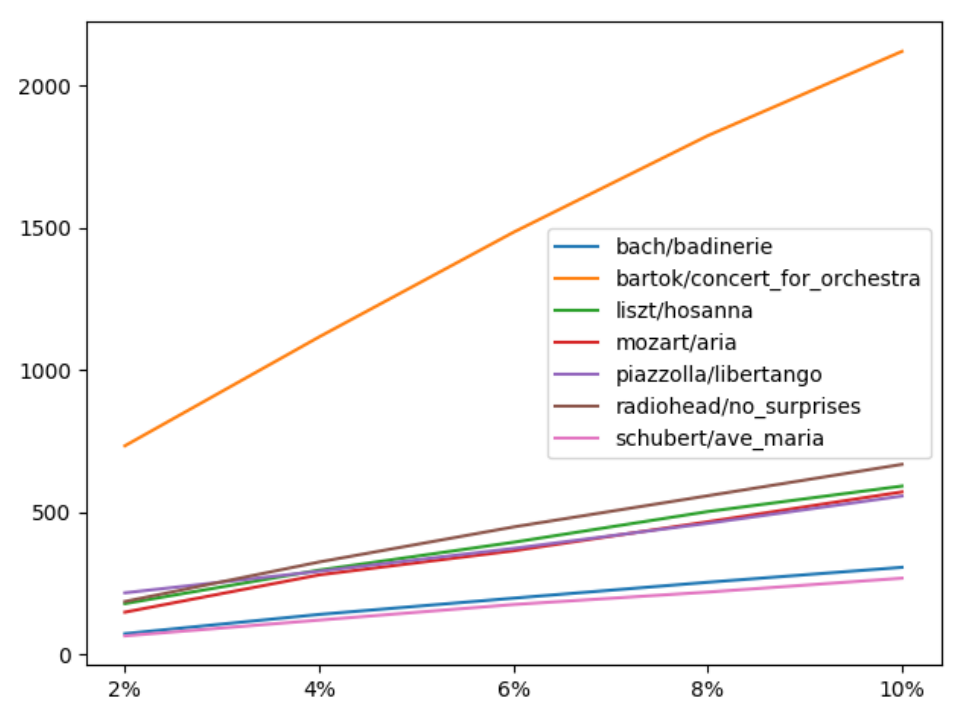

Figura 4.9: Médias de valores para erros de Antecipação

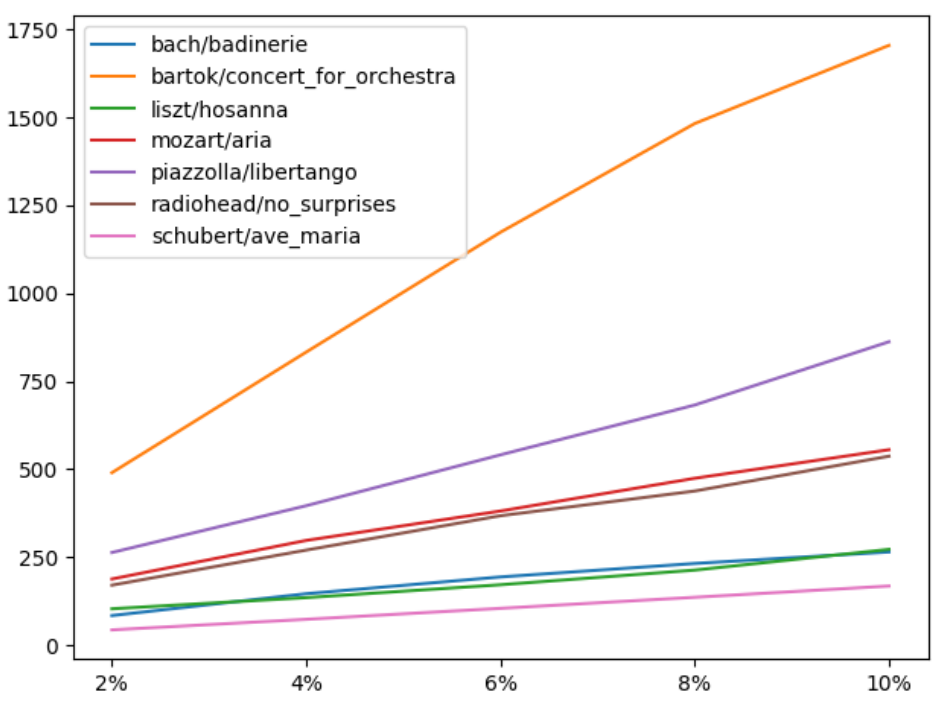

Figura 4.10: Médias de valores para erros de Atraso

porém também estão sujeitos a produzir relatos errados em diversos casos de deleção.

O primeiro caso é o das notas que se repetem na partitura e uma delas é omitida na entrada. Todos os algoritmos estão sujeitos a relatar um casamento com a primeira nota ao invés da segunda (mesmo que a intenção do músico fosse tocar apenas a segunda nota). Outro caso é o de duas (ou mais) deleções seguidas. A segunda nota tocada (após todas as deleções) poderia não ser casada corretamente porque sua nota correspondente na partitura está fora do horizonte visível do rastreador. Isso pode acontecer com os algoritmos de Dannenberg1984 com uma janela pequena e de Lippe92 com um skip_number pequeno. Por último, devemos lembrar que Baird93 considera uma única deleção no modelo de casamento sem interrupções. A partir dos gráficos e de nossa análise, podemos concluir que o MetaRastrerador é bastante sensível a erros de deleção.

Por último, devemos analisar os desvios médios das duas classes de erro de adição (antes e depois) apresentados nas figuras 4.7 e 4.8. A adição de uma nota pode gerar um resultado desastroso para um algoritmo de rastreamento, pois a nota extra pode estar presente em um ponto posterior da partitura e isso pode gerar um falso relato. Além disso, erros de adição geram como efeito colateral erros de duração na nota original, que é encurtada para permitir a inserção de uma nota nova sem atrasar as notas seguintes. Mais ainda, o caso de adição (antes) gera um erro adicional de atraso 


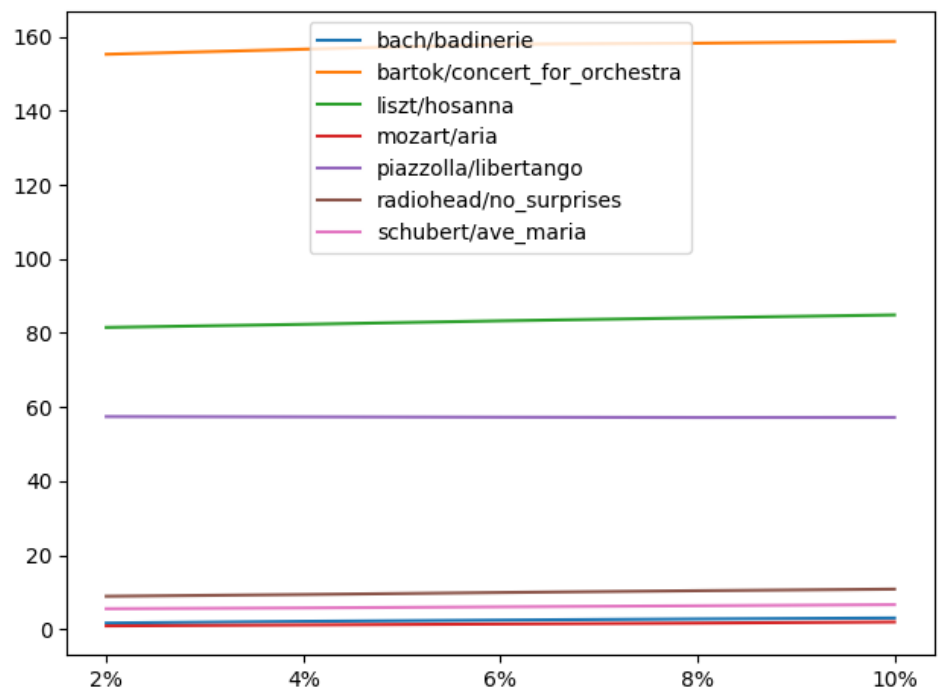

Figura 4.11: Médias de valores para erros de Encurtamento

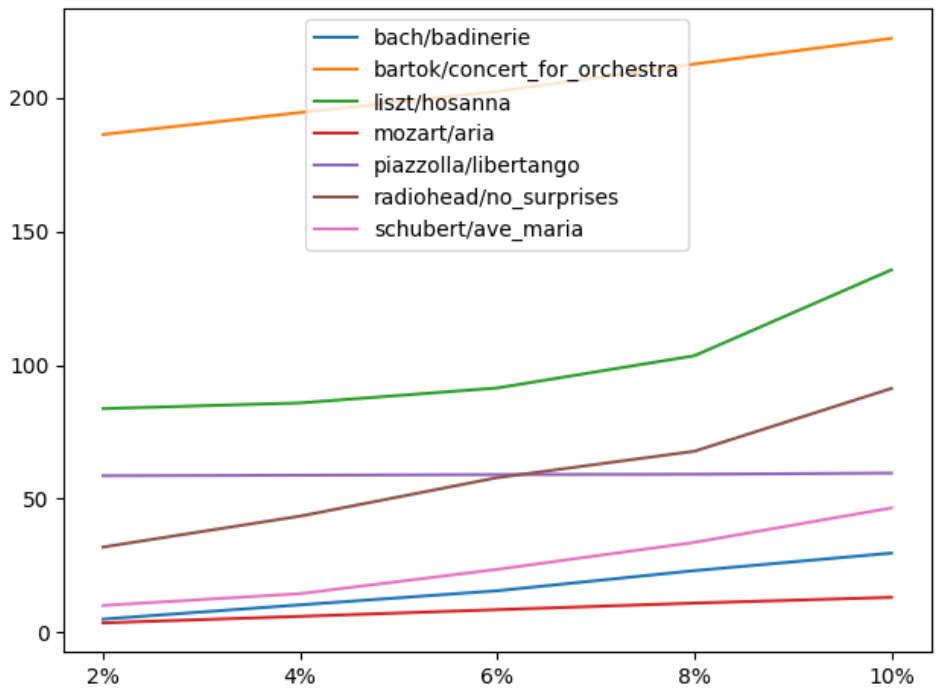

Figura 4.12: Médias de valores para erros de Prolongação

da nota original, que terá como consequência a produção de um relato com tempo errado para essa nota e um aumento no erro acumulado pelo relógio virtual.

Além de termos outras classes de erros (encurtamento e atraso) que aparecem como consequência das adições, temos um número maior de notas na entrada em comparação com a partitura. $\mathrm{O}$ algoritmo de Vantomme1995 novamente irá apresentar resultados ruins, pelo mesmo comportamento apontado para os erros de deleção (os eventos vão sendo casados conforme chegam, não havendo nenhuma verificação se as alturas são diferentes). Tais observações nos ajudam a entender o porquê do MetaRastreador obter resultados tão inferiores para adições.

Na sequência, iremos analisar o desempenho do sistema em função das peças. Olharemos para a quantidade, densidade e durações das notas. A tabela abaixo possui as estatísticas compiladas. 


$\begin{array}{llllll}\text { artista } & \text { arquivo } & \text { média das durações }(\mathrm{ms}) & \text { número de notas } & \text { tempo total (ms) } & \text { densidade (notas/seg) } \\ \text { bach } & \text { badinerie.mid } & 176.991150 & 452 & 80500 & 5.614907 \\ \text { bartok } & \text { concert_for_orchestra.mid } & 99.365931 & 951 & 221543 & 4.292620 \\ \text { liszt } & \text { hosanna.mid } & 1122.916129 & 155 & 231677 & 0.669035 \\ \text { mozart } & \text { aria.mid } & 324.201087 & 368 & 169607 & 2.169722 \\ \text { piazzolla } & \text { libertango.mid } & 161.794483 & 725 & 178790 & 4.055037 \\ \text { radiohead } & \text { no_surprises.mid } & 980.402299 & 174 & 223343 & 0.779071 \\ \text { schubert } & \text { ave_maria.mid } & 652.564356 & 101 & 80970 & 1.247376\end{array}$

A partir dos gráficos apresentados acima, podemos claramente notar que a peça que teve os piores resultados em 7 das 8 classes de erro foi a de Bartók. Se observarmos a tabela das estatísticas das músicas podemos observar que essa peça é a que possui a menor duração média de notas e a segunda maior densidade. Em relação aos melhores resultados temos a peça de Schubert em 5 classes de erro. Se observarmos as estatísticas dessa peça, veremos que ela possui a terceira maior média de durações de notas e a terceira menor densidade de notas.

Olhando apenas para essas duas peças poderíamos concluir que peças com baixas densidades de notas e altas durações médias são mais facilmente acompanhadas pelo nosso MetaRastreador. Porém, isso não é verdade. Se olharmos para as outras peças que aparecem com piores ou melhores resultados encontraremos diversos contraexemplos.

Por exemplo, para erros de substituição a peça de Liszt obteve piores resultados que a de Bártok, e ela possui a maior média de durações e a menor densidade de notas de todas as peças analisadas. Outros exemplos são as peças de Mozart e Bach que apresentaram os melhores resultados nas classes de substituição, encurtamento e prolongação. A peça de Bach possui a maior densidade de todas e a terceira menor média de durações; a de Mozart está localizada exatamente no meio nas listas ordenadas de durações e de densidades. A partir dessas observações, não conseguimos apontar uma correlação clara entre as estatísticas das músicas e os resultados gerais do MetaRastreador.

Por último, nesta seção, gostaríamos de explicitar algo que não fica evidente nos dados das tabelas acima (por utilizarmos os módulos dos erros): a tendência da evolução do relógio virtual para os erros de deleção e adição. A partir de nossa interface gráfica conseguimos visualizar as curvas de andamento e constatar dois fatos curiosos: quanto mais deleções, observamos a detecção de andamentos cada vez menores, conforme ilustrado na figura 4.13; quanto mais adições, observamos a deteç̧ão de andamentos cada vez maiores, conforme ilustrado na figura 4.14.

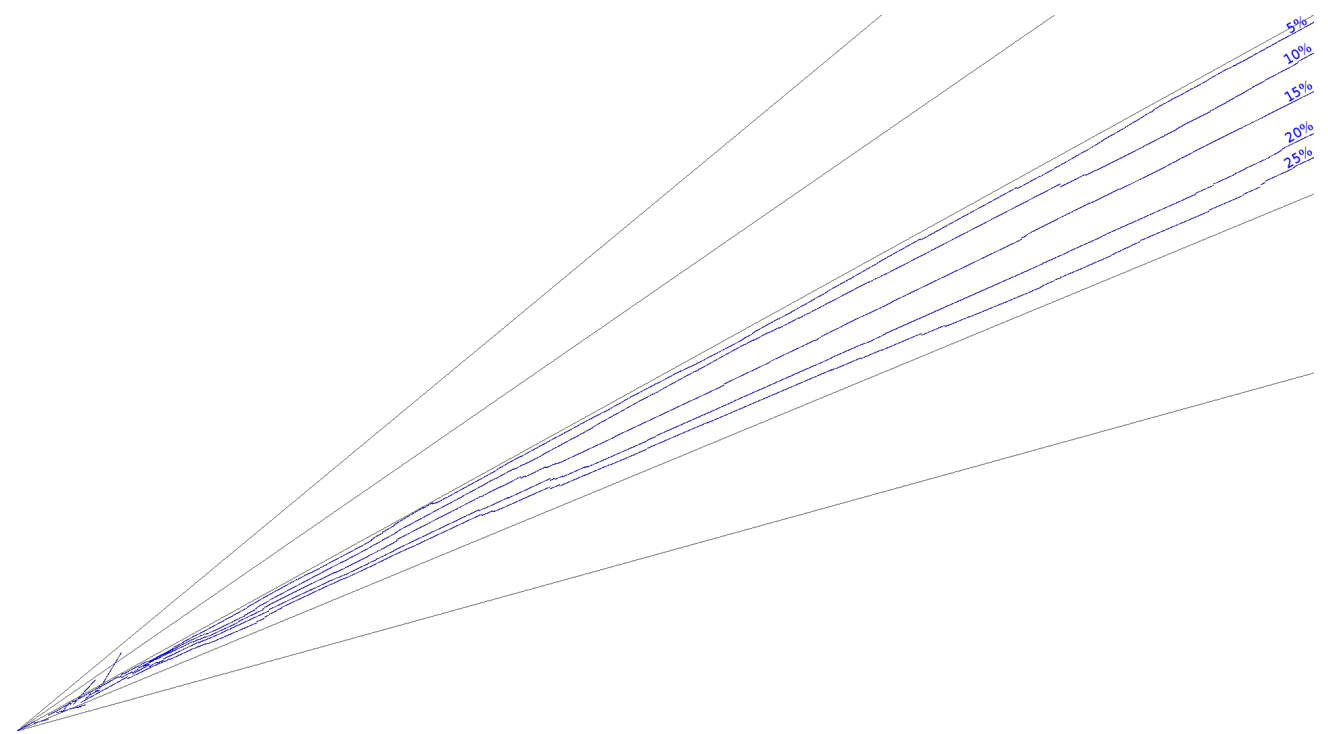

Figura 4.13: Variação da curva de evolução do tempo virtual conforme porcentagem de erros de deleção.

Isso se deve aos comportamentos descritos a seguir. Para uma deleção, observe a figura 4.15. Nela o segundo B irá ser casado com o B da partitura relativo ao evento omitido da entrada. Do ponto de vista do Acompanhador, o B relatado terá uma variação de tempo de $200 \mathrm{~ms}$ em relação 


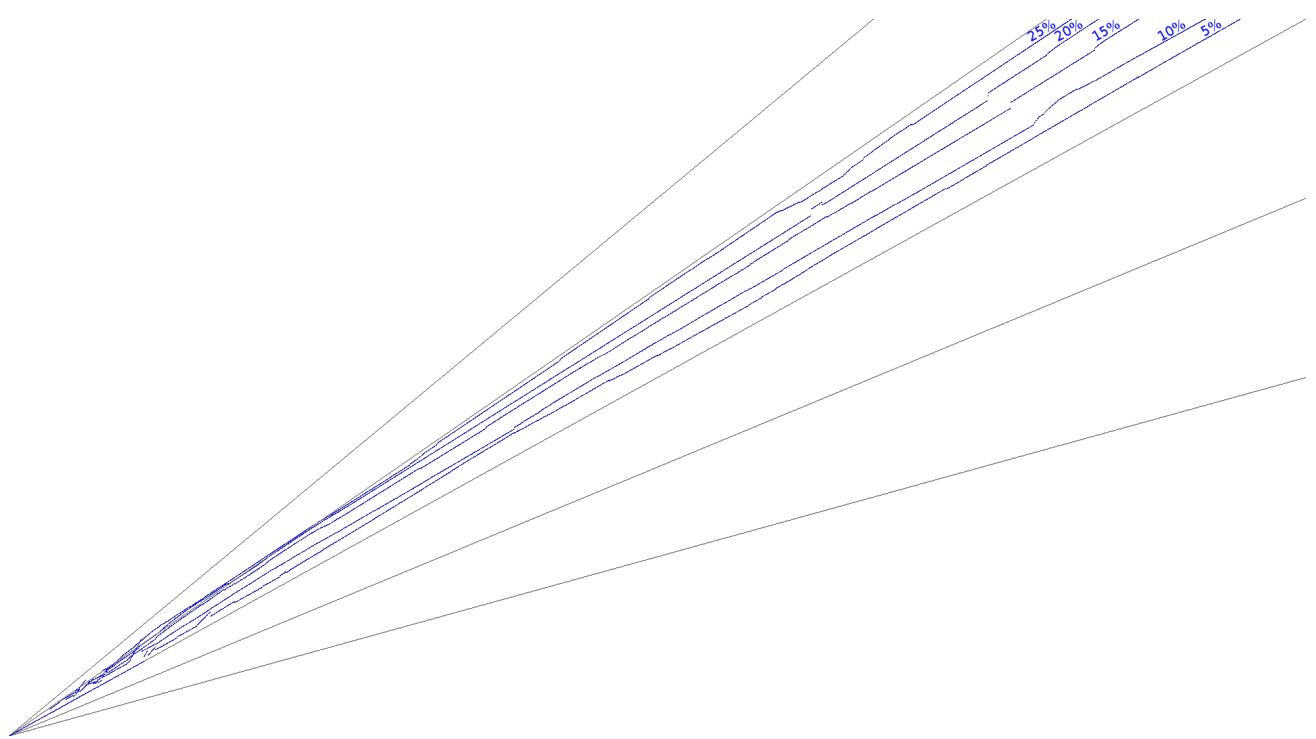

Figura 4.14: Variação da curva de evolução do tempo virtual conforme porcentagem de erros de adição.

ao A anterior. Isso é o dobro do esperado e sugere um andamento igual à metade do original.

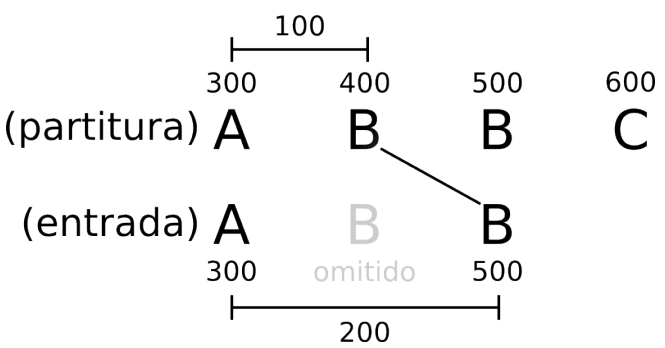

Figura 4.15: Exemplo de como um erro de deleção influencia na deteç̧ão de um andamento menor.

Para uma nota adicional, observe a figura 4.16. Nela o C extra da entrada será casado com o C da partitura. O Acompanhador irá receber um relato de um $\mathrm{C}$ com intervalo de tempo de $100 \mathrm{~ms}$ em relação ao A. Isso é metade do valor esperado e sugere um andamento igual ao dobro do original.

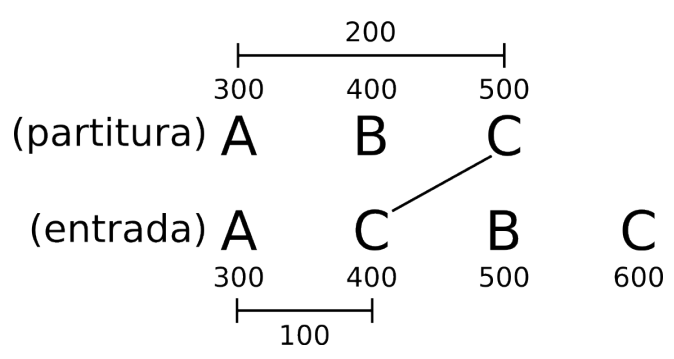

Figura 4.16: Exemplo de como um erro de adição influencia na detecção de um andamento maior.

No próximo capítulo iremos encerrar nosso texto, fazendo as considerações finais do projeto em questão e apontando os planos para o futuro. 


\section{Capítulo 5}

\section{Conclusão}

O principal objetivo do trabalho aqui apresentado era implementar um sistema modular de código aberto ${ }^{1}$ com mais de uma alternativa de algoritmo para os módulos Rastreador e Acompanhador, e este objetivo foi atingido. Além disso, foi desenvolvido um elemento adicional para o sistema - o MetaRastreador - que combina todas as técnicas de rastreamento implementadas, executando-as em paralelo e obtendo uma maior confiabilidade nas informações extraídas da entrada, considerando diversas opiniões diferentes sobre a posição do músico na partitura.

Os resultados apresentados no capítulo anterior ajudam a caracterizar a qualidade das técnicas escolhidas dentro da literatura abordada. Os experimentos também evidenciam o fato de que o MetaRastreador gera resultados satisfatórios quando ao menos metade dos rastreadores consegue seguir a execução razoavelmente. Em relação às classes de erro, obtivemos resultados (para o MetaRastreador) diferentes conforme o caso:

- erros de substituição, encurtamento e prolongação foram os que produziram os melhores resultados.

- erros de antecipação e atraso produziram resultados inferiores, porém ainda aceitáveis.

- erros de deleção e adição (antes e depois) foram os que produziram as piores estatísticas. Essas são as classes de erro cujas entradas possuem número de notas diferente do esperado conforme a partitura, e se mostraram as mais difíceis de serem acompanhadas pelo MetaRastreador implementado.

Para o futuro, existem diversas técnicas que ainda podem ser estudadas e incorporadas ao sistema. Para o módulo pré-processador da entrada é possível ampliar as opções; seriam muitas as vantagens de se poder utilizar instrumentos acústicos através de uma entrada de áudio, usando um transcritor de áudio para MIDI. Além disso, existem artigos recentes [DH03, MKC05, AW15] que utilizam características sonoras (tais como vetores de croma) para fazer rastreamento de partitura sem transcrever a entrada.

Para o módulo rastreador, consideramos incorporar técnicas probabilísticas que são abordadas em artigos mais recentes [KG12, NNS13, GR13, $\left.\mathrm{NNS}^{+} 14, \mathrm{NCC}^{+} 05\right]$ e que são utilizadas em sistemas de acompanhamento musical automatizado robustos, como Music Plus One ${ }^{2}$, Antescofo ${ }^{3}$ e Eurydice $^{4}$.

Além disso, seria interessante investigar outras técnicas especializadas em erros de adição. Tais erros produziram médias inaceitáveis nos experimentos. Ao observarmos as tabelas de resultados vimos que nem todos os algoritmos são igualmente afetados por adições. A qualidade do MetaRastreador foi prejudicada, pois os algoritmos que tratam bem esse tipo de erro estavam em minoria

\footnotetext{
${ }^{1} \mathrm{O}$ código fonte pode ser encontrado em https://github.com/rppbodo/musical-accompaniment

${ }^{2}$ http://music.informatics.indiana.edu/ craphael/music_plus_one/

${ }^{3}$ http://repmus.ircam.fr/antescofo

${ }^{4}$ http://hil.t.u-tokyo.ac.jp/software/Eurydice/index-e.html
} 
entre as técnicas utilizadas. Caso estivessem acompanhados de outras técnicas mais robustas, teríamos resultados melhores para o MetaRastreador.

O tipo de paralelismo utilizado no MetaRastreador considerou diversos rastreadores em uma mesma posição, mas eles poderiam estar também espalhados em diversos pontos da partitura. Isso aumenta a chance de se obter emparelhamentos de maior qualidade (menor custo), além de dar uma maior liberdade ao músico, permitindo que ele execute a partitura em qualquer sequência, além de poder estudar trechos em loop [DM88, AW10b].

Para o módulo Acompanhador, além da flexibilidade, seria conveniente realizar o acompanhamento de forma expressiva. Diversas técnicas existem para a síntese expressiva (principalmente no âmbito temporal), e poderíamos adaptá-las para o sistema, tornando a experiência do músico um pouco mais próxima da experiência com músicos reais.

As questões temporais da expressividade são as mais facilmente tratadas considerando o protocolo MIDI, que lida com tempos de ataques e durações de notas de forma trivial. Os cuidados a serem tomados em relação a esse aspecto da expressividade incluem questões como, por exemplo, o que fazer com o acompanhamento quando o executante altera instantaneamente o andamento.

Diversos autores discutiram esse problema de diversos pontos de vista [Cly83, SAF83, Cla85, Jaf85]. Peter Desain e coautores [DH93], por exemplo, fizeram experimentos para comparar diversas performances de uma mesma peça executadas em diferentes andamentos por um pianista e, posteriormente, por um sequenciador MIDI. Como seria de se esperar, o sequenciador ajustou todas as durações ao andamento de forma linear, característica essa não observada nas execuções do pianista. Alguns ornamentos, por exemplo, foram tocados com aproximadamente a mesma duração em diversos andamentos. A sugestão dada por estes autores consiste em inserir alterações aleatórias nas durações dos eventos; no entanto, tal abordagem é prejudicial para a sincronização de vários instrumentos e, além disso, a aleatoriedade na soma das durações pode gerar um acúmulo de erro não-natural para o ouvido humano. Músicos reais tendem a compensar flutuações de andamento, por exemplo, encurtando ou alongando uma nota cujo início foi atrasado ou antecipado.

Um outro quesito de decisão muito importante observado nas abordagens estudadas é se as informações de tempo devem ter alta granularidade (isto é, se trabalharemos com informações locais ao nível das notas) ou se elas devem ter baixa granularidade (isto é, se trabalharemos com informações globais ao nível, por exemplo, dos compassos). Ambos os níveis de detalhamento das informações apresentam pontos positivos e negativos na qualidade da geração de performances expressivas.

Um artigo de 1985 por Eric Clarke, por exemplo, analisava variações nos tempos das notas em diversas execuções de uma obra de Erik Satie para piano [Cla85]. Informações temporais em um nível tão baixo assim são extremamente precisas e funcionam muito bem quando estamos pensando em uma única peça musical. Peter Desain e coautores afirmam [DH93], no entanto, que informações com essa granularidade são pouco reaproveitáveis em outras obras, mesmo se estivéssemos trabalhando com diferentes interpretações de uma mesma peça.

David Jaffe, também em um artigo de 1985, já propunha a utilização de mapas de tempo que continham informações globais sobre a evolução temporal de uma obra [Jaf85]. Esses mapas eram funções estritamente crescentes e contínuas que representavam as deformações feitas por um intérprete nos tempos definidos na partitura. Tais mapas foram testados por Peter Desain e coautores [DH93] e foi obtida uma execução com melhores resultados em relação à expressividade de uma variação de uma peça de Beethoven (Nel cor più non mi sento) a partir de um mapa de tempo obtido de uma performance do tema original.

Existem ainda na literatura artigos que utilizam modelos generativos em oposição às técnicas de síntese por medições, pois são baseadas em opiniões e intuições de especialistas. Manfred Clynes propôs o conceito de pulso do compositor, que visava obter uma espécie de transcrição da personalidade de um compositor em padrões relacionados a métricas [Cly83], enquanto Johan Sundberg e coautores propuseram um método de síntese por regras musicais [SAF83].

As questões temporais da expressividade são tratadas por diversos trabalhos até os dias de hoje [KG12, GR13]. Florian Krebs e coautores [KG12] sugerem a mistura de diversas fontes de 
informações para aumentar a qualidade do resultado final. Eles utilizam anotações de alteração de andamento da partitura (como accelerando e ritardando) para se antecipar em relação a uma mudança brusca de andamento.

Outros aspectos da expressividade podem ser tratados na geração do acompanhamento, por exemplo modificando a dinâmica do acompanhamento quando há uma mudança significativa nas intensidades das notas vindas da performance ao vivo do solista. De forma muito similar ao controle do andamento, a abordagem mais simples seria utilizar curvas de dinâmica no acompanhamento ajustadas linearmente pelos valores de MIDI velocity recebidos do solista.

Em relação à experiência do usuário, o sistema poderia contar futuramente com uma interface gráfica que mostrasse dinamicamente a partitura, avançando-a automaticamente conforme a posição do músico. Pode-se considerar a possibilidade de implementar essa interface como um plugin de acompanhamento musical automatizado para o software MuseScore ${ }^{5}$.

Uma funcionalidade adicional poderia ser implementada incorporando o histórico de execuções de uma mesma peça musical, permitindo ao usuário ouvir e revisar suas execuções passadas, além de descartar execuções consideradas indesejáveis. Levando em consideração a possibilidade de aprendizado por parte do sistema, seria importante tratar separadamente as situações de erros de execução (que não devem ser aprendidos) e de nuances de interpretação (que deveriam ser aprendidas). Uma solução possível é pedir para o músico escolher o nível de tolerância do sistema a diferenças de realização da parte solista, tratando-as preferencialmente como erros ou como decisões interpretativas conforme o caso, e definindo consequentemente o quanto o sistema irá aproveitar da entrada para sua aprendizagem.

Em relação aos experimentos objetivos, diversas outras medidas poderiam ser extraídas do sistema ainda. Dentre elas, o cálculo da latência nas computações e a consequência da variação de andamento na entrada. Para a primeira, poderíamos medir os intervalos de tempo entre a chegada de uma nota, a emissão do relato relativo a ela, a geração de um evento de acompanhamento simultâneo e a execução do áudio desse evento na saída. Para a segunda, poderíamos gerar lotes de arquivos cujos andamentos variam no decorrer da peça e medir se as curvas de evolução do relógio virtual refletem as dos andamentos da entrada.

Finalmente, seria importante realizar experimentos subjetivos com diferentes tipos de usuários, desde estudantes principiantes até solistas experientes, a fim de confrontar os resultados com os experimentos objetivos realizados e obter uma melhor caracterização do impacto perceptual do acompanhamento automático realizado frente a situações musicais diversas.

\footnotetext{
${ }^{5}$ https://musescore.com/
} 


\section{Referências Bibliográficas}

[A+96] MIDI Manufacturers Association et al. The Complete MIDI 1.0 Detailed Specification: Incorporating all Recommended Practices. MIDI Manufacturers Association, 1996. 6, 32,49

[A $\mathrm{A}^{+}$08] MIDI Manufacturers Association et al. White paper: Comparison of midi and osc. 2008. 6

[AW10a] Andreas Arzt e Gerhard Widner. Simple tempo models for real-time music tracking. Em Proceedings of the 2010 Sound and Music Computing Conference, 2010. 29

[AW10b] Andreas Arzt e Gerhard Widner. Towards effective any-time music tracking. Em Proceedings of the Fifth Starting Artificial Intelligence Researchers' Symposium, 2010. x, 41, 42,62

[AW15] Andreas Arzt e Gerhard Widmer. Real-time music tracking using multiple performances as a reference. Em Proceedings of the 2015 International Society for Music Information Retrieval Conference, 2015. 61

[BBZ93] Bridget Baird, Donald Blevins e Noe Zahle. Artificial intelligence and music: Implementing an interactive computer performer. Computer Music Journal, 1993. ix, 3, 18, 19, $20,26,40$

[BD85] Joshua Bloch e Roger Dannenberg. Real-time accompaniment of polyphonic keyboard performance. Em Proceedings of the 1985 International Computer Music Conference, 1985. ix, 2, 3, 9, 25, 26, 31

[Cla85] Eric Clarke. Some aspects of rhythm and expression in performances of erik satie's "gnossienne no. 5". Music Perception, 1985. 62

[CLB99] Pedro Cano, Alex Loscos e Jordi Bonada. Score-performance matching using hmms. Em Proceedings of the 1999 International Computer Music Conference, 1999. 3

[CLRS01] Thomas Cormen, Charles Leiserson, Ronald Rivest e Clifford Stein. Introduction to Algorithms. The MIT Press, 2001. 11

[Cly83] Manfred Clynes. Expressive microstructure in music, linked to living qualities. Studies of Music Performance, 1983. 62

[CNB97] David Cooper, Kia-Chuan Ng e Roger Boyle. Midi extensions for musical notation (2): Expressive midi. Em Eleanor Selfridge-Field, editor, Beyond MIDI: The Handbook of Musical Codes. MIT Press, 1997. ix, 8

[Con08] Arshia Cont. Antescofo: Anticipatory synchronization and control of interactive parameters in computer music. Em Proceedings of the 2008 International Computer Music Conference, 2008. 3 
[Dan84] Roger Dannenberg. An on-line algorithm for real-time accompaniment. Em Proceedings of the 1984 International Computer Music Conference, 1984. ix, 3, 10, 12, 13, 23, 24, 31,38

[Dan89] Roger Dannenberg. Real-time scheduling and computer accompaniment. Em Max Mathews e John Pierce, editors, Current Research in Computer Music. MIT Press, 1989. 1

[DH93] Peter Desain e Henkjan Honing. Tempo curves considered harmful. Contemporary Music Review, 1993. 62

[DH03] Roger Dannenberg e Ning Hu. Polyphonic audio matching for score following and intelligent audio editors. Computer Science Department, 2003. 61

[DM88] Roger Dannenberg e Hirofumi Mukaino. New techniques for enhanced quality of computer accompaniment. Em Proceedings of the 1988 International Computer Music Conference, 1988. x, 9, 41, 42, 62

[DPZ02] P. Dutilleux, G. De Poli e U. Zolzer. Time-segment processing. Em DAFX: digital audio effects. Wiley Online Library, 2002. 32

[FS09] Adrian Freed e Andrew Schmeder. Features and future of open sound control version 1.1 for nime. Em Proceedings of the 2009 Conference on New Interfaces for Musical Expression, 2009. 6

[FSZ07] Adrian Freed, Andy Schmeder e Michael Zbyszynski. Open sound control: A flexible protocol for sensor networking. 2007. 6

[GR13] Yupeng Gu e Christopher Raphael. Creating expressive piano performance using a low-dimensional performance model. Em Proceedings of the 2013 Sound and Music Computing Conference, 2013. 61, 62

[Hen11] David Henningsson. Fluidsynth realtime and thread safety challenges. Em Proceedings of the 2011 Linux Audio Conference, 2011. 33

[HH93] Yasuo Horiuchi e Tanaka Hozumi. A computer accompaniment system with independence. Em Proceedings of the 1993 International Computer Music Conference, 1993. 3

[Jaf85] David Jaffe. Ensemble timing in computer music. Computer Music Journal, 1985. 62

[KG12] Florian Krebs e Maarten Grachten. Combining score and filter based models to predict tempo fluctuations in expressive music performances. Em Proceedings of the 2012 Sound and Music Computing Conference, 2012. 61, 62

[Lac67] Osvaldo Lacerda. Compêndio de Teoria Elementar da Música. Ricordi Brasileira, 1967. 10

[LP92] Cort Lippe e Miller Puckette. Score following in practice. Em Proceedings of the 1992 International Computer Music Conference, 1992. ix, 3, 13, 14, 39

[MKC05] Meinard Muller, Frank Kurth e Michael Clausen. Audio matching via chroma-based statistical features. Em Proceedings of the 2005 International Society for Music Information Retrieval Conference, 2005. 61

[MQ05] Adriano Mitre e Marcelo Queiroz. Um sistema automático de transcrição melódica. Simpósio Brasileiro de Computação Musical, 2005. 5 
$\left[\mathrm{NCC}^{+} 05\right]$ Eita Nakamura, Philippe Cuvillier, Arshia Cont, Nobutaka Ono e Shigeki Sagayama. Autoregressive hidden semi-markov model of symbolic music performance for score following. Em Proceedings of the 2005 International Society for Music Information Retrieval Conference, 2005. 61

[NNS13] Tomohiko Nakamura, Eita Nakamura e Shigeki Sagayama. Acoustic score following to musical performance with errors and arbitrary repeats and skips for automatic accompaniment. Em Proceedings of the 2013 Sound and Music Computing Conference, 2013. 3,61

[NNS $\left.{ }^{+} 14\right]$ Eita Nakamura, Tomohiko Nakamura, Yasuyuki Saito, Nobutaka Ono e Shigeki Sagayama. Outer-product hidden markov model and polyphonic midi score following. Journal of New Music Research, 2014. 61

[OD01] Nicola Orio e François Déchelle. Score following using spectral analysis and hidden markov models. Em Proceedings of the 2001 International Computer Music Conference, 2001. 3

[OLS03] Nicola Orio, Serge Lemouton e Diemo Schwarz. Score following: State of the art and new developments. Em Proceedings of the 2003 Conference on New Interfaces for Musical Expression, 2003. 3

[Pir11] André Salim Pires. Métodos de segmentação musical baseados em descritores sonoros. Dissertação de Mestrado, Instituto de Matemática e Estatística da Universidade de São Paulo, 2011. 5

[Rap99] Christopher Raphael. Automatic segmentation of acoustic musical signals using hidden markov models. IEEE Transactions on Pattern Analysis and Machine Intelligence, 1999. 3

[Rap04] Christopher Raphael. Musical accompaniment systems. CHANCE, 2004. 3, 28, 29

[Rap09] Christopher Raphael. Current directions with music plus one. Em Proceedings of the 2009 Sound and Music Computing Conference, 2009. 28

[Rap10] Christopher Raphael. Music plus one and machine learning. Em Proceedings of the 27th International Conference on Machine Learning, 2010. 3

[Ros92] David Rosenthal. Emulation of human rhythm perception. Computer Music Journal, 1992. 22

[SAF83] Johan Sundberg, Anders Askenfelt e Lars Frydén. Musical performance: A synthesisby-rule approach. Computer Music Journal, 1983. 62

[SGQ12] Flávio Schiavoni, Antônio Goulart e Marcelo Queiroz. Apis para o desenvolvimento de aplicações de áudio. Em IV Seminário Música Ciência Tecnologia, 2012. 35, 36

[Sta94] Richard Stallman. Why software should not have owners. https://www.gnu.org/philosophy/why-free.html, 1994. 7

[Van95] Jason Vantomme. Score following by temporal pattern. Computer Music Journal, 1995. $\mathrm{x}, 3,21,22,41$

[Ver84] Barry Vercoe. The synthetic performer in the context of live performance. Em Proceedings of the 1984 International Computer Music Conference, 1984. 3

[VP85] Barry Vercoe e Miller Puckette. Synthetic rehearsal: Training the synthetic performer. Em Proceedings of the 1985 International Computer Music Conference, 1985. 3, 16, 26, 39 
[Web04] Steven Weber. The Success of Open Source. Harvard University Press, 2004. 2 